University of New Haven

University of

New Haven

Digital Commons@ New Haven

Chemistry and Chemical Engineering Faculty

Publications

Chemistry and Chemical Engineering

$10-6-2015$

\title{
Highly Selective Hydrogenation and Hydrogenolysis Using a Copper-doped Porous Metal Oxide Catalyst
}

Laurene Petitjean

Yale University

Raphael Gagne

University of New Haven

Evan Beach

Yale University

Dequan Xiao

University of New Haven, DXiao@NewHaven.edu

Paul Anastas

Yale University

Follow this and additional works at: http://digitalcommons.newhaven.edu/chemicalengineeringfacpubs

Part of the Chemical Engineering Commons, and the Chemistry Commons

\section{Publisher Citation}

Petitjean, L., Gagne, R., Beach, E. S., Xiao, D., \& Anastas, P. T. (2016). Highly selective hydrogenation and hydrogenolysis using a copper-doped porous metal oxide catalyst. Green Chemistry, 18(1), 150-156.

\section{Comments}

This is the authors' accepted version of the article published in Green Chemistry. The final publication is available at Springer via http://dx.doi.org/ 10.1039/C5GC01464F 


\section{COMMUNICATION}

Cite this: DOI: 10.1039/xoxxooooox

\section{Highly Selective Hydrogenation and Hydrogenolysis using a Copper-doped Porous Metal Oxide Catalyst}

Received ooth January 2012, Accepted ooth January 2012

DOI: $10.1039 /$ xoxxooooox

www.rsc.org/

\author{
Laurene Petitjean ${ }^{a}$, Raphael Gagne ${ }^{\mathrm{b}}$, Evan S. Beach ${ }^{\mathrm{a}}$, Dequan Xiao ${ }^{\mathrm{b}}$, Paul T. \\ Anastas $^{\mathrm{a} *}$
}

\begin{abstract}
A copper-doped porous metal oxide catalyst in combination with hydrogen shows selective and quantitative hydrogenolysis of benzyl ketones and aldehydes, and hydrogenation of alkenes. The approach provides an alternative to noble-metal catalysed reductions and stoichiometric Wolff-Kishner and Clemmensen methods.
\end{abstract}

Sustainability has emerged as a global concern and has prompted chemists to develop procedures that minimize impact on the environment. Catalysis is the basis for many improvements in sustainable chemical transformations, facilitating the use of reduced energy and material inputs for processes that society requires ${ }^{2}$. Heterogeneous catalysis, in particular, provides many advantages such as increased catalyst stability and lifetime, as well as ease of catalyst separation from the product mixture ${ }^{2}$. Additionally, methods based on supported heterogeneous catalysts show superior applicability for industrial scale-up ${ }^{3}$. Supply vulnerabilities and depletion of natural resources have increased the attractiveness of catalysts based on earth-abundant metals ${ }^{1}$.

The hydrogenation of unsaturated functional groups such as carbon-carbon double bonds and the hydrogenolysis of carbonoxygen bonds are both important reactions in synthetic chemistry ${ }^{4}$ particularly in the liquid fuels sector ${ }^{5}$ where catalytic methods are used to reduce oxygen content and improve hydrogen/carbon ratios ${ }^{6}$. Reductions of alkenes are typically conducted with high selectivity using noble metal catalysts that are active under mild conditions ${ }^{3}$. For example, hydrogenation of the propene moiety in eugenol can be performed using $\mathrm{Pd} / \mathrm{C}$ in combination with stoichiometric triethylsilane and an acid quench ${ }^{7}$. One of the earliest reports of eugenol reduction used an insoluble rhodium catalyst in water ${ }^{8}$. Even with noble metal catalysts, selectivity can frequently be difficult to achieve. The reduction of eugenol with a heterogeneous $\mathrm{Pt} / \mathrm{\gamma}-\mathrm{Al}_{2} \mathrm{O}_{3}$ catalyst in combination with $0.14 \mathrm{MPa}$ of $\mathrm{N}_{2} / \mathrm{H}_{2}$ stream (9o/10) at 300 ${ }^{\circ} \mathrm{C}$ yielded dozens of products in addition to guaiacol and $\mathrm{n}$ propylguaiacol ${ }^{9}$. Hydrogenolysis of ketones or aldehydes from aryl- substituted compounds is even more difficult to effect selectively. Catalytic methods commonly use noble metals and typically require forcing conditions ${ }^{3}$. A recent report of selective catalytic vanillin hydrogenolysis utilizes $\mathrm{Au}$ on carbon nanotubes ${ }^{10}$, while another employs Pd nanoparticles supported on mesoporous $\mathrm{N}$-doped carbon to provide creosol $^{11}$. Various other supported Pd catalysts have been used but show lower selectivity in the reduction of vanillin to creosol ${ }^{12-}$ ${ }^{14}$, yielding mixtures of creosol and vanillyl alcohol.

Alternatively, selective but stoichiometric methods such as WolffKishner $^{15}$ or Clemmensen ${ }^{16}$ conditions are extensively utilized for carbonyl removal. They historically employ toxic reagents such as hydrazine and mercury and generate hazardous waste. Recently, methods have been developed to avoid use of noble metals or the above stoichiometric reactions for hydrogenation and hydrogenolysis. Both $\mathrm{Ni}$ nanoparticles ${ }^{17}$ and a Ni/Al alloy catalyst ${ }^{18}$ are capable of hydrogenating eugenol to propyl-guaiacol. Unfortunately, the catalysts' synthesis either employs several equivalents of toxic reagent or is energy intensive. Thus, easily synthesized green catalysts based on earth abundant elements could provide promising solutions for the large-scale applications of catalytic hydrogenation and hydrogenolysis.

A general challenge for all catalytic methods of hydrogenation or hydrogenolysis, particularly by those based on earth abundant elements, is improving selectivity. For example, using a $\mathrm{CoMo} / \mathrm{Al}_{2} \mathrm{O}_{3}$ catalyst to reduce vanillin at $300^{\circ} \mathrm{C}$ and $5 \mathrm{MPa} \mathrm{H}_{2}$ showed poor conversion and provided mixtures of over four compounds including creosol $^{19}$. Copper has the advantages of being an earth-abundant metal and having low tendency to catalyze arene hydrogenation, preventing over-reduction and thus improving selectivity ${ }^{3}$. Recently, Kong et al. reported the use of copper-doped HZSM-5 zeolite for hydrogenolysis of aryl aldehydes and ketones ${ }^{20}$. Porous metal oxides (PMOs), derived from hydrotalcite-like precursors of general formula $\mathrm{Mg}_{6} \mathrm{Al}_{2} \mathrm{CO}_{3}(\mathrm{OH})_{16}$. $\mathrm{R}_{4} \mathrm{H}_{2} \mathrm{O}$, are promising catalysts for a wide range of applications. This is due to their high potential for tunability through altering the $\mathrm{M}^{2+}: \mathrm{M}^{3+}$ ratio and metal dopants. Other advantages 


\section{Green Chemistry}

include high surface area, stability against sintering, simplicity of preparation, and ease of handling ${ }^{21,22}$. Thus, doping copper into hydrotalcite-derived compounds can be a promising strategy for a wide range of reduction methods. For example, Kaneda et Al. successfully utilised a copper-nanoparticle catalyst synthesized from Cu-Al hydrotalcite to effect the quantitative hydrogenolysis of glycerol to 1,2-propanediol ${ }^{23}$.

In this communication, the reactivity and selectivity of copperdoped PMO (Cu-PMO) is evaluated. Our previous work with the catalyst suggested it was capable of very selective transformations ${ }^{24}$. This work clarifies the scope of the reactivity towards various $\mathrm{C}-\mathrm{C}$ and $\mathrm{C}-\mathrm{O}$ bond configurations. Density functional theory (DFT) calculations were performed to evaluate the thermodynamic bias of each reaction at relevant pressures. The computational results are integrated with experimental data from Cu-PMO catalysed reductions to show improvements in efficiency and selectivity provided by the catalyst.

$\mathrm{Cu}-\mathrm{PMO}$ is synthesized by co-precipitation of $\mathrm{Cu}, \mathrm{Mg}$ and $\mathrm{Al}$

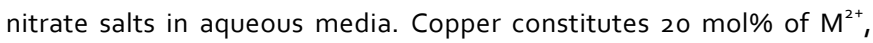
with $\mathrm{M}^{2+}: \mathrm{M}^{3+}$ kept at 3:1. Elemental analyses proved that the metals are incorporated in the anticipated amounts, furnishing a catalyst with metal ratios of $\mathrm{CU}_{0.57} \mathrm{Mg}_{2.25} \mathrm{Al}_{1.00}$ (See ESI). XRPD measurements indicate that $\mathrm{Cu}-\mathrm{PMO}$ changes from a hydrotalcite-like structure to become an amorphous material after calcination in air for 24 hours at $460^{\circ} \mathrm{C}$. Cu-PMO was previously reported to have a surface area of $\sim 137$ $\mathrm{m}^{2} / \mathrm{g}^{25}$.

The Gibbs free energy of different reaction pathways was determined using the high-performance computational chemistry software NWChem ${ }^{26}$. The structures were built in .xyz format using the model-building program Avogadro ${ }^{27}$. Initial molecular geometries were then optimized using density functional theory at the B3LYP/6319* level. The optimized structures were subjected to thermochemistry analysis based on vibrational frequency calculations and solvation energy calculations using the COSMO solvation mode ${ }^{28}$. The output of the vibrational frequency calculations provided the zero-point correction to energy $\left(E_{1}\right)$, thermal correction to enthalpy $(\mathrm{H})$ and total entropy $(\mathrm{S})$. The solvation calculation provided the total density function theory (DFT) energy $\left(E_{0}\right)$ and the electrostatic solvation energy $\left(E_{s}\right)$. Equation 1 was used to determine the change in Gibbs free energy $(\mathrm{dG})$.

$$
d G=H-T S(1)
$$

This information was then used to compute Gibbs free energy (G) of each structure in gas phase by equation 2 .

$$
G=d G+E_{0}+E_{1}(2)
$$

For specific hydrogenation or hydrogenolysis reactions, we followed the Born-Haber cycle to compute the reaction Gibbs energy in solutions (see ESI). $\mathrm{R}$ is the organic molecule prior to hydrogenation, $\mathrm{H}_{2}$ is molecular hydrogen, and $\mathrm{RH}_{2}$ is the organic molecule after hydrogenation. In the notations of $\Delta G$ terms, ' $g$ ' denotes gas phase, 'solu' denotes solution, and ' $s$ ' denotes solvation.

The reaction Gibbs free energy in gas phase was first computed using equation (3):

$$
\Delta G_{g}=G\left(R H_{2}, g\right)-G(R, g)-G\left(H_{2}, g\right) \text { (3) }
$$

Then, the reaction Gibbs free energy in solution was computed by equation (4):

$$
\Delta G_{\text {solu }}=\Delta G_{g}+\Delta G_{s, R H_{2}}-\Delta G_{s, R}-\Delta G_{s, H_{2}}(4)
$$

To examine the chemoselectivity of eugenol reduction, DFT calculations were performed to evaluate the thermodynamic feasiblity of potential products at varying pressures of hydrogen


Fig 1 (a) Potential pathways of eugenol reduction (b) Changes in Gibbs free energy with varying $\mathrm{H}_{2}$ pressure at $180^{\circ} \mathrm{C}$

\begin{tabular}{|c|c|c|c|c|c|c|c|}
\hline Entry & $\begin{array}{l}\text { Catalyst } \\
\text { (mol\%) }\end{array}$ & $\begin{array}{c}\text { Temp } \\
\left({ }^{\circ} \mathrm{C}\right)\end{array}$ & $\begin{array}{c}\text { Time } \\
\text { (h) }\end{array}$ & $\begin{array}{l}\mathrm{H}_{2}^{\mathrm{c}} \mathrm{C} \\
(\mathrm{MPa})\end{array}$ & $\begin{array}{l}\text { Ponversion }{ }^{b} \\
\text { (\%) }\end{array}$ & $\begin{array}{l}\text { Yield }^{\mathbf{b}} \\
\text { S1 (\%) }\end{array}$ & $\begin{array}{c}\text { Yield }^{b} \\
\text { IsoE (\%) }\end{array}$ \\
\hline (1) & Cu-PMO (11) & 180 & 18 & 4 & 100 & $>95$ & 0 \\
\hline (2) & Cu-PMO (11) & 100 & 18 & 4 & 100 & $>95$ & 0 \\
\hline (3) & Cu-PMO (11) & 60 & 18 & 4 & 53 & 39 & 0 \\
\hline (4) & Cu-PMO (11) & 22 & 18 & 4 & 0 & 0 & 0 \\
\hline (5) & Cu-PMO (11) & 100 & 3 & 4 & 100 & $>95$ & 0 \\
\hline (6) & Cu-PMO (11) & 70 & 3 & 4 & $<5$ & $\operatorname{tr}$ & 0 \\
\hline (7) & Cu-PMO (11) & 100 & 3 & 1 & 40 & 40 & 0 \\
\hline (8) & Cu-PMO (11) & 100 & 4 & 1 & 100 & $>95$ & 0 \\
\hline (9) & PMO (250 mg) & 180 & 18 & 4 & 57.5 & 35 & 18 \\
\hline (10) & - & 180 & 18 & 4 & 26 & 15 & 0 \\
\hline \multicolumn{2}{|c|}{ (11) $\mathrm{Cu}(\mathrm{OAc})_{2} \mathrm{H}_{2} \mathrm{O}(0.3)$} & 3) 180 & 18 & 4 & 90 & 60 & 0 \\
\hline$(12)$ & PMO (250 mg) & 100 & 4 & 1 & 0 & 0 & 0 \\
\hline$(13)$ & - & 100 & 4 & 1 & $<5$ & $\operatorname{tr}$ & 0 \\
\hline \multicolumn{3}{|c|}{$(14) \mathrm{Cu}(\mathrm{OAc})_{2 .} \mathrm{H}_{2} \mathrm{O}(0.3) 100$} & 4 & 1 & 15 & $\operatorname{tr}$ & 0 \\
\hline
\end{tabular}

Table 1 Reduction of eugenol ${ }^{\mathrm{a}}$

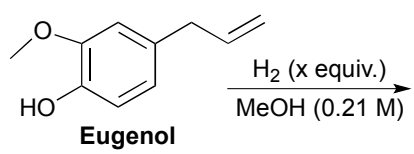<smiles>C/C=C/c1ccc(O)c(OC)c1</smiles>

(a) All reactions were carried out in a high pressure $100 \mathrm{~mL}$ Parr Reactor using Eugenol $(6.456 \mathrm{mmol})$ in $\mathrm{MeOH}(30 \mathrm{~mL})$ (b) Conversion and Yield determined by ${ }^{1} \mathrm{H}$ NMR Spectroscopy using DMF or Dodecane as internal standards (c) Pressure as added at room temperature; $t r=$ trace 
(Figure 1). At reaction conditions over $1 \mathrm{MPa}$ of hydrogen pressure at $180{ }^{\circ} \mathrm{C}$, several pathways are calculated to be thermodynamically favourable: hydrogenation of the alkene, as well as hydrogenolysis of the methoxy-aryl bonds. Interestingly, the most thermodynamically favorable product at $\mathrm{H}_{2}$ pressures of 0.1-6 MPa is predicted to be the catechol resulting from aryl-ether bond cleavage (Path 2, Figure 1). This is potentially due to the added entropy gain from methane release after bond cleavage. However, experiments with Cu-PMO did not yield catechol product, suggesting that the production of catechol is subjected to the kinetic control of the catalysis.

The hydrogenation of the propene group occurs under our reaction conditions, as it is thermodynamically allowed at various $\mathrm{H}_{2}$ pressure (see Figure $1 \mathrm{~b}$, path 1 ), Experiments also found that the hydrogenation of propene is under the control of reaction kinetics (Table 1). Product $\mathrm{S}_{\mathbf{1}}$ is obtained quantitatively after stirring for $18 \mathrm{~h}$ in a sealed Parr Reactor at $180^{\circ} \mathrm{C}$ with an initial pressure of $4 \mathrm{MPa}$ of hydrogen (Table 1, Entry 1). The efficiency was excellent at temperatures as low as $100^{\circ} \mathrm{C}$, but dropped with further decrease in temperature (Table 1, Entries 2-4). Optimal conditions appear to be around $3 \mathrm{~h}$ reaction at $100^{\circ} \mathrm{C}$ (Table 1 , Entry 5). Lowering hydrogen pressure slows the reaction, yet quantitative yields of $\mathrm{S}_{\mathbf{1}}$ can be obtained in only $4 \mathrm{~h}$ at $100{ }^{\circ} \mathrm{C}$ and $1 \mathrm{MPa}$ of hydrogen (Table 1 , comparing Entries 5, 7 and 8). The control experiments suggest that hydrogenation of eugenol is kinetically controlled. Only trace reactivity was observed even after $21 \mathrm{~h}$ at $180^{\circ} \mathrm{C}$ with $4 \mathrm{MPa}$ of hydrogen (Table 1, Entry 10).

The phase of the reaction mixture could play an important role in the efficiency and selectivity of reduction, by altering the mechanism of catalysis ${ }^{29,30}$. In the present system, methanol remains in the liquid phase throughout the reaction under all conditions reported ${ }^{31}$. The system pressure increased as the temperature approached the set point, typically reaching $1.4 \mathrm{MPa}$ at $100{ }^{\circ} \mathrm{C}$ and $5.9 \mathrm{MPa}$ at $180^{\circ} \mathrm{C}$. Accordingly the density varies in the early stages of the reaction. For a transformation performed at $180{ }^{\circ} \mathrm{C}$ and $4 \mathrm{MPa}$, the hydrogen pressure is introduced at room temperature and a density of 790.5 $\mathrm{g} / \mathrm{mL}$ is expected for methanol ${ }^{31}$. Once the set temperature is reached, the pressure has increased and the density of methanol is calculated to be $608.6 \mathrm{~g} / \mathrm{mL}^{31}$. For the milder reaction conditions, the effect is lower; at the start of the reaction, a density of $787.6 \mathrm{~g} / \mathrm{mL}$ is expected at room temperature and $1 \mathrm{MPa} \mathrm{H}_{2}$. A lower experimental density of methanol at $712.6 \mathrm{~g} / \mathrm{mL}$ can be reached with $100^{\circ} \mathrm{C}$ and $1.4 \mathrm{MPa} \mathrm{H}_{2}$. A lower solvent density may facilitate hydrogen solvation and increase the reaction rate. Changes in solvent density could also alter solvent polarity, in turn affecting reduction efficiency and selectivity ${ }^{32}$.

Cu-PMO is able to overcome the transition state barrier associated with hydrogenation of eugenol. Interestingly, the Cu-free porous-metal oxide (PMO) material derived from $\mathrm{Mg} / \mathrm{Al}$ hydrotalcite is also active for eugenol hydrogenation (Table 1, Entry 9). This control indicates that $\mathrm{Cu}$ is essential for reaction efficiency as well as selectivity, since the PMO-promoted hydrogenation of eugenol yields isoeugenol in $15 \%$ yield (2:1 ratio trans:cis). Eugenol isomerization is known to be catalyzed by hydrotalcite-like compounds due to their solid base character ${ }^{33}$. With hydrotalcite-like compounds, reduced reactivity for isomerization is observed if the catalyst is calcined to a PMO, or when polar solvents are utilized ${ }^{34}$. In the present case, a calcined catalyst is utilized in polar methanol, yet isomerization is still observed. This suggests that the rate of $\mathrm{PMO}$-catalysed hydrogenation of both eugenol and isoeugenol are low enough to allow isoeugenol to be observed as a co-product.

The use of a homogeneous copper catalyst for eugenol hydrogenation is not as effective as Cu-PMO (Table 1, Entry 11). The Cu-PMO loading ( $11 \mathrm{~mol} \%$ ) furnishes $0.3 \mathrm{~mol} \%$ of $\mathrm{Cu}$ which is identical to the absolute amount of $\mathrm{Cu}$ in the $\mathrm{Cu}(\mathrm{OAC})_{2}$ experiment, yet $\mathrm{Cu}$-PMO performs significantly better. Control experiments with milder conditions were performed (Table 1, Entries 12-14) and it is evident that the CU-PMO structure and composition are essential for overcoming the transition state energy barrier leading to the reduction product $\mathbf{S}_{1}$.

In an effort to explore the applicability of our method towards C-O bonds, DFT calculations of vanillin reduction products thermodynamic stability, at varying hydrogen pressure, were first performed (Figure 2). As for eugenol, the most thermodynamically favored product is predicted to be that from cleavage of the aryl-methoxy moiety, due to entropy gain. For analogous reasons, formation of creosol also displays negative Gibbs free energy at all studied hydrogen pressures. Hydrogenation of the aromatic unit is calculated to be particularly disfavored. It is more difficult to obtain the product of aromatic hydrogenation for vanillin than eugenol, correlating with the increased electron-donating ability of the propene unit versus the aldehyde (as also indicated by a pKa of 10.19 for eugenol and 7.38 for vanillin $)^{35}$. Hydrogenation of the aldehyde to the corresponding benzylic alcohol also displays a positive change in Gibbs free energy, most likely because the conjugation of the aldehyde to the aromatic unit makes it more difficult to reduce.
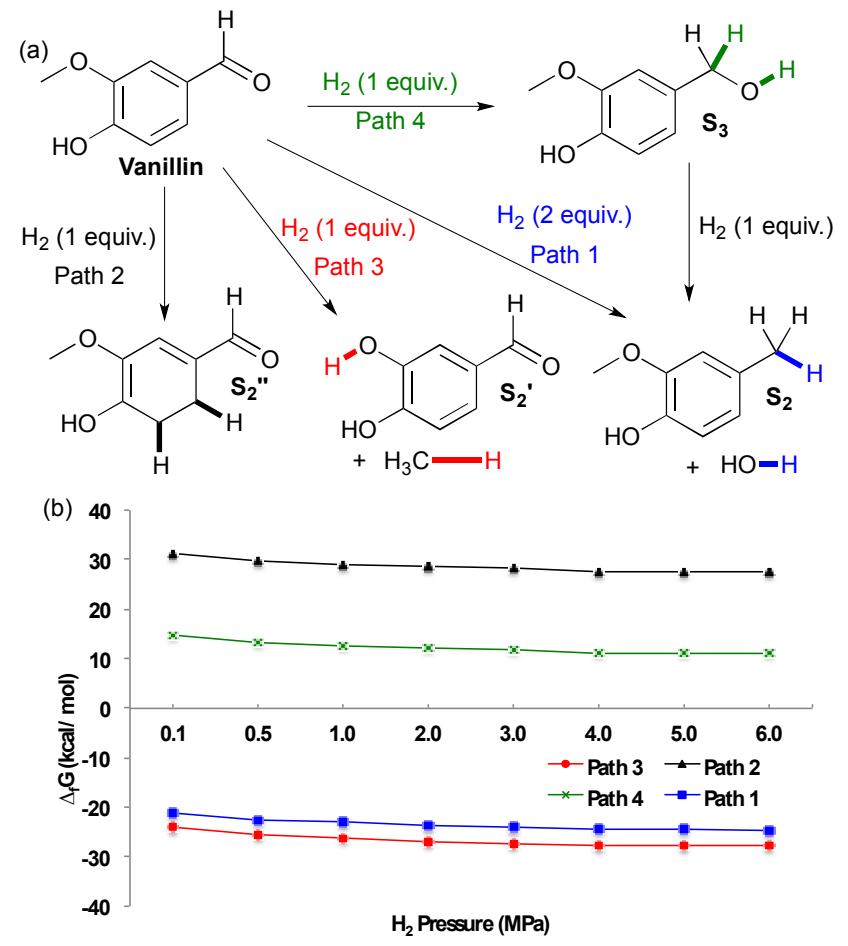

Fig 2 (a) Potential pathways of vanillin reduction (b) Changes in Gibbs free energy with varying $\mathrm{H}_{2}$ pressure at $180^{\circ} \mathrm{C}$ 
Table 2 Reduction of vanillin ${ }^{a}$

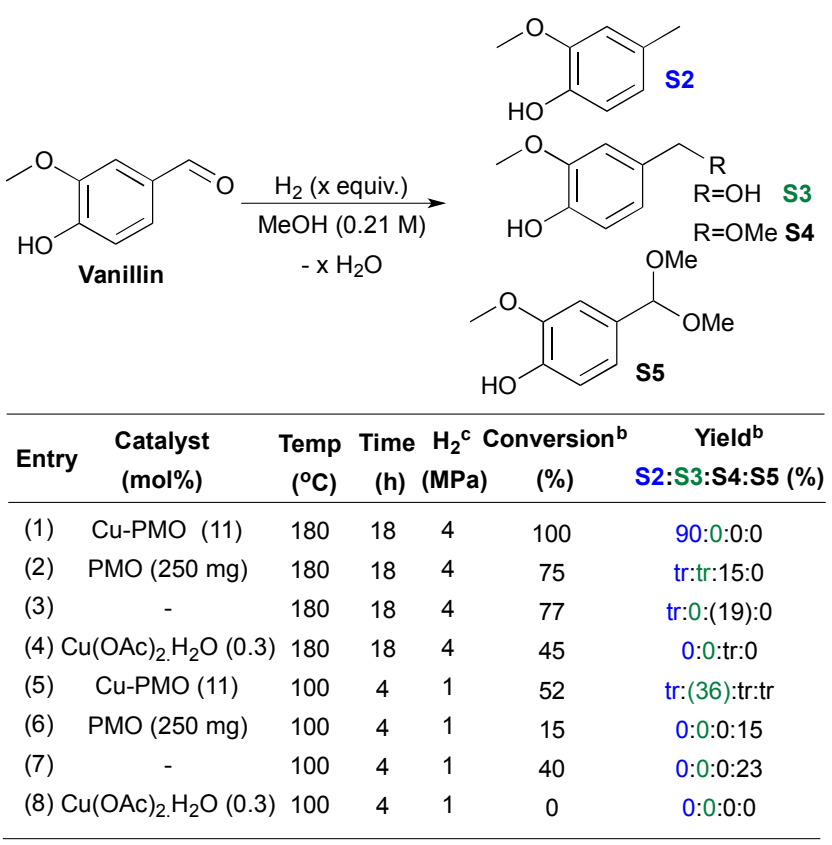

(a) All reactions were carried out in a high pressure $100 \mathrm{~mL}$ Parr Reactor using vanillin $(6.572 \mathrm{mmol})$ in $\mathrm{MeOH}(31.3 \mathrm{~mL})(\mathrm{b})$ Conversion and yield determined by ${ }^{1} \mathrm{H}$ NMR spectroscopy using Dodecane or DMF as internal standards, isolated yield in parentheses (c) Pressure measured at room temperature; $\operatorname{tr}=$ trace
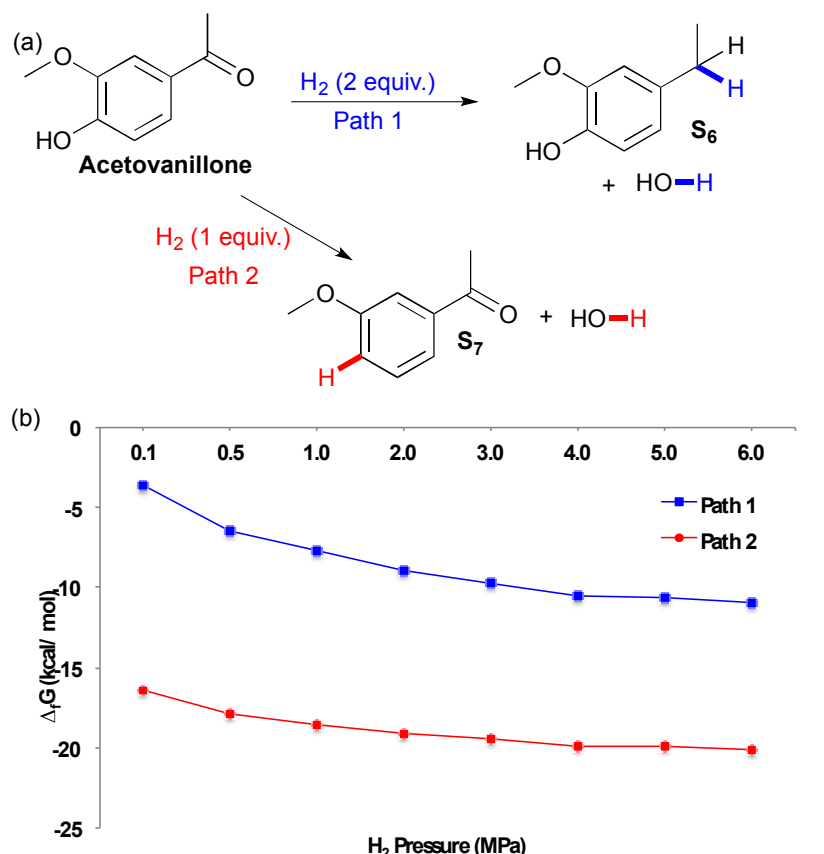

Fig 3 (a) Potential pathways of acetovanillone reduction (b) Changes in Gibbs free energy with varying $\mathrm{H}_{2}$ pressure at $180^{\circ} \mathrm{C}$

It is interesting that experimentally, Cu-PMO does not favor cleavage of the methoxy bond that is predicted to be the most thermodynamically favored pathway (Table 2), implicating highly selective kinetic control by the Cu-PMO catalyst. Many other systems have shown similar, although less pronounced, selectivity ${ }^{10-14,36-38}$. At
Table 3 Reduction of acetovanillone ${ }^{a}$



(a) All reactions were carried out in a high pressure $100 \mathrm{~mL}$ Parr Reactor using acetovanillone (6.456 mmol) in MeOH $(30 \mathrm{~mL})$ (b) Conversion and Yield determined by ${ }^{1} \mathrm{H}$ NMR Spectroscopy using DMF as internal standard (c) Conversion determined by recovery of starting material (d) Pressure as measured at room temperature; nd $=$ not determined

$4 \mathrm{MPa}$ of hydrogen and $180^{\circ} \mathrm{C}$ for $18 \mathrm{~h}$, full hydrogenolysis of vanillin to creosol (S2) was observed (Table 2, Entry 1). Interestingly, the catalyst seems to be required for hydrogenolysis, as a different product distribution is seen in its absence (Table 2, Entries 2-3). $\mathrm{S}_{4}$ is obtained in $15-19 \%$ yield with poor mass balance using Cu-free PMO or no catalyst. Using homogeneous copper acetate, conversion of vanillin and formation of $\mathbf{S}_{\mathbf{4}}$ is suppressed compared to the same reaction with no catalyst (Table 2, Entries $3 \& 4$ ). Importantly, no creosol was observed with copper acetate, suggesting that both the $\mathrm{Cu}$ loading (overall composition) and structure of Cu-PMO are necessary for selective conversion to $\mathbf{S 2}$. At lower temperature, lower hydrogen pressure and shorter time, Cu-PMO yields a different product distribution, mainly $S_{3}$ (Table 2, Entry 5). This result suggests that $\mathbf{S}_{\mathbf{3}}$ may be an intermediate in the formation of $\mathbf{S}_{\mathbf{2}}$, as expected. This was confirmed by the direct quantitative reduction of $\mathbf{S}_{\mathbf{3}}$ to $\mathbf{S}_{2}$ using Cu-PMO at $180^{\circ} \mathrm{C}$ and $4 \mathrm{MPa} \mathrm{H}_{2}$ (see ESI). If Cu is excluded from the reaction at lower temperature and pressure, no reduction of vanillin is observed (Table 2, Entries 6-7). Instead, acetal $\mathbf{S}_{5}$ is obtained which probably results from addition of methanol to the aldehyde, followed by elimination of water and addition of a second equivalent of methanol. The observation of product $\mathrm{S}_{5}$ is significant since acetal formation is typically effected by acid catalysis, yet there is no explicit source of acid in the present conditions ${ }^{39}$. The catalysis provided by $\mathrm{PMO}$ or $\mathrm{Cu}(\mathrm{OAc})_{2}$ is not sufficient to overcome transition state barriers for hydrogenolysis of vanillin. Overall, the vanillin studies again lead to the conclusion that the Cu-PMO structure and copper loading are essential for efficiency and selectivity.

The effect of increased steric hindrance and a more electron rich reduction centre was probed by studying acetovanillone (Figure 3). Calculations of the change in Gibbs free energy with varying pressure at $180^{\circ} \mathrm{C}$ indicate that both hydrogenolysis of the aryl ketone and cleavage of the aryl ether are thermodynamically favored. Although fission of the phenolic ring appears more thermodynamically favourable than hydrogenolysis of the ketone, the catalyst biases selectivity so that solely the ethyl-substituted phenol is obtained experimentally (Table 3). Indeed, no conversion of acetovanillone 
Table 4 Scope of hydrogenolysis of ketones by $\mathrm{Cu}-\mathrm{PMO}^{\mathrm{a}, \mathrm{c}}$

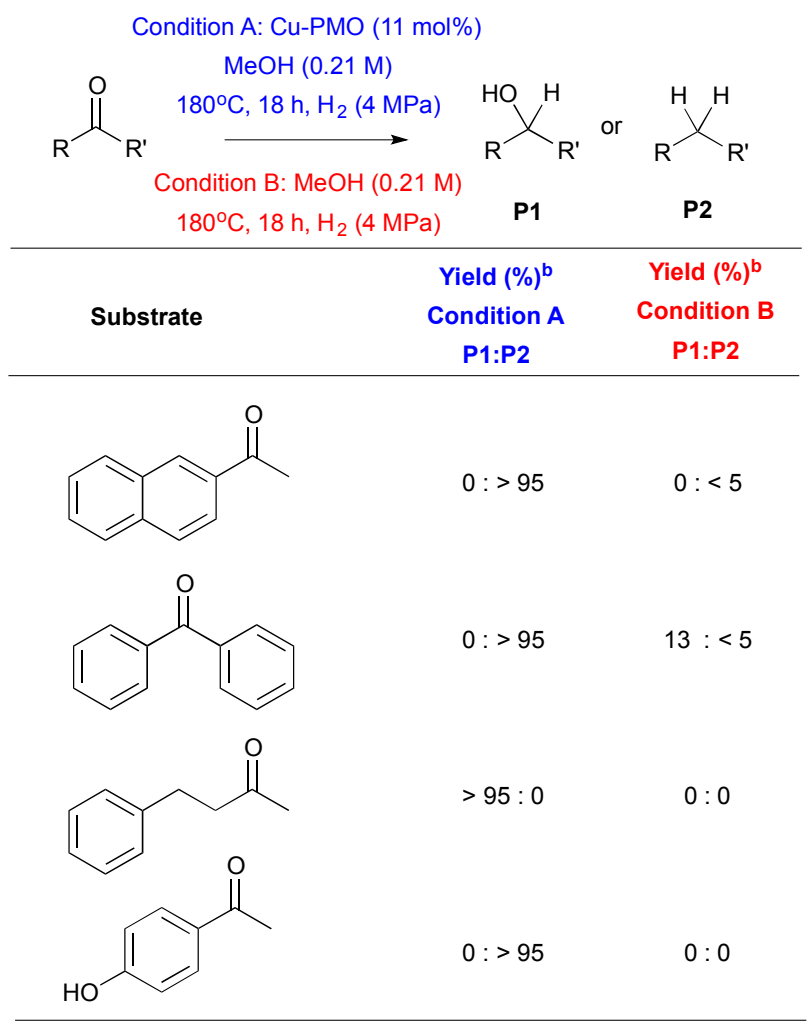

(a) All reactions were carried out in a high pressure $100 \mathrm{~mL}$ Parr Reactor using $6.456 \mathrm{mmol}$ substrate (b) Conversion and Yield determined by ${ }^{1} \mathrm{H}$ NMR Spectroscopy using DMF as internal standard (s) Pressure as measured at room temperature; nd = not determined

was seen except when using $\mathrm{Cu}-\mathrm{PMO}$ at $180^{\circ} \mathrm{C}, 4 \mathrm{MPa}$ of hydrogen for $18 \mathrm{~h}$ (Table 3, Entry 1) which effected selective and efficient hydrogenolysis of the ketone, yielding $\mathbf{S} 6$ quantitatively.

To investigate the robustness, selectivity and utility of Cu-PMO, several other ketones were investigated (Table 4). Benzyl ketones are very well tolerated, as evidenced by the quantitative hydrogenolysis of 2-acetonaphthone, 4'-hydroxyacetophenone and benzophenone. In contrast, the aliphatic ketone benzylacetone furnishes the corresponding alcohol quantitatively under the same conditions. Control experiments attribute both reactivity and selectivity to $\mathrm{Cu}$ PMO.

Even though the hydrogenolysis of methoxy-aryl bonds or phenol groups are also thermodynamically allowed, our Cu-PMO catalyst showed has a high selectivity (with mostly $>95 \%$ yields) for the hydrogenation or hydrogenolysis of carbonyl groups and C-C double bonds, indicating strong kinetic control of the catalysis. Many other catalytic systems have shown similar product distributions but with lower selectivity ${ }^{10-14,36-38}$.

Moreover, our Cu-PMO catalyst has the advantage of being composed entirely of earth-abundant materials and of operating at very low loadings of $\mathrm{Cu}(0.3 \mathrm{~mol} \%)$. Compared to other earthabundant metal catalysts ${ }^{20,}{ }^{21}, \mathrm{Cu}-\mathrm{PMO}$ is resilient to phenolic units and is able to accommodate electron-rich and sterically hindered substrates.
Recycling experiments of eugenol hydrogenation (see ESI) showed that it was possible to recycle the catalyst up to 11 times before noticing a decrease in activity. Analyses by ICP-OES of the spent catalyst revealed that the original metal ratio is retained after reaction. SEM and TEM images of CU-PMO before and after reaction show little changes in the aggregation pattern and structure of the catalyst. XRPD pattern of spent CU-PMO shows it is still amorphous after reaction. XPS investigations of recovered CU-PMO versus fresh catalyst indicate some reduction of $\mathrm{Cu}(\mathrm{II})$ to $\mathrm{Cu}(\mathrm{I})$ and possibly $\mathrm{Cu}(\mathrm{o})$ after reaction (see ESI).

In summary, we have developed a very selective method for hydrogenolysis of benzyl ketones and aldehydes as a greener alternative to Wolff-Kishner and Clemmensen conditions or noblemetal catalysed reductions. Additionally, our method allows selective reductions of alkenes. Ongoing investigations in our laboratory aim to extend the utility of the Cu-PMO system and elucidate its mechanism of reduction.

Research at University of New Haven is supported by the new faculty start-up fund and 2014 summer research grant and research fellowship of the University of New Haven. The Center for Green Chemistry and Green Engineering at Yale U. thanks the Yale School of Forestry and Environmental Studies for its support. We thank Amanda Lounsbury for the TEM images of CU-PMO.

\section{Notes and references}

1. P. T. Anastas and J. C. Warner, Green Chemistry: Theory and Practice, Oxford University Press, Oxford, 1998.

2. R. A. Sheldon, I. Arends and U. Hanefeld, Green Chemistry and Catalysis, WILEY-VCH, Weinheim, Germany, 2007.

3. S. Nishimura, Handbook of Heterogeneous Catalytic Hydrogenation for Organic Synthesis, John Wiley \& Sons, Inc., United States of America, 2001.

4. M. R. Arnold, Industrial \& Engineering Chemistry, 1956, 48, 1629-1642.

5. D. D. Laskar, B. Yang, H. Wang and J. Lee, Biofuels, Bioprod. Biorefin., 2013, 7, 602-626.

6. C. Zhang, J. Xing, L. Song, H. Xin, S. Lin, L. Xing and X. Li, Catal. Today, 2014, 234, 145-152.

7. S. Tuokko and P. M. Pihko, Org. Process Res. Dev., 2014, 18, 1740-1751.

8. C. Larpent, R. Dabard and H. Patin, Tet. Lett., 1987, 28, 2507-2510.

9. T. Nimmanwudipong, R. C. Runnebaum, S. E. Ebeler, D. E. Block and B. C. Gates, Catal. Lett., 2012, 142, 151-160.

10.X. Yang, Y. Liang, X. Zhao, Y. Song, L. Hu, X. Wang, Z. Wang and J. Qiu, RSC Adv., 2014, 4, 31932-31936.

11.X. Xu, Y. Li, Y. Gong, P. Zhang, H. Li and Y. Wang, J. Am. Chem. Soc., 2012, 134, 16987-1699o.

12.Z. Zhu, H. Tan, J. Wang, S. Yu and K. Zhou, Green Chem., 2014, 16, 26362643.

13. A. Modvig, T. L. Andersen, R. H. Taaning, A. T. Lindhardt and T. Skrydstrup, J. Org. Chem., 2014, 79, 5861-5868.

14. Q. Wang, Y. Yang, Y. Li, W. Yu and Z. J. Hou, Tetrahedron, 2006, 62, 6107-6112.

15. L. Wolff, Justus Liebigs Annalen der Chemie, 1912, 394, 86-108.

16.E. Clemmensen, Berichte der deutschen chemischen Gesellschaft, 1913, 46, 1837-1843.

17. F. Alonso, P. Riente and M. Yus, Tetrahedron, 2009, 65, 10637-10643.

18.J. Petro, L. Hegedus and I. E. Sajo, Appl. Catal., A, 2006, 308, 50-55.

19.A. L. Jongerius, R. Jastrzebski, P. C. A. Bruijnincx and B. M. Weckhuysen, J. Catal., 2012, 285, 315-323.

20. X. Kong and L. Chen, Catal. Commun., 2014, 57, 45-49. 
21.M. R. Sturgeon, M. H. O'Brien, P. N. Ciesielski, R. Katahira, J. S. Kruger, S. C. Chmely, J. Hamlin, K. Lawrence, G. B. Hunsinger, T. D. Foust, R. M. Baldwin, M. J. Biddy and G. T. Beckham, Green Chem., 2014, 16, 824835 .

22. D. P. Debecker, E. M. Gaigneaux and G. Busca, Chem. Eur. J., 2009, 15, 3920-3935.

23.T. Mizugaki, R. Arundhathi, T. Mitsudome, K. Jitsukawa and K. Kaneda, Chem. Lett., 2013, 42, 729-731.

24. K. Barta, G. R. Warner, E. S. Beach and P. T. Anastas, Green Chem., 2014, 16, 191-196.

25. G. S. Macala, T. D. Matson, C. L. Johnson, R. S. Lewis, A. V. Iretskii and P. C. Ford, ChemSusChem, 2009, 2, 215-217.

26. M. Valiev, E. J. Bylaska, N. Govind, K. Kowalski, T. P. Straatsma, H. J. J. Van Dam, D. Wang, J. Nieplocha, E. Apra, T. L. Windus and W. A. de Jong, Comp. Phys. Comm., 2010, 181, 1477-1489.

27.M. Hanwell, D. Curtis, D. Lonie, T. Vandermeersch, E. Zurek and G. Hutchison, J. Cheminformatics, 2012, 4, 17.

28. A. Klamt and G. Schuurmann, J. Chem. Soc., Perkin Trans. 2, 1993, DOI: 10.1039/P29930000799, 799-805.

29. H. Wang, A. Sapi, C. M. Thompson, F. Liu, D. Zherebetskyy, J. M. Krier, L. M. Carl, X. Cai, L.-W. Wang and G. A. Somorjai, J. Am. Chem. Soc., 2014, 136, 10515-10520.

30.U. K. Singh and M. A. Vannice, App. Cat. A.: Gen., 2001, 213, 1-24.

31.I. H. Bell, J. Wronski, S. Quoilin and V. Lemort, Ind. \& Eng. Chem. Res., 2014, 53, 2498-2508.

32.C. Reichardt and T. Welton, Solvents and Solvent Effects in Organic Chemistry, Wiley-VCH, Weinheim, Germany, 4th edn., 2011.

33.C. M. Jinesh, C. A. Antonyraj and S. Kannan, Catal. Today, 2009, 141, $176-181$.

34.D. Kishore and S. Kannan, App. Cat. A.: Gen., 2004, 270, 227-235.

35.N. V. Shorina, D. S. Kosyakov and K. G. Bogolitsyn, Russ J Appl Chem, 2005, 78, 125-129.

36.X. Yang, Y. Liang, Y. Cheng, W. Song, X. Wang, Z. Wang and J. Qiu, Catal. Commun., 2014, 47, 28-31.

37. F. H. Mahfud, S. Bussemaker, B. J. Kooi, G. H. Ten Brink and H. J. Heeres, J. Mol. Cat. A: Chem., 2007, 277, 127-136.

38.M. B. Ezhova, A. Z. Lu, B. R. James and T. O. Hu, Chem. Ind. (Boca Raton, FL, U. S.), 2005, 104, 135-143.

39.P. G. M. Wuts and T. W. Greene, Greene's Protective Groups in Organic Synthesis, John Wiley \& Sons, Inc., Hoboken, New Jersey, 4th edn., 2007. 


\title{
SUPPORTING INFORMATION
}

\section{Highly Selective Hydrogenation and Hydrogenolysis using a Copper- doped Porous Metal Oxide Catalyst}

\author{
Laurene Petitjean $^{\mathrm{a}}$, Raphael Gagne ${ }^{\mathrm{b},}$ Evan S. Beach ${ }^{\mathrm{a}}$, Dequan Xiao ${ }^{\mathrm{b} *}$, Paul T. Anastas ${ }^{\mathrm{a}^{*}}$ \\ ${ }^{\mathrm{a} C e n t e r}$ for Green Chemistry and Green Engineering \\ Yale University, New Haven, CT 06520 \\ ${ }^{\mathrm{b}}$ Department of Chemistry and Chemical Engineering \\ University of New Haven, West Haven, CT 06516
}

$\begin{array}{llr}\text { 1. } & \text { EXPERIMENTAL SECTION } & \mathbf{1} \\ \text { A. } & \text { GENERAL EXPERIMENTAL } & \mathbf{1} \\ \text { B. } & \text { SYNTHESIS OF THE CU-PMO CATALYST } \\ \text { C. } & \text { SYNTHESIS OF THE PMO CONTROL } \\ \text { D. } & \text { GENERAL PROCEDURES FOR HYDROGENATION OF LIGNIN MODEL COMPOUNDS } \\ \text { E. PRODUCT ISOLATION AND CHARACTERIZATION } & \mathbf{3} \\ \text { F. REDUCTION OF S3 WITH CU-PMO } & \mathbf{9} \\ \text { G. } & \text { RECYCLING STUDIES WITH CU-PMO } \\ \text { H. BORN-HABER CYCLE USED FOR CALCULATING GIBBS FREE ENERGY OF REACTIONS IN } & \mathbf{1 8} \\ \text { SOLUTION } & \mathbf{2 3} \\ \end{array}$

2. ANALYTICAL DATA 29

3. REFERENCES $\quad 42$

\section{Experimental Section}

a. General Experimental

Chemicals and solvents were purchased from Sigma-Aldrich, Alfa-Aesar, JT Baker or TCI and used as received. All hydrogenation reactions were set-up in a $100 \mathrm{~mL}$ stainless-steel Parr reactor equipped with a mechanical stirrer. The reactions were then pressurized under hydrogen atmosphere (Tech Air, Ultra High Purity). The loaded reactor was placed on the bench-top Parr stand equipped with a Parr 4843 controller.

Proton nuclear magnetic resonance $\left({ }^{1} \mathrm{H}\right.$ NMR) spectra were acquired using Agilent DD2 $400 \mathrm{MHz}$, Agilent DD2 $500 \mathrm{MHz}$, Agilent DD2 $600 \mathrm{MHz}$ or Varian Inova $500 \mathrm{MHz}$ spectrometers. Chemical shifts $(\delta)$ are reported in parts per million (ppm) and are calibrated to the residual solvent peak. Coupling constants $(J)$ are reported in $\mathrm{Hz}$. 
Multiplicities are reported using the following abbreviations: $\mathrm{s}=\operatorname{singlet} ; \mathrm{d}=$ doublet; $\mathrm{t}=$ triplet; $\mathrm{m}=$ multiplet (range of multiplet is given). Carbon nuclear magnetic resonance $\left({ }^{13} \mathrm{C}\right.$ NMR) spectra were acquired using Agilent DD2 $600 \mathrm{MHz}$ spectrometer. Chemical shifts $(\delta)$ are reported in parts per million (ppm) and are calibrated to the residual solvent peak. Fourier-transform infrared (FT-IR) spectra were recorded on a Thermo Nicolet 6700 spectrometer. X-Ray Powder Diffraction (XRPD) measurements were performed on a Bruker D8-focus X-Ray diffractometer equipped with a $\mathrm{Cu}$ line-focus sealed tube, a divergent beam geometer and a $\mathrm{NaI}$ scintillation detector. Measurements were made with a $40 \mathrm{kV}, 40 \mathrm{~mA}$ beam in the range $2 \theta$ from $3^{\circ}$ to $80^{\circ}$ locked couple scan type, a step size of $0.05^{\circ}$ and a scan speed of 1 second/step. Analytical thin layer chromatography was performed on pre-coated $250 \mu \mathrm{m}$ layer thickness silica gel $60 \mathrm{~F}_{254}$ Plates (EMD Chemicals Inc.). Visualization was performed by ultraviolet light and/or by staining with potassium permanganate, vanillin or iodine. Purifications by column chromatography were performed using SilicaFlash F60 silica gel (40-63 $\mu \mathrm{m}, 230-400$ mesh, Silicycle). Scanning Electron Microscopy (SEM) was performed on a Hitachi SU-70 SEM with an in0lens arrangement at $10 \mathrm{kV}$ working voltage and about $11 \mathrm{~mm}$ lens to detector distance, with a tilt angle of $35^{\circ}$. Transmission Electron Microscopy (TEM) was performed on a FEI Tecnai Osiris TEM with the field operation gun operated at $200 \mathrm{kV}$. Images were acquired digitally. Elemental analyses were performed using inductively coupled plasma optical emission spectroscopy (ICP-OES) on a Perkin Elmer Optima 3000 equiped with a Scott nebulizer. The Sc standard was measured at $361.384 \mathrm{~nm}, \mathrm{Cu}$ at $324.754 \mathrm{~nm}, \mathrm{Mg}$ at $279.079 \mathrm{~nm}$ and $\mathrm{Al}$ at $308.215 \mathrm{~nm}$. Samples were prepared for ICP-OES by dissolving a known solid amount in $2 \mathrm{~mL}$ of $6 \mathrm{M}$ nitric acid and diluting to $50 \mathrm{~mL}$ with $\mathrm{DI}_{2} \mathrm{O}$. Elemental components were quantified by comparison with purchased calibration standards. XPS analysis was performed using a ThermoScientific ESCALAB 250 instrument at the University of Oregon. Spectra were collected using a monochromatic Al X-ray source. A low energy electron flood and top-side contact were used for charge neutralization. Survey spectra were collected using a pass energy of $150 \mathrm{eV}$. Multiplex composition scans were acquired with $20 \mathrm{eV}$ pass energy. Spectra were referenced by setting the $\mathrm{C} 1 \mathrm{~s}$ hydrocarbon peak to $284.8 \mathrm{eV}$. 


\section{b. Synthesis of the Cu-PMO Catalyst}

A solution of $\mathrm{Al}\left(\mathrm{NO}_{3}\right)_{3} .9 \mathrm{H}_{2} \mathrm{O}(18.8 \mathrm{~g}, 0.05$ mol, 1 equiv. $), \mathrm{Mg}\left(\mathrm{NO}_{3}\right)_{2} \cdot 6 \mathrm{H}_{2} \mathrm{O}$ (30.76 g, $0.12 \mathrm{~mol}, 2.4$ equiv.) and $\mathrm{Cu}\left(\mathrm{NO}_{3}\right)_{2} .2 .5 \mathrm{H}_{2} \mathrm{O}$ (7.0g, 0.03 mol, 0.6 equiv.) in 300 $\mathrm{mL}$ distilled (DI) water was added dropwise over four hours to a stirring solution of $\mathrm{Na}_{2} \mathrm{CO}_{3} \cdot \mathrm{H}_{2} \mathrm{O}$ (6.2 g, 0.05 mol, 1 equiv.) in $375 \mathrm{~mL}$ distilled water. The $\mathrm{pH}$ was kept constant at $\mathrm{pH} \sim 10$ by adding aliquots of $1 \mathrm{M} \mathrm{NaOH}$ aqueous solution. Upon completion of the addition, the mixture is allowed to stir vigorously at room temperature for three days. The blue precipitate is collected by vacuum filtration and washed with $1.5 \mathrm{~L}$ distilled water. The filter cake is then suspended in a solution of $\mathrm{Na}_{2} \mathrm{CO}_{3}$ solution $(62 \mathrm{~g}$, 0.5 mol, 10 equiv.) in $\mathrm{DI} \mathrm{H}_{2} \mathrm{O}(250 \mathrm{~mL}, 2 \mathrm{M})$ and allowed to stir at room temperature overnight. Upon completion, the precipitate is collected by vacuum filtration and washed with $\mathrm{DI} \mathrm{H}_{2} \mathrm{O}(2.5 \mathrm{~L})$. The filter is left to dry overnight in a $105^{\circ} \mathrm{C}$ oven to obtain copper doped hydrotalcite. The solid is ground by mortar and pestle and subjected to calcination at $460^{\circ} \mathrm{C}$ in air for $24 \mathrm{~h}$ to obtain $\mathrm{Cu}-\mathrm{PMO}(9.21 \mathrm{~g})$ as a green powder. The $\mathrm{Cu}-\mathrm{PMO}$ was analyzed by XRPD (Figure S1), SEM (Figure S2) and TEM (Figure S3). Elemental analysis of Cu-PMO was performed by ICP-OES (Table S1). XPS measurements of $\mathrm{Cu}-$ PMO were also performed to determine metal speciation (Figure S4).

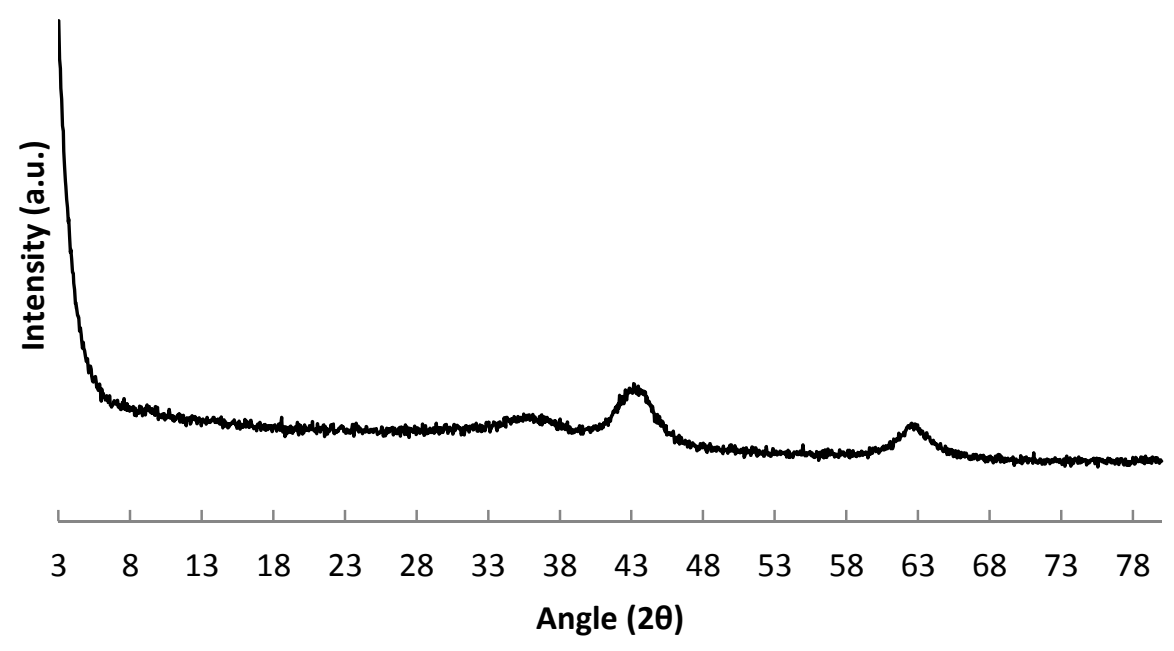

Figure S1: XPRD of Cu-PMO catalyst 
Table S1: Metal Ion Composition of Cu-PMO determined by ICP-OES

\begin{tabular}{|c|c|c|c|}
\hline & $\mathbf{C u}$ & Mg & Al \\
\hline Concentration (mg/L) & 26.09 & 39.37 & 19.36 \\
\hline Mass in solution (mg) & 1.305 & 1.969 & 0.968 \\
\hline Amount in solution (mmol) & 0.0205 & 0.0806 & 0.0359 \\
\hline Normalized Ratio of Metals & 0.57 & 2.25 & 1.00 \\
\hline
\end{tabular}



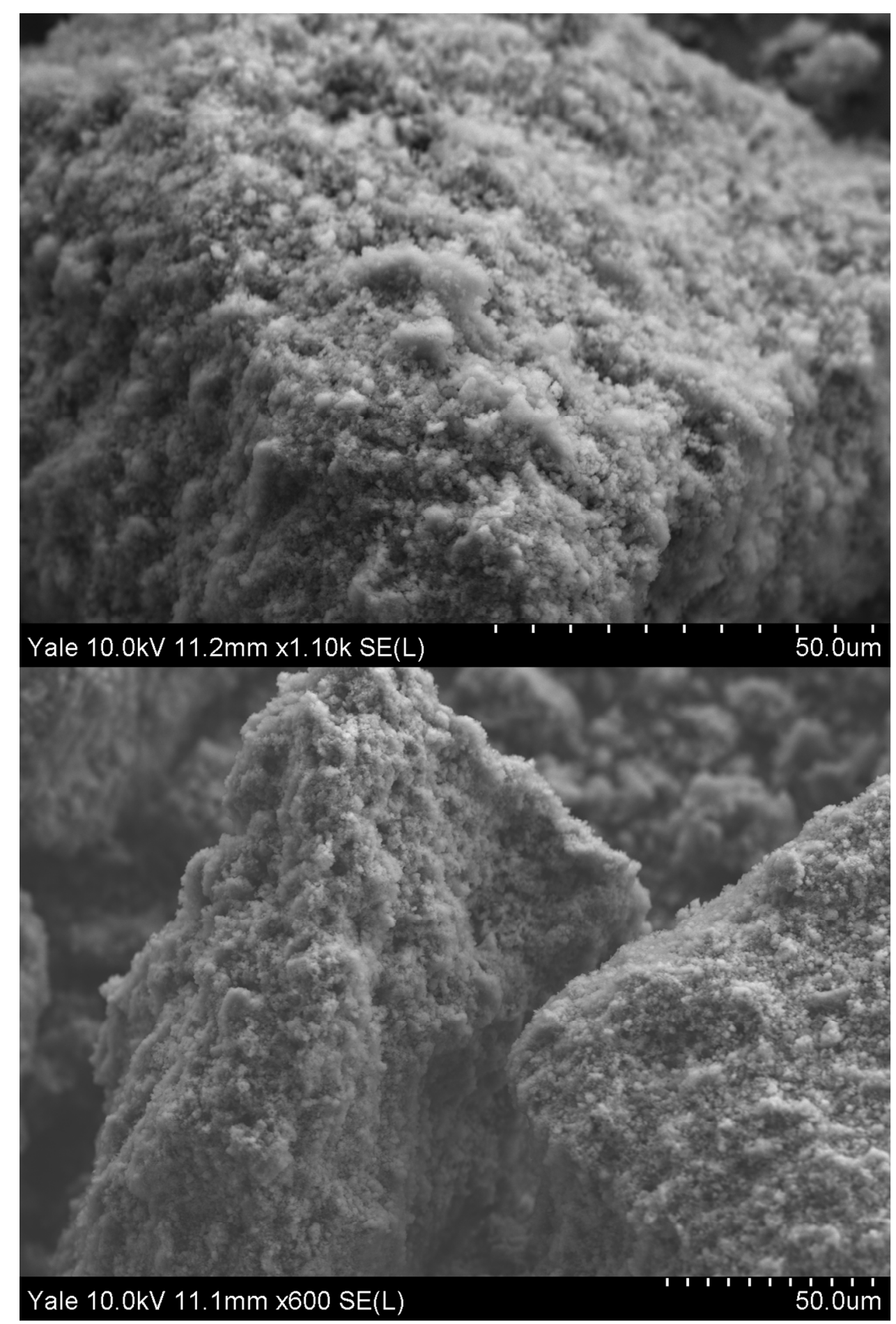

Figure S2: SEM images of Cu-PMO 


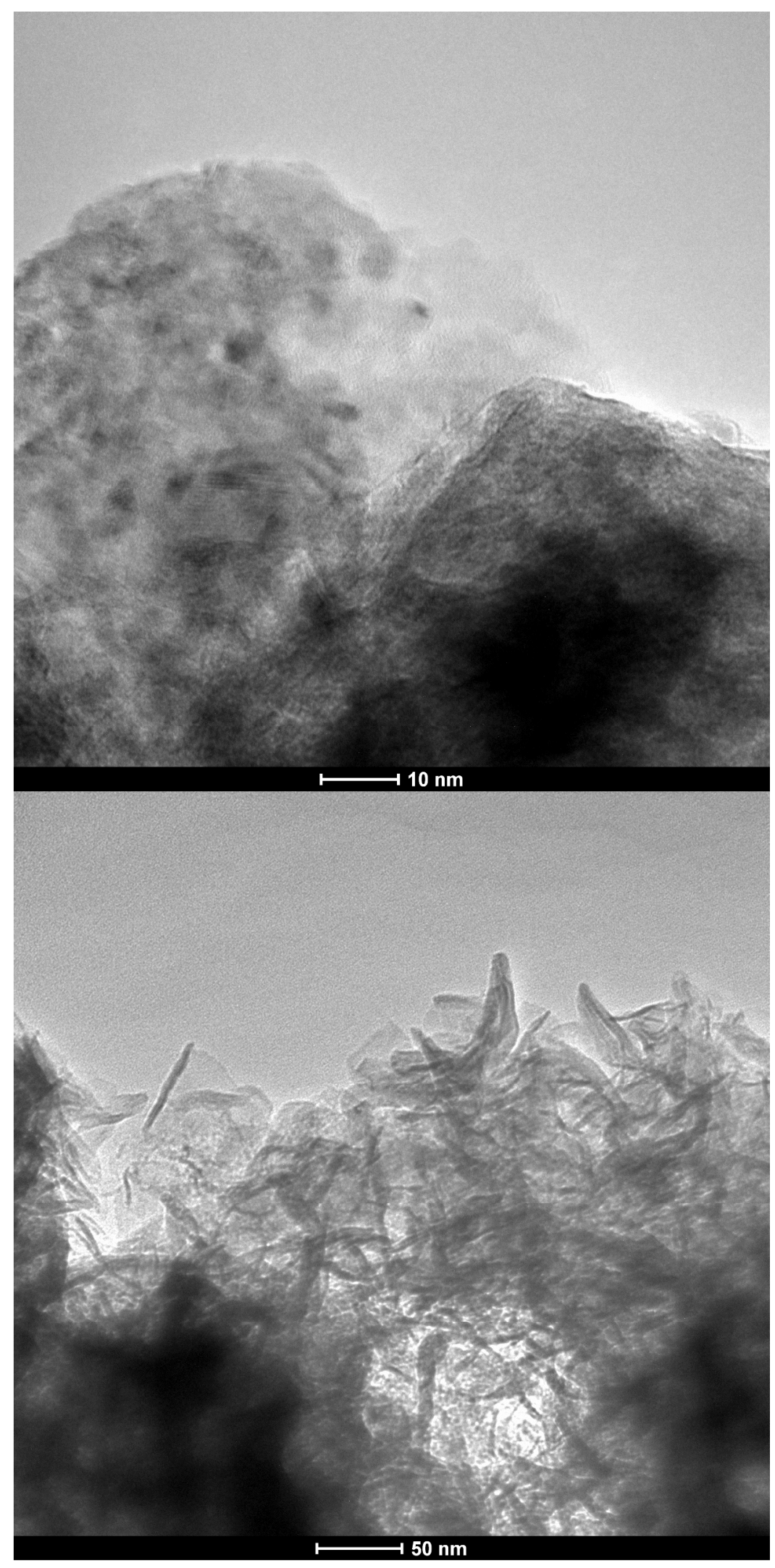

Figure S3: TEM Images of Cu-PMO 


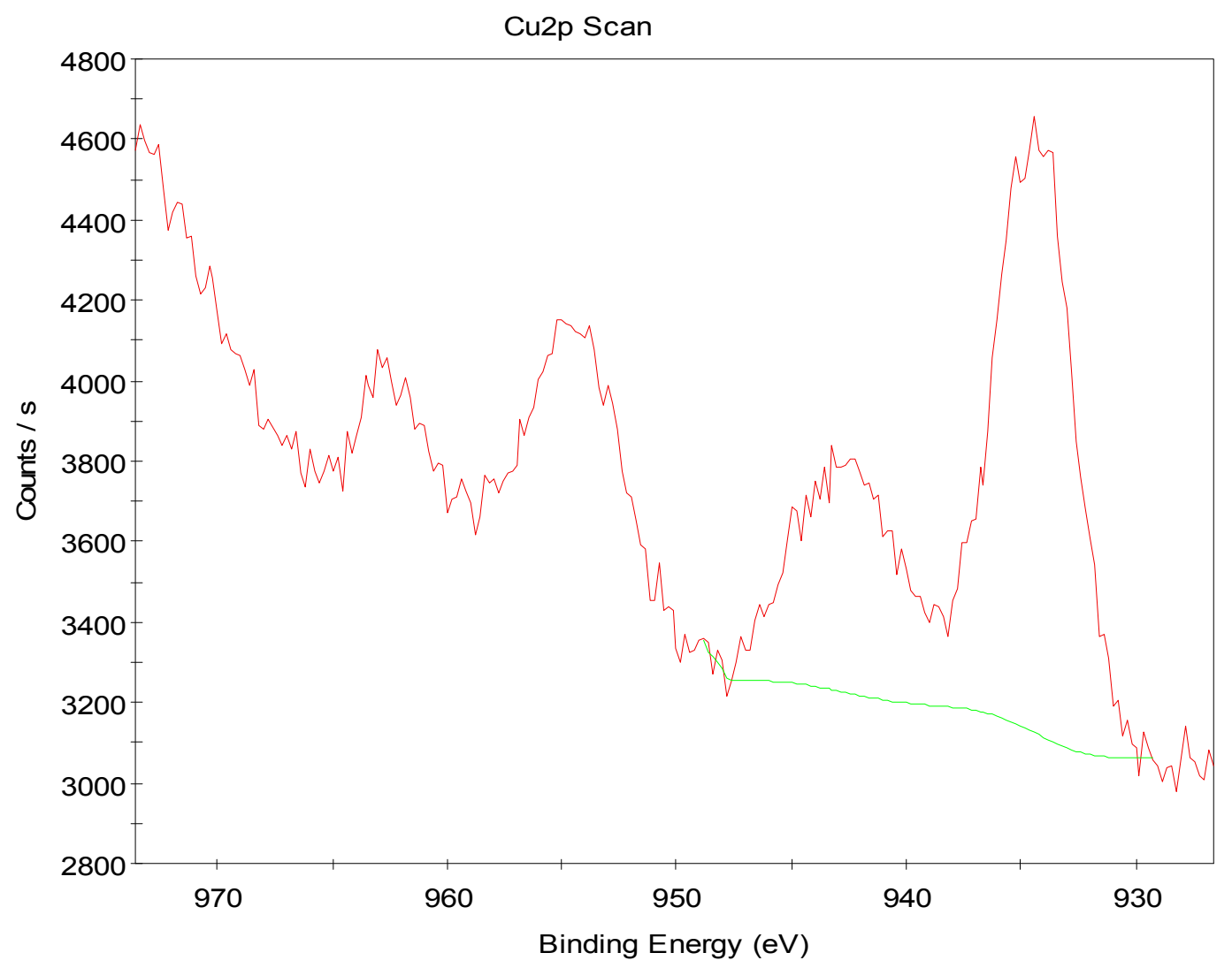

Figure S4: $\mathrm{Cu} 2 \mathrm{p} 3$ XPS of fresh $\mathrm{Cu}-\mathrm{PMO}$ catalyst 


\section{c. Synthesis of the PMO control}

A solution of $\mathrm{Al}\left(\mathrm{NO}_{3}\right)_{3} .9 \mathrm{H}_{2} \mathrm{O}$ (18.8 g, 0.05 mol, 1 equiv.), $\mathrm{Mg}\left(\mathrm{NO}_{3}\right)_{2} \cdot 6 \mathrm{H}_{2} \mathrm{O}$ (38.46 g, $0.15 \mathrm{~mol}, 3$ equiv.) in $300 \mathrm{~mL}$ distilled (DI) water was added dropwise over four hours to a stirring solution of $\mathrm{Na}_{2} \mathrm{CO}_{3} \cdot \mathrm{H}_{2} \mathrm{O}(6.2 \mathrm{~g}, 0.05 \mathrm{~mol}, 1$ equiv. $)$ in $375 \mathrm{~mL}$ distilled water. The $\mathrm{pH}$ was kept constant at $\mathrm{pH} \sim 10$ by adding aliquots of $1 \mathrm{M} \mathrm{NaOH}$ aqueous solution. Upon completion of the addition, the mixture is allowed to stir vigorously at room temperature for three days. The white precipitate is collected by vacuum filtration and washed with $1.5 \mathrm{~L}$ distilled water. The filter cake is then suspended in a solution of $\mathrm{Na}_{2} \mathrm{CO}_{3}$ solution (62 g, $0.5 \mathrm{~mol}, 10$ equiv.) in $\mathrm{DI}_{2} \mathrm{O}(250 \mathrm{~mL}, 2 \mathrm{M})$ and allowed to stir at room temperature overnight. Upon completion, the precipitate is collected by vacuum filtration and washed with $\mathrm{DI}_{2} \mathrm{O}(2.5 \mathrm{~L})$. The filter is left to dry overnight in a $105^{\circ} \mathrm{C}$ oven to obtain hydrotalcite. The solid is ground by mortar and pestle and subjected to calcination at $460^{\circ} \mathrm{C}$ in air for $24 \mathrm{~h}$ to obtain PMO (8.56 g) as a white powder. The PMO was analyzed by XRPD (Figure S5).

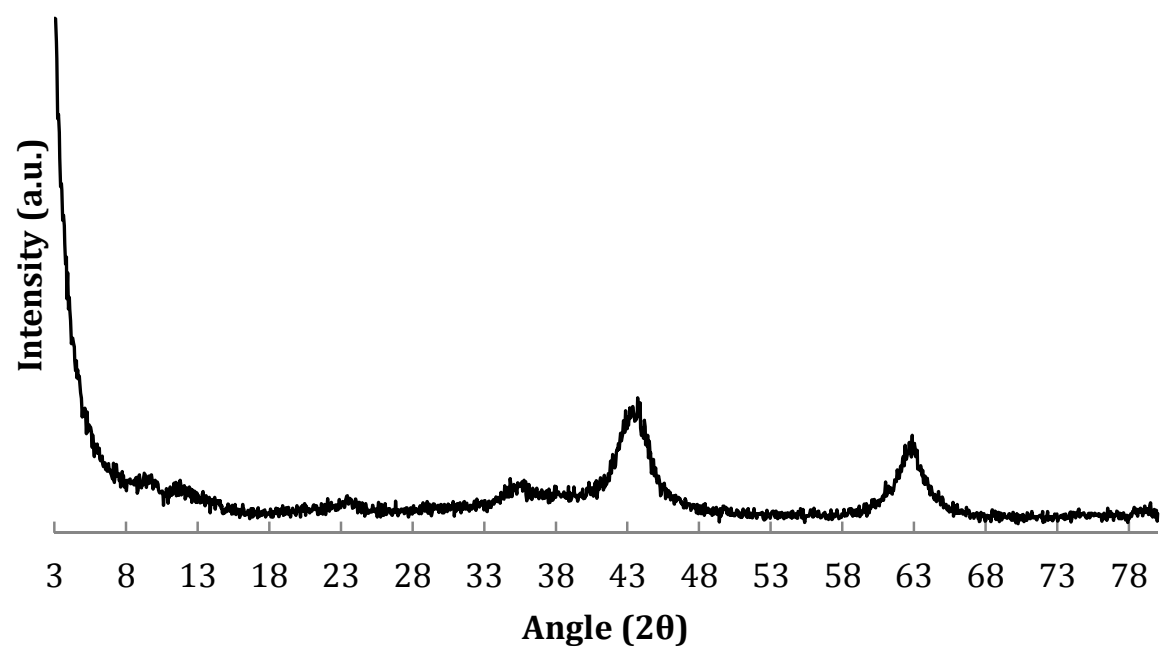

Figure S5: XPRD of PMO 


\section{d. General Procedures for Hydrogenation and Hydrogenolysis}

Amounts used for each reagent are summarized in Table S2-S5.

Representative Procedure A: Substrate (1 equiv.), Cu-PMO (11 mol\%) and dodecane (if applicable, used as internal standard, 0.15 equiv.) were added to a $100 \mathrm{~mL}$ Parr reactor. Methanol $(0.21 \mathrm{M})$ was added by syringe. The reaction vessel was sealed and pressurized to the appropriate pressure of hydrogen. The sealed reactor was placed on the Parr stand and connected to the Parr controller. The heating mantle was lifted to the Parr reactor and heating was turned on. The reaction was allowed to stir vigorously for the appropriate amount of time. Pressure and temperature time points were recorded. Upon completion, the heating mantle was lowered and the Parr reactor was cooled with a slow stream of water until it reached $40^{\circ} \mathrm{C}$ internal temperature. At this point, the Parr reactor was lifted from its stand and placed in a tap water bath until internal temperature reached $19^{\circ} \mathrm{C}$. The internal pressure was released and the Parr reactor was opened. The mixture was filtered over a pad of celite and concentrated in vacuo to afford a residue, which was analyzed directly by ${ }^{1} \mathrm{H}$ NMR (if applicable, after addition of 0.15 equiv. dimethylformamide (DMF) as an internal standard).

Representative Procedure B: Substrate (1 equiv.), PMO and dodecane (if applicable, used as internal standard, 0.15 equiv.) were added to a $100 \mathrm{~mL}$ Parr reactor. Methanol $(0.21 \mathrm{M})$ was added by syringe. The reaction vessel was sealed and pressurized to the appropriate pressure of hydrogen. The sealed reactor was placed on the Parr stand and connected to the Parr controller. The heating mantle was lifted to the Parr reactor and heating was turned on. The reaction was allowed to stir vigorously for the appropriate amount of time. Pressure and temperature time points were recorded. Upon completion, the heating mantle was lowered and the Parr reactor was cooled with a slow stream of water until it reached $40^{\circ} \mathrm{C}$ internal temperature. At this point, the Parr reactor was lifted from its stand and placed in a tap water bath until internal temperature reached $19^{\circ} \mathrm{C}$. The internal pressure was released and the Parr reactor was opened. The mixture was filtered over a pad of celite and concentrated in vacuo to afford a residue, which was analyzed 
directly by ${ }^{1} \mathrm{H}$ NMR (if applicable, after addition of 0.15 equiv. dimethylformamide (DMF) as an internal standard).

Representative Procedure C: Substrate (1 equiv.) and dodecane (if applicable, used as internal standard, 0.15 equiv.) were added to a $100 \mathrm{~mL}$ Parr reactor. Methanol (0.21 M) was added by syringe. The reaction vessel was sealed and pressurized to the appropriate pressure of hydrogen. The sealed reactor was placed on the Parr stand and connected to the Parr controller. The heating mantle was lifted to the Parr reactor and heating was turned on. The reaction was allowed to stir vigorously for the appropriate amount of time. Pressure and temperature time points were recorded. Upon completion, the heating mantle was lowered and the Parr reactor was cooled with a slow stream of water until it reached $40^{\circ} \mathrm{C}$ internal temperature. At this point, the Parr reactor was lifted from its stand and placed in a tap water bath until internal temperature reached $19^{\circ} \mathrm{C}$. The internal pressure was released and the Parr reactor was opened. The mixture was filtered over a pad of celite and concentrated in vacuo to afford a residue, which was analyzed directly by ${ }^{1} \mathrm{H}$ NMR (if applicable, after addition of 0.15 equiv. dimethylformamide (DMF) as an internal standard).

Representative Procedure D: Substrate (1 equiv.) and $\mathrm{Cu}(\mathrm{OAc})_{2} \cdot \mathrm{H}_{2} \mathrm{O}$ were added to a $100 \mathrm{~mL}$ Parr reactor. Methanol $(0.21 \mathrm{M})$ was added by syringe. The reaction vessel was sealed and pressurized to the appropriate pressure of hydrogen. The sealed reactor was placed on the Parr stand and connected to the Parr controller. The heating mantle was lifted to the Parr reactor and heating was turned on. The reaction was allowed to stir vigorously for the appropriate amount of time. Pressure and temperature time points were recorded. Upon completion, the heating mantle was lowered and the Parr reactor was cooled with a slow stream of water until it reached $40^{\circ} \mathrm{C}$ internal temperature. At this point, the Parr reactor was lifted from its stand and placed in a tap water bath until internal temperature reached $19^{\circ} \mathrm{C}$. The internal pressure was released and the Parr reactor was opened. The mixture was filtered over a pad of celite and concentrated in vacuo to afford a residue, which was analyzed directly by ${ }^{1} \mathrm{H}$ NMR (after addition of 0.15 equiv. dimethylformamide (DMF) as an internal standard). 
Table S2: Amounts and reagents used for Eugenol Reduction (Table 1)

\begin{tabular}{|c|c|c|c|c|c|c|c|}
\hline Entry & Eugenol & Catalyst & Solvent & $\begin{array}{l}\text { Internal } \\
\text { Standard }\end{array}$ & Temp. & Time & $\begin{array}{c}\text { Hydrogen } \\
\text { Pressure }\end{array}$ \\
\hline $1^{\ddagger}$ & $\begin{array}{c}1.00 \mathrm{~mL}, \\
1.06 \mathrm{~g} \\
6.456 \mathrm{mmol}\end{array}$ & $\begin{array}{c}\mathrm{Cu}-\mathrm{PMO} \\
250 \mathrm{mg} \\
0.75 \mathrm{mmol}\end{array}$ & $\begin{array}{l}\mathrm{MeOH} \\
30 \mathrm{~mL} \\
0.21 \mathrm{M}\end{array}$ & $\begin{array}{c}\text { DMF } \\
74.6 \mu \mathrm{L} \\
0.968 \mathrm{mmol}\end{array}$ & $180^{\circ} \mathrm{C}$ & $18 \mathrm{~h}$ & $4 \mathrm{MPa}$ \\
\hline $2^{\ddagger}$ & $\begin{array}{c}1.00 \mathrm{~mL}, \\
1.06 \mathrm{~g} \\
6.456 \mathrm{mmol}\end{array}$ & $\begin{array}{c}\mathrm{Cu}-\mathrm{PMO} \\
250 \mathrm{mg} \\
0.75 \mathrm{mmol}\end{array}$ & $\begin{array}{l}\mathrm{MeOH} \\
30 \mathrm{~mL} \\
0.21 \mathrm{M}\end{array}$ & $\begin{array}{c}\text { Dodecane } \\
0.21 \mathrm{~mL} \\
0.968 \mathrm{mmol}\end{array}$ & $100^{\circ} \mathrm{C}$ & $18 \mathrm{~h}$ & $4 \mathrm{MPa}$ \\
\hline $3^{t}$ & $\begin{array}{c}1.00 \mathrm{~mL}, \\
1.06 \mathrm{~g} \\
6.456 \mathrm{mmol}\end{array}$ & $\begin{array}{c}\mathrm{Cu}-\mathrm{PMO} \\
250 \mathrm{mg} \\
0.75 \mathrm{mmol}\end{array}$ & $\begin{array}{l}\mathrm{MeOH} \\
30 \mathrm{~mL} \\
0.21 \mathrm{M}\end{array}$ & $\begin{array}{c}\text { Dodecane } \\
0.21 \mathrm{~mL} \\
0.968 \mathrm{mmol}\end{array}$ & $60^{\circ} \mathrm{C}$ & $18 \mathrm{~h}$ & $4 \mathrm{MPa}$ \\
\hline $4^{t}$ & $\begin{array}{c}1.00 \mathrm{~mL}, \\
1.06 \mathrm{~g} \\
6.456 \mathrm{mmol}\end{array}$ & $\begin{array}{c}\mathrm{Cu}-\mathrm{PMO} \\
250 \mathrm{mg} \\
0.75 \mathrm{mmol}\end{array}$ & $\begin{array}{l}\mathrm{MeOH} \\
30 \mathrm{~mL} \\
0.21 \mathrm{M}\end{array}$ & $\begin{array}{c}\text { Dodecane } \\
0.21 \mathrm{~mL} \\
0.968 \mathrm{mmol}\end{array}$ & $22^{\circ} \mathrm{C}$ & $18 \mathrm{~h}$ & $4 \mathrm{MPa}$ \\
\hline $5^{\dagger}$ & $\begin{array}{c}1.00 \mathrm{~mL}, \\
1.06 \mathrm{~g} \\
6.456 \mathrm{mmol}\end{array}$ & $\begin{array}{c}\mathrm{Cu}-\mathrm{PMO} \\
250 \mathrm{mg} \\
0.75 \mathrm{mmol}\end{array}$ & $\begin{array}{l}\mathrm{MeOH} \\
30 \mathrm{~mL} \\
0.21 \mathrm{M}\end{array}$ & $\begin{array}{c}\text { Dodecane } \\
0.21 \mathrm{~mL} \\
0.968 \mathrm{mmol}\end{array}$ & $100^{\circ} \mathrm{C}$ & $3 \mathrm{~h}$ & $4 \mathrm{MPa}$ \\
\hline $6^{\ddagger}$ & $\begin{array}{c}1.00 \mathrm{~mL}, \\
1.06 \mathrm{~g} \\
6.456 \mathrm{mmol}\end{array}$ & $\begin{array}{c}\mathrm{Cu}-\mathrm{PMO} \\
250 \mathrm{mg} \\
0.75 \mathrm{mmol}\end{array}$ & $\begin{array}{l}\mathrm{MeOH} \\
30 \mathrm{~mL} \\
0.21 \mathrm{M}\end{array}$ & $\begin{array}{c}\text { Dodecane } \\
0.21 \mathrm{~mL} \\
0.968 \mathrm{mmol}\end{array}$ & $70^{\circ} \mathrm{C}$ & $3 \mathrm{~h}$ & $4 \mathrm{MPa}$ \\
\hline 7 & $\begin{array}{c}1.00 \mathrm{~mL}, \\
1.06 \mathrm{~g}, \\
6.456 \mathrm{mmol}\end{array}$ & $\begin{array}{c}\mathrm{Cu}-\mathrm{PMO} \\
250 \mathrm{mg} \\
0.75 \mathrm{mmol}\end{array}$ & $\begin{array}{l}\mathrm{MeOH} \\
30 \mathrm{~mL} \\
0.21 \mathrm{M}\end{array}$ & $\begin{array}{c}\text { DMF } \\
74.6 \mu \mathrm{L} \\
0.968 \mathrm{mmol}\end{array}$ & $100^{\circ} \mathrm{C}$ & $3 \mathrm{~h}$ & $1 \mathrm{MPa}$ \\
\hline $8^{\ddagger}$ & $\begin{array}{c}1.00 \mathrm{~mL}, \\
1.06 \mathrm{~g} \\
6.456 \mathrm{mmol}\end{array}$ & $\begin{array}{c}\mathrm{Cu}-\mathrm{PMO} \\
250 \mathrm{mg} \\
0.75 \mathrm{mmol}\end{array}$ & $\begin{array}{l}\mathrm{MeOH} \\
30 \mathrm{~mL} \\
0.21 \mathrm{M}\end{array}$ & $\begin{array}{c}\text { DMF } \\
74.6 \mu \mathrm{L} \\
0.968 \mathrm{mmol}\end{array}$ & $100^{\circ} \mathrm{C}$ & $4 \mathrm{~h}$ & $1 \mathrm{MPa}$ \\
\hline $9^{\S}$ & $\begin{array}{c}1.00 \mathrm{~mL}, \\
1.06 \mathrm{~g} \\
6.456 \mathrm{mmol}\end{array}$ & $\begin{array}{c}\text { PMO } \\
250 \mathrm{mg}\end{array}$ & $\begin{array}{l}\mathrm{MeOH} \\
30 \mathrm{~mL} \\
0.21 \mathrm{M}\end{array}$ & $\begin{array}{c}\text { DMF } \\
74.6 \mu \mathrm{L} \\
0.968 \mathrm{mmol}\end{array}$ & $180^{\circ} \mathrm{C}$ & $18 \mathrm{~h}$ & $4 \mathrm{MPa}$ \\
\hline $10^{\#}$ & $\begin{array}{c}1.00 \mathrm{~mL} \\
1.06 \mathrm{~g} \\
6.456 \mathrm{mmol}\end{array}$ & - & $\begin{array}{l}\mathrm{MeOH} \\
30 \mathrm{~mL} \\
0.21 \mathrm{M}\end{array}$ & $\begin{array}{c}\text { DMF } \\
74.6 \mu \mathrm{L} \\
0.968 \mathrm{mmol}\end{array}$ & $180^{\circ} \mathrm{C}$ & $21 \mathrm{~h}$ & $4 \mathrm{MPa}$ \\
\hline
\end{tabular}


Table S2 contn.: Amounts and reagents used for Eugenol Reduction (Table 1)

\begin{tabular}{|c|c|c|c|c|c|c|c|}
\hline $11^{\phi}$ & $\begin{array}{c}1.00 \mathrm{~mL}, \\
1.06 \mathrm{~g} \\
6.456 \mathrm{mmol}\end{array}$ & $\begin{array}{c}\mathrm{Cu}(\mathrm{OAc})_{2} \cdot \mathrm{H}_{2} \mathrm{O} \\
4.5 \mathrm{mg} \\
0.0225 \mathrm{mmol}\end{array}$ & $\begin{array}{l}\mathrm{MeOH} \\
30 \mathrm{~mL} \\
0.21 \mathrm{M}\end{array}$ & $\begin{array}{c}\text { DMF } \\
74.6 \mu \mathrm{L} \\
0.968 \mathrm{mmol}\end{array}$ & $180^{\circ} \mathrm{C}$ & $18 \mathrm{~h}$ & $4 \mathrm{MPa}$ \\
\hline $12^{\S}$ & $\begin{array}{c}1.00 \mathrm{~mL}, \\
1.06 \mathrm{~g} \\
6.456 \mathrm{mmol}\end{array}$ & $\begin{array}{c}\text { PMO } \\
250 \mathrm{mg}\end{array}$ & $\begin{array}{l}\mathrm{MeOH} \\
30 \mathrm{~mL} \\
0.21 \mathrm{M}\end{array}$ & $\begin{array}{c}\text { DMF } \\
74.6 \mu \mathrm{L} \\
0.968 \mathrm{mmol}\end{array}$ & $100^{\circ} \mathrm{C}$ & $4 \mathrm{~h}$ & $1 \mathrm{MPa}$ \\
\hline $13^{\#}$ & $\begin{array}{c}1.00 \mathrm{~mL}, \\
1.06 \mathrm{~g} \\
6.456 \mathrm{mmol}\end{array}$ & - & $\begin{array}{l}\mathrm{MeOH} \\
30 \mathrm{~mL} \\
0.21 \mathrm{M}\end{array}$ & $\begin{array}{c}\text { DMF } \\
74.6 \mu \mathrm{L} \\
0.968 \mathrm{mmol}\end{array}$ & $100^{\circ} \mathrm{C}$ & $4 \mathrm{~h}$ & $1 \mathrm{MPa}$ \\
\hline $14^{\phi}$ & $\begin{array}{c}1.00 \mathrm{~mL} \\
1.06 \mathrm{~g} \\
6.456 \mathrm{mmol}\end{array}$ & $\begin{array}{c}\mathrm{Cu}(\mathrm{OAc})_{2} \cdot \mathrm{H}_{2} \mathrm{O} \\
4.5 \mathrm{mg} \\
0.0225 \mathrm{mmol}\end{array}$ & $\begin{array}{l}\mathrm{MeOH} \\
30 \mathrm{~mL} \\
0.21 \mathrm{M}\end{array}$ & $\begin{array}{c}\text { DMF } \\
74.6 \mu \mathrm{L} \\
0.968 \mathrm{mmol}\end{array}$ & $100^{\circ} \mathrm{C}$ & $4 \mathrm{~h}$ & $1 \mathrm{MPa}$ \\
\hline
\end{tabular}

${ }^{\ddagger}$ Reactions were performed according to representative Procedure A; ${ }^{\S}$ Reactions were performed according to representative Procedure B; "Reactions were performed according to representative Procedure $\mathrm{C}$; ${ }^{\phi}$ Reactions were performed according to representative Procedure D. 
Table S3: Amounts and reagents used for Vanillin Reduction (Table 2)

\begin{tabular}{|c|c|c|c|c|c|c|c|}
\hline Entry & Vanillin & Catalyst & Solvent & $\begin{array}{l}\text { Internal } \\
\text { Standard }\end{array}$ & Temp. & Time & $\begin{array}{l}\text { Hydrogen } \\
\text { Pressure }\end{array}$ \\
\hline $1^{*}$ & $\begin{array}{c}1.00 \mathrm{~g} \\
6.572 \mathrm{mmol}\end{array}$ & $\begin{array}{c}\mathrm{Cu}-\mathrm{PMO} \\
239.4 \mathrm{mg} \\
0.75 \mathrm{mmol}\end{array}$ & $\begin{array}{c}\mathrm{MeOH} \\
31.3 \mathrm{~mL} \\
0.21 \mathrm{M}\end{array}$ & $\begin{array}{c}\text { Dodecane } \\
0.22 \mathrm{~mL} \\
0.986 \mathrm{mmol}\end{array}$ & $180^{\circ} \mathrm{C}$ & $18 \mathrm{~h}$ & $4 \mathrm{MPa}$ \\
\hline $2^{\S}$ & $\begin{array}{c}1.00 \mathrm{~g} \\
6.572 \mathrm{mmol}\end{array}$ & $\begin{array}{c}\text { PMO } \\
239.4 \mathrm{mg}\end{array}$ & $\begin{array}{c}\mathrm{MeOH} \\
31.3 \mathrm{~mL} \\
0.21 \mathrm{M}\end{array}$ & $\begin{array}{c}\text { DMF } \\
76 \mu \mathrm{L} \\
0.986 \mathrm{mmol}\end{array}$ & $180^{\circ} \mathrm{C}$ & $18 \mathrm{~h}$ & $4 \mathrm{MPa}$ \\
\hline $\mathbf{3}^{\#}$ & $\begin{array}{c}1.00 \mathrm{~g} \\
6.572 \mathrm{mmol}\end{array}$ & - & $\begin{array}{c}\mathrm{MeOH} \\
31.3 \mathrm{~mL} \\
0.21 \mathrm{M}\end{array}$ & $\begin{array}{c}\text { DMF } \\
76 \mu \mathrm{L} \\
0.986 \mathrm{mmol}\end{array}$ & $180^{\circ} \mathrm{C}$ & $18 \mathrm{~h}$ & $4 \mathrm{MPa}$ \\
\hline $4^{\phi}$ & $\begin{array}{c}1.00 \mathrm{~g} \\
6.572 \mathrm{mmol}\end{array}$ & $\begin{array}{c}\mathrm{Cu}(\mathrm{OAc})_{2} \cdot \mathrm{H}_{2} \mathrm{O} \\
4.6 \mathrm{mg} \\
0.023 \mathrm{mmol}\end{array}$ & $\begin{array}{c}\mathrm{MeOH} \\
31.3 \mathrm{~mL} \\
0.21 \mathrm{M}\end{array}$ & $\begin{array}{c}\text { DMF } \\
76 \mu \mathrm{L} \\
0.986 \mathrm{mmol}\end{array}$ & $180^{\circ} \mathrm{C}$ & $18 \mathrm{~h}$ & $4 \mathrm{MPa}$ \\
\hline $5^{\ddagger}$ & $\begin{array}{c}1.00 \mathrm{~g} \\
6.572 \mathrm{mmol}\end{array}$ & $\begin{array}{c}\mathrm{Cu}-\mathrm{PMO} \\
239.4 \mathrm{mg} \\
0.75 \mathrm{mmol}\end{array}$ & $\begin{array}{c}\mathrm{MeOH} \\
31.3 \mathrm{~mL} \\
0.21 \mathrm{M}\end{array}$ & $\begin{array}{c}\text { Dodecane } \\
0.22 \mathrm{~mL} \\
0.986 \mathrm{mmol}\end{array}$ & $100^{\circ} \mathrm{C}$ & $4 \mathrm{~h}$ & $1 \mathrm{MPa}$ \\
\hline $6^{\S}$ & $\begin{array}{c}1.00 \mathrm{~g} \\
6.572 \mathrm{mmol}\end{array}$ & $\begin{array}{c}\text { PMO } \\
239.4 \mathrm{mg}\end{array}$ & $\begin{array}{c}\mathrm{MeOH} \\
31.3 \mathrm{~mL} \\
0.21 \mathrm{M}\end{array}$ & $\begin{array}{c}\text { DMF } \\
76 \mu \mathrm{L} \\
0.986 \mathrm{mmol}\end{array}$ & $100^{\circ} \mathrm{C}$ & $4 \mathrm{~h}$ & $1 \mathrm{MPa}$ \\
\hline $7^{\#}$ & $\begin{array}{c}1.00 \mathrm{~g} \\
6.572 \mathrm{mmol}\end{array}$ & - & $\begin{array}{c}\mathrm{MeOH} \\
31.3 \mathrm{~mL} \\
0.21 \mathrm{M}\end{array}$ & $\begin{array}{c}\text { DMF } \\
76 \mu \mathrm{L} \\
0.986 \mathrm{mmol}\end{array}$ & $100^{\circ} \mathrm{C}$ & $4 \mathrm{~h}$ & $1 \mathrm{MPa}$ \\
\hline $8^{\phi}$ & $\begin{array}{c}1.00 \mathrm{~g} \\
6.572 \mathrm{mmol}\end{array}$ & $\begin{array}{c}\mathrm{Cu}(\mathrm{OAc})_{2} \cdot \mathrm{H}_{2} \mathrm{O} \\
4.6 \mathrm{mg} \\
0.026 \mathrm{mmol}\end{array}$ & $\begin{array}{c}\mathrm{MeOH} \\
31.3 \mathrm{~mL} \\
0.21 \mathrm{M}\end{array}$ & $\begin{array}{c}\text { DMF } \\
76 \mu \mathrm{L} \\
0.986 \mathrm{mmol}\end{array}$ & $100^{\circ} \mathrm{C}$ & $4 \mathrm{~h}$ & $1 \mathrm{MPa}$ \\
\hline
\end{tabular}

${ }^{\star}$ Reactions were performed according to representative Procedure A; ${ }^{\S}$ Reactions were performed according to representative Procedure B; " Reactions were performed according to representative Procedure $\mathrm{C} ;{ }^{\phi}$ Reactions were performed according to representative Procedure D. 
Table S4: Amounts and reagents used for Acetovanillone Reduction (Table 3)

\begin{tabular}{|c|c|c|c|c|c|c|c|}
\hline Entry & $\begin{array}{c}\text { Aceto- } \\
\text { Vanillone }\end{array}$ & Catalyst & Solvent & $\begin{array}{l}\text { Internal } \\
\text { Standard }\end{array}$ & $\begin{array}{c}\text { Temp } \\
\text {. }\end{array}$ & Time & $\begin{array}{l}\text { Hydrogen } \\
\text { Pressure }\end{array}$ \\
\hline $1^{\ddagger}$ & $\begin{array}{c}1.072 \mathrm{~g}, \\
6.456 \mathrm{mmol}\end{array}$ & $\begin{array}{c}\mathrm{Cu}-\mathrm{PMO} \\
250 \mathrm{mg} \\
0.75 \mathrm{mmol}\end{array}$ & $\begin{array}{l}\mathrm{MeOH} \\
30 \mathrm{~mL} \\
0.21 \mathrm{M}\end{array}$ & $\begin{array}{c}\text { DMF } \\
74.6 \mu \mathrm{L} \\
0.968 \mathrm{mmol}\end{array}$ & $180^{\circ} \mathrm{C}$ & $18 \mathrm{~h}$ & $4 \mathrm{MPa}$ \\
\hline $2^{\S}$ & $\begin{array}{c}1.072 \mathrm{~g}, \\
6.456 \mathrm{mmol}\end{array}$ & $\begin{array}{c}\text { PMO } \\
250 \mathrm{mg}\end{array}$ & $\begin{array}{l}\mathrm{MeOH} \\
30 \mathrm{~mL} \\
0.21 \mathrm{M}\end{array}$ & - & $180^{\circ} \mathrm{C}$ & $18 \mathrm{~h}$ & $4 \mathrm{MPa}$ \\
\hline $3^{\#}$ & $\begin{array}{c}1.072 \mathrm{~g}, \\
6.456 \mathrm{mmol}\end{array}$ & - & $\begin{array}{l}\mathrm{MeOH} \\
30 \mathrm{~mL} \\
0.21 \mathrm{M}\end{array}$ & $\begin{array}{c}\text { DMF } \\
76 \mu \mathrm{L} \\
0.986 \mathrm{mmol}\end{array}$ & $180^{\circ} \mathrm{C}$ & $18 \mathrm{~h}$ & $4 \mathrm{MPa}$ \\
\hline $4^{\phi}$ & $\begin{array}{c}1.072 \mathrm{~g}, \\
6.456 \mathrm{mmol}\end{array}$ & $\begin{array}{c}\mathrm{Cu}(\mathrm{OAc})_{2} \cdot \mathrm{H}_{2} \mathrm{O} \\
4.5 \mathrm{mg} \\
0.0225 \mathrm{mmol}\end{array}$ & $\begin{array}{l}\mathrm{MeOH} \\
30 \mathrm{~mL} \\
0.21 \mathrm{M}\end{array}$ & $\begin{array}{c}\text { DMF } \\
74.6 \mu \mathrm{L} \\
0.968 \mathrm{mmol}\end{array}$ & $180^{\circ} \mathrm{C}$ & $18 \mathrm{~h}$ & $4 \mathrm{MPa}$ \\
\hline $5^{\ddagger}$ & $\begin{array}{c}1.072 \mathrm{~g}, \\
6.456 \mathrm{mmol}\end{array}$ & $\begin{array}{c}\mathrm{Cu}-\mathrm{PMO} \\
250 \mathrm{mg} \\
0.75 \mathrm{mmol}\end{array}$ & $\begin{array}{l}\mathrm{MeOH} \\
30 \mathrm{~mL} \\
0.21 \mathrm{M}\end{array}$ & $\begin{array}{c}\text { DMF } \\
74.6 \mu \mathrm{L} \\
0.968 \mathrm{mmol}\end{array}$ & $100^{\circ} \mathrm{C}$ & $4 \mathrm{~h}$ & $1 \mathrm{MPa}$ \\
\hline
\end{tabular}

${ }^{\ddagger}$ Reactions were performed according to representative Procedure A; ${ }^{\S}$ Reactions were performed according to representative Procedure B; ${ }^{\#}$ Reactions were performed according to representative Procedure $\mathrm{C}$; ${ }^{\phi}$ Reactions were performed according to representative Procedure D. 
Table S5: Amounts and reagents used for substrate scope investigation (Table 4)

\begin{tabular}{|c|c|c|c|c|c|c|c|}
\hline Entry & Substrate & Catalyst & Solvent & $\begin{array}{c}\text { Internal } \\
\text { Standard }\end{array}$ & Temp. & Time & $\begin{array}{c}\text { Hydrogen } \\
\text { Pressure }\end{array}$ \\
\hline $1^{\ddagger}$ & $\begin{array}{c}\text { 2-acetonaphthone } \\
1098.9 \mathrm{mg} \\
6.456 \mathrm{mmol}\end{array}$ & $\begin{array}{c}\mathrm{Cu}-\mathrm{PMO} \\
250 \mathrm{mg} \\
0.75 \\
\mathrm{mmol}\end{array}$ & $\begin{array}{l}\mathrm{MeOH} \\
30 \mathrm{~mL} \\
0.21 \mathrm{M}\end{array}$ & $\begin{array}{c}\text { DMF } \\
74.6 \mu \mathrm{L} \\
0.968 \mathrm{mmol}\end{array}$ & $180^{\circ} \mathrm{C}$ & $18 \mathrm{~h}$ & $4 \mathrm{MPa}$ \\
\hline $2^{\#}$ & $\begin{array}{c}\text { 2-acetonaphthone } \\
1098.9 \mathrm{mg} \\
6.456 \mathrm{mmol}\end{array}$ & - & $\begin{array}{l}\mathrm{MeOH} \\
30 \mathrm{~mL} \\
0.21 \mathrm{M}\end{array}$ & $\begin{array}{c}\text { DMF } \\
74.6 \mu \mathrm{L} \\
0.968 \mathrm{mmol}\end{array}$ & $180^{\circ} \mathrm{C}$ & $18 \mathrm{~h}$ & $4 \mathrm{MPa}$ \\
\hline $3^{+}$ & $\begin{array}{l}\text { Benzophenone } \\
1176 \mathrm{mg} \\
6.456 \mathrm{mmol}\end{array}$ & $\begin{array}{c}\mathrm{Cu}-\mathrm{PMO} \\
250 \mathrm{mg} \\
0.75 \\
\mathrm{mmol}\end{array}$ & $\begin{array}{l}\mathrm{MeOH} \\
30 \mathrm{~mL} \\
0.21 \mathrm{M}\end{array}$ & $\begin{array}{c}\text { DMF } \\
74.6 \mu \mathrm{L} \\
0.968 \mathrm{mmol}\end{array}$ & $180^{\circ} \mathrm{C}$ & $18 \mathrm{~h}$ & $4 \mathrm{MPa}$ \\
\hline $4^{\#}$ & $\begin{array}{c}\text { Benzophenone } \\
1176 \mathrm{mg} \\
6.456 \mathrm{mmol}\end{array}$ & - & $\begin{array}{l}\mathrm{MeOH} \\
30 \mathrm{~mL} \\
0.21 \mathrm{M}\end{array}$ & $\begin{array}{c}\text { DMF } \\
74.6 \mu \mathrm{L} \\
0.968 \mathrm{mmol}\end{array}$ & $180^{\circ} \mathrm{C}$ & $18 \mathrm{~h}$ & $4 \mathrm{MPa}$ \\
\hline
\end{tabular}

${ }^{\ddagger}$ Reactions were performed according to representative Procedure A; ${ }^{\#}$ Reactions were performed according to representative Procedure C. 
Table S5 cont.: Amounts and reagents used for substrate scope investigation (Table 4)

\begin{tabular}{|c|c|c|c|c|c|c|c|}
\hline Entry & Substrate & Catalyst & Solvent & $\begin{array}{l}\text { Internal } \\
\text { Standard }\end{array}$ & Temp. & Time & $\begin{array}{c}\text { Hydrogen } \\
\text { Pressure }\end{array}$ \\
\hline $5^{\ddagger}$ & $\begin{array}{c}\text { Benzylacetone } \\
956.8 \mathrm{mg} \\
0.97 \mathrm{~mL} \\
6.456 \mathrm{mmol}\end{array}$ & $\begin{array}{c}\mathrm{Cu}-\mathrm{PMO} \\
250 \mathrm{mg} \\
0.75 \\
\mathrm{mmol}\end{array}$ & $\begin{array}{l}\mathrm{MeOH} \\
30 \mathrm{~mL} \\
0.21 \mathrm{M}\end{array}$ & $\begin{array}{c}\text { DMF } \\
74.6 \mu \mathrm{L} \\
0.968 \mathrm{mmol}\end{array}$ & $180^{\circ} \mathrm{C}$ & $18 \mathrm{~h}$ & $4 \mathrm{MPa}$ \\
\hline $6^{\#}$ & $\begin{array}{c}\text { Benzylacetone } \\
956.8 \mathrm{mg} \\
0.97 \mathrm{~mL} \\
6.456 \mathrm{mmol}\end{array}$ & - & $\begin{array}{l}\mathrm{MeOH} \\
30 \mathrm{~mL} \\
0.21 \mathrm{M}\end{array}$ & $\begin{array}{c}\text { DMF } \\
74.6 \mu \mathrm{L} \\
0.968 \mathrm{mmol}\end{array}$ & $180^{\circ} \mathrm{C}$ & $18 \mathrm{~h}$ & $4 \mathrm{MPa}$ \\
\hline $7^{+}$ & $\begin{array}{c}\text { 4'-hydroxy } \\
\text { acetophenone } \\
879.0 \mathrm{mg} \\
6.456 \mathrm{mmol}\end{array}$ & $\begin{array}{c}\mathrm{Cu}-\mathrm{PMO} \\
250 \mathrm{mg} \\
0.75 \\
\mathrm{mmol}\end{array}$ & $\begin{array}{l}\mathrm{MeOH} \\
30 \mathrm{~mL} \\
0.21 \mathrm{M}\end{array}$ & $\begin{array}{c}\text { DMF } \\
74.6 \mu \mathrm{L} \\
0.968 \mathrm{mmol}\end{array}$ & $180^{\circ} \mathrm{C}$ & $18 \mathrm{~h}$ & $4 \mathrm{MPa}$ \\
\hline $8^{\#}$ & $\begin{array}{c}\text { 4'-hydroxy } \\
\text { acetophenone } \\
879.0 \mathrm{mg} \\
6.456 \mathrm{mmol}\end{array}$ & & $\begin{array}{l}\mathrm{MeOH} \\
30 \mathrm{~mL} \\
0.21 \mathrm{M}\end{array}$ & $\begin{array}{c}\text { DMF } \\
74.6 \mu \mathrm{L} \\
0.968 \mathrm{mmol}\end{array}$ & $180^{\circ} \mathrm{C}$ & $18 \mathrm{~h}$ & $4 \mathrm{MPa}$ \\
\hline
\end{tabular}

${ }^{*}$ Reactions were performed according to representative Procedure A; ${ }^{\#}$ Reactions were performed according to representative Procedure C. 


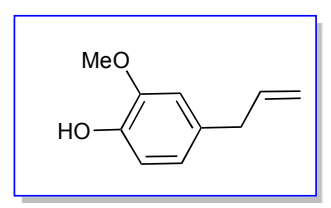

Full Conversion

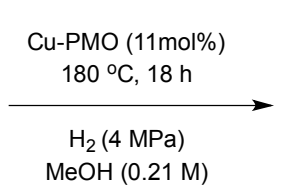

$\mathrm{MeOH}(0.21 \mathrm{M})$



$100 \%$ NMR Yield

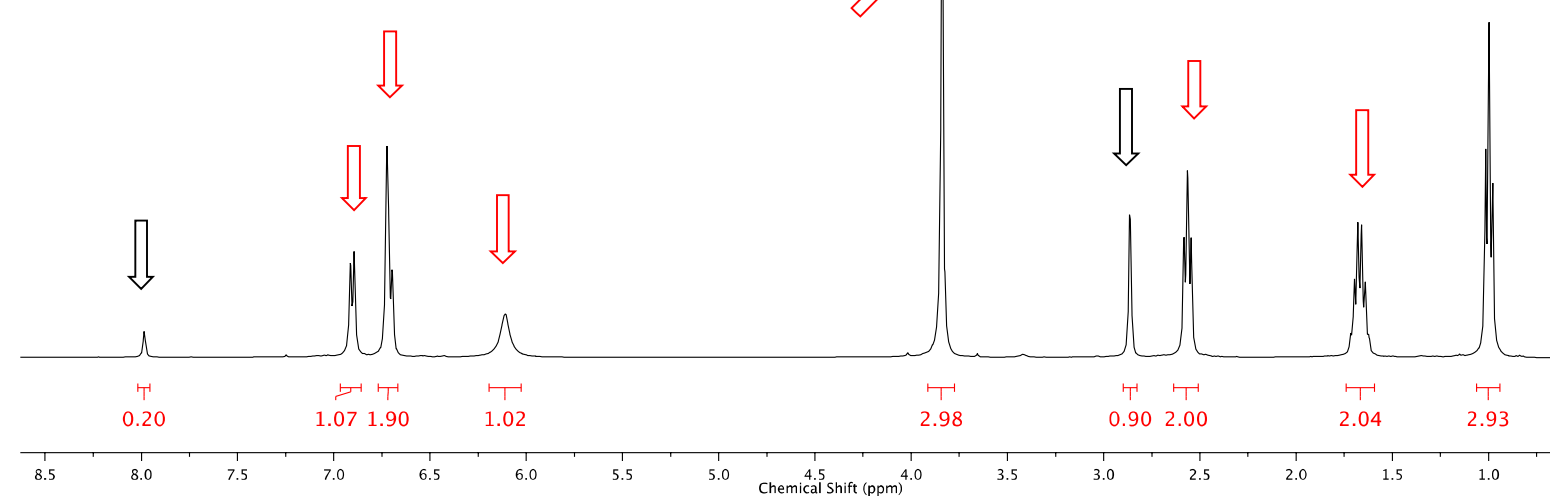

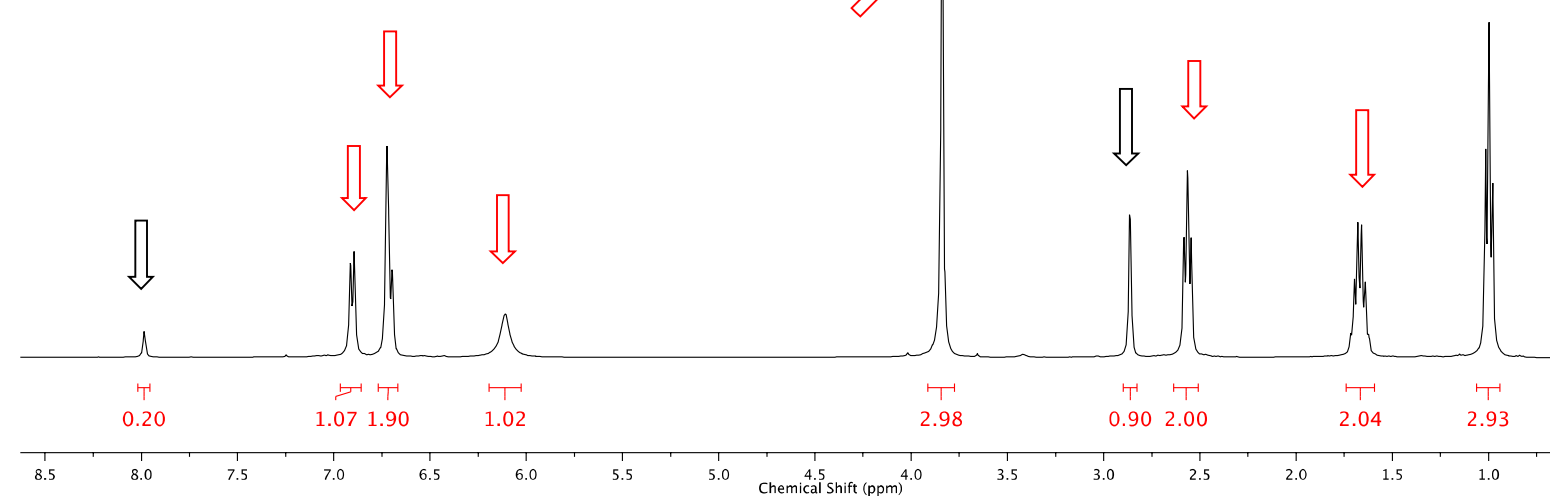

Figure S6: Crude NMR of a representative reaction showing complete conversion to S1. Conditions: Eugenol (6.456 mmol), Cu-PMO (11 mol\%), MeOH (0.21 M), $\mathrm{H}_{2}$ (40 bars), $180^{\circ} \mathrm{C}, 18 \mathrm{~h}, \mathrm{DMF}$ (as internal standard, 0.15 equiv.).

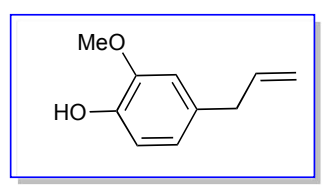

$58 \%$ conversion

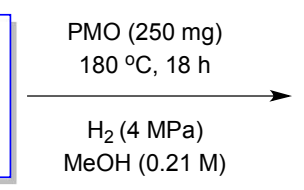

$\mathrm{MeOH}(0.21 \mathrm{M})$

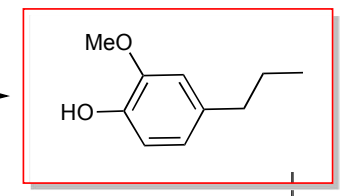

$35 \%$ NMR Yield

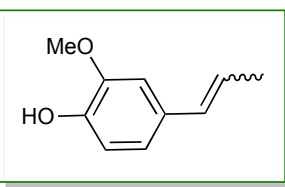

$18 \%$ NMR Yield

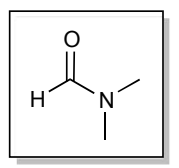

Internal Standard

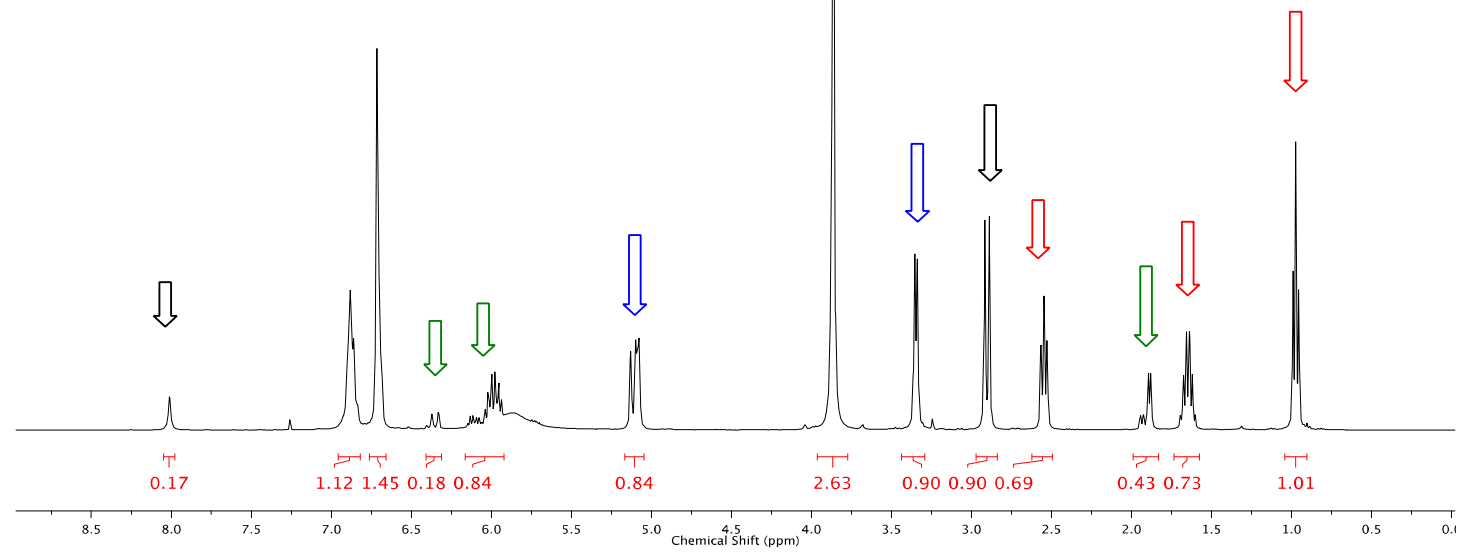

Figure S7: Crude NMR of a representative reaction showing eugenol (58\% conversion), S1 (35\% NMR yield) and IsoE (18\% NMR yield). Conditions: Eugenol (6.456 mmol), PMO (250 mg), $\mathrm{MeOH}(0.21 \mathrm{M}), \mathrm{H}_{2}$ (40 bars), $180^{\circ} \mathrm{C}, 18 \mathrm{~h}, \mathrm{DMF}$ (as internal standard, 0.15 equiv.). 


\section{e. Product Isolation and Characterization}

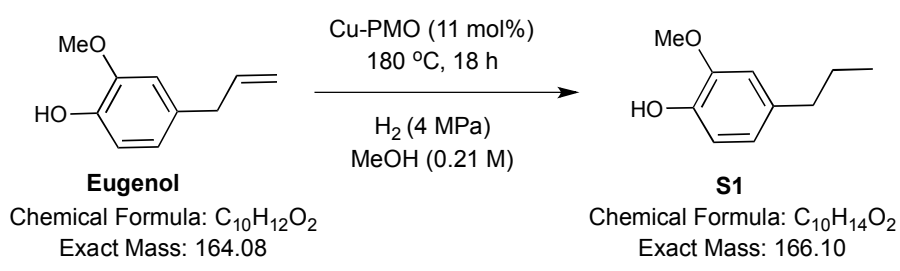

This reaction was performed following General Procedure A (Table S1, Entry 1). The crude reaction mixture was subjected to column chromatography (1\% Ethyl Acetate in Hexanes) to afford pure S1 (1029 mg, $96 \%$ isolated yield) as a clear pale yellow oil.

$\mathbf{R}_{\mathbf{f}}=0.14$ (silica gel, 95:5 Hexanes:EtOAc); ${ }^{1} \mathbf{H}$ NMR (600 MHz, Chloroform- $d$ ) $\delta 6.83$ (dd, $J=7.7,0.6 \mathrm{~Hz}, 1 \mathrm{H}), 6.70-6.65(\mathrm{~m}, 2 \mathrm{H}), 5.44$ (s, 1H), 3.88 (s, 3H), $2.56-2.49$ (m, 2H), 1.68 - $1.56(\mathrm{~m}, 2 \mathrm{H}), 0.93(\mathrm{t}, J=7.3 \mathrm{~Hz}, 3 \mathrm{H}) ;{ }^{13} \mathbf{C}$ NMR (151 MHz, Chloroform- $\left.d\right) \delta$ $146.21,143.46,134.67,120.92,114.00,110.95,55.81,37.74,24.86,13.80$. IR (neat) $v=$ $3444.8,2957.9,2931.3,2670.6,1607.1,1512.5,1285.8,1232.0,1150.3 \mathrm{~cm}^{-1}$.

Analytical data is identical to that reported in the literature. ${ }^{l}$

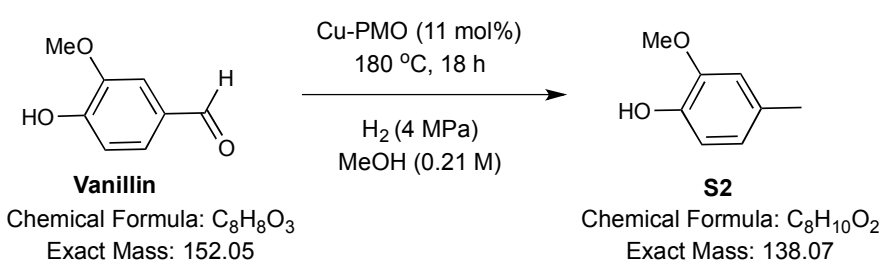

This reaction was performed following General Procedure A (Table S2, Entry 1). The crude reaction mixture was subjected to column chromatography $(5 \%$ Ethyl Acetate in Hexanes) to afford pure S2 (544.4 mg, $60 \%$ isolated yield) as a clear oil.

$\mathbf{R}_{\mathbf{f}}=0.39$ (silica gel, 3:1 Hexanes:EtOAc); ${ }^{1} \mathbf{H}$ NMR $(400 \mathrm{MHz}$, Chloroform- $d) \delta 6.81(\mathrm{~d}$, $J=7.8 \mathrm{~Hz}, 1 \mathrm{H}), 6.66(\mathrm{~d}, J=8.8 \mathrm{~Hz}, 2 \mathrm{H}), 5.44(\mathrm{~s}, 1 \mathrm{H}), 3.87(\mathrm{~s}, 3 \mathrm{H}), 2.29(\mathrm{~s}, 3 \mathrm{H}) ;{ }^{13} \mathrm{C}$ NMR (101 MHz, Chloroform- $d$ ) $\delta$ 146.22, 143.28, 129.58, 121.47, 114.07, 111.62, 55.80, 21.05; IR (neat) $\mathrm{v}=3444.8,2938.7,1606.9,1512.0,1463.7,1423.3,1363.2$, $1268.4,1231.3,1203.0,1148.6,1120.5,1032.0 \mathrm{~cm}^{-1}$.

Analytical data is identical to that reported in the literature. ${ }^{2}$ 


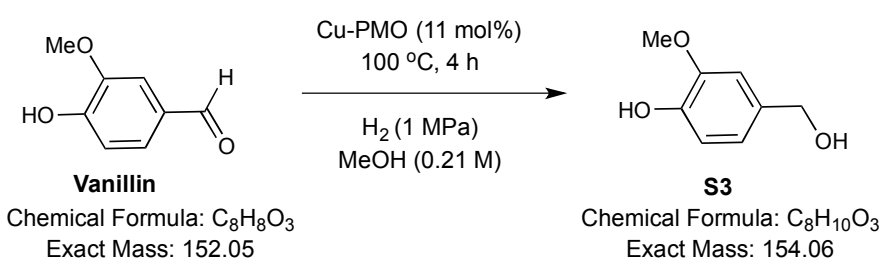

This reaction was performed following General Procedure A (Table S2, Entry 4). The crude reaction mixture was subjected to column chromatography (5\% Ethyl Acetate in Hexanes to 50\% Ethyl Acetate in Hexanes) to afford pure S3 (364.5 mg, 36 \% isolated yield) as a white solid.

$\mathbf{R}_{\mathbf{f}}=0.11$ (silica gel, 3:1 Hexanes:EtOAc); ${ }^{1} \mathbf{H}$ NMR (400 MHz, Chloroform- $\left.d\right) \delta 6.94-$ $6.85(\mathrm{~m}, 7 \mathrm{H}), 6.84(\mathrm{dd}, J=8.0,1.8 \mathrm{~Hz}, 3 \mathrm{H}), 5.60(\mathrm{~s}, 3 \mathrm{H}), 4.60(\mathrm{~d}, J=5.8 \mathrm{~Hz}, 7 \mathrm{H}), 3.90$ (s, 10H), 1.56 (s, 3H); ${ }^{13}$ C NMR (101 MHz, Chloroform-d) $\delta$ 146.62, 145.23, 132.91, 120.20, 114.22, 109.89, 65.46, 55.89; IR (neat) $\mathrm{v}=3437.8,3152.3,2965.5,2889.2$, $1602.9,1511.4,1430.8,1372.2,1233.8,1152.4,1123.0 \mathrm{~cm}^{-1}$.

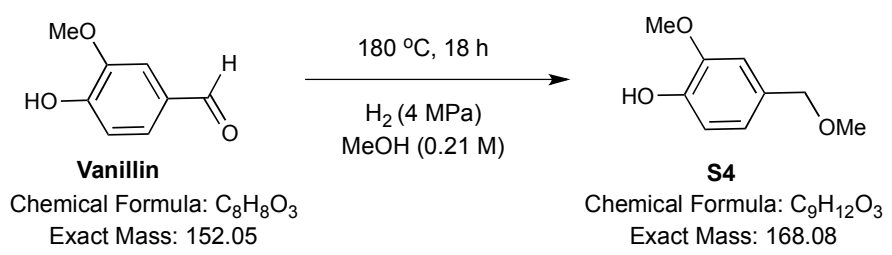

This reaction was performed following General Procedure C (Table S2, Entry 3). The crude reaction mixture was subjected to column chromatography (5\% Ethyl Acetate in Hexanes to 25\% Ethyl Acetate in Hexanes) to afford pure S4 (209.9 mg, $19 \%$ isolated yield) as a clear oil.

$\mathbf{R}_{\mathbf{f}}=0.29$ (silica gel, 3:1 Hexanes:EtOAc); ${ }^{1} \mathbf{H}$ NMR $(600 \mathrm{MHz}$, Chloroform- $d) \delta 6.89-$ $6.85(\mathrm{~m}, 2 \mathrm{H}), 6.81$ (dd, $J=8.0,1.8 \mathrm{~Hz}, 1 \mathrm{H}), 5.61$ (s, 1H), 4.37 (s, 2H), 3.89 (s, 3H), 3.36 (s, 3H); ${ }^{13}$ C NMR (151 MHz, Chloroform-d) $\delta$ 146.55, 145.22, 130.07, 121.10, 114.01, 110.41, 74.72, 57.81, 55.86; IR (neat) $\mathrm{v}=3370.8,2935.1,1605.0,1514.0,1463.1$, $1429.1,1363.5,1271.0,1238.5,1185.4,1152.4,1079.7 \mathrm{~cm}^{-1}$.

Analytical data is identical to that reported in the literature. ${ }^{3}$ 




This reaction was performed following General Procedure C (Table S2, Entry 6). The crude reaction mixture was subjected to column chromatography (5\% Ethyl Acetate in Hexanes) to afford pure $\mathbf{S 5}$ (130.2 $\mathrm{mg}, 10 \%$ isolated yield) as a clear oil.

$\mathbf{R}_{\mathbf{f}}=0.33$ (silica gel, 3:1 Hexanes:EtOAc); ${ }^{1} \mathbf{H}$ NMR (400 MHz, Chloroform- $d$ ) $\delta 7.03-$ 6.85 (m, 12H), 5.64 (d, $J=0.8 \mathrm{~Hz}, 3 \mathrm{H}), 5.29$ (s, 3H), 3.96 (s, 1H), 3.90 (s, 11H), $3.51-$ 3.45 (m, 1H), $3.32(\mathrm{~s}, 19 \mathrm{H}), 3.31$ (s, 1H), $1.29-1.19$ (m, 2H); ${ }^{13} \mathbf{C}$ NMR (151 MHz, Chloroform- $d$ ) $\delta 146.46,145.75,130.15,119.91,113.89,108.86,103.28,55.89,52.75$; IR (neat) $\mathrm{v}=3393.9,2938.8,2830.3,1608.2,1513.8,1464.0,1426.4,1348.2,1267.7$, $1155.3,1096.5,1031.6,985.5 \mathrm{~cm}^{-1}$.
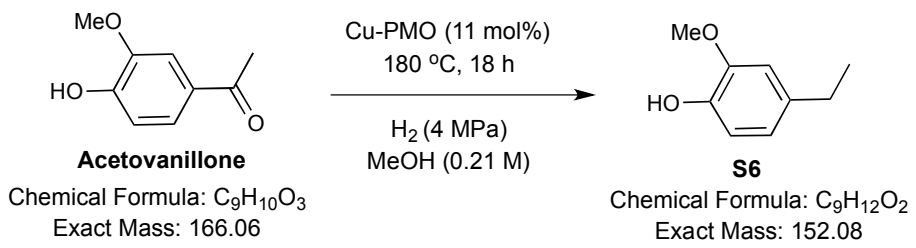

This reaction was performed following General Procedure A (Table S3, Entry 1). The crude reaction mixture was subjected to a silica plug (eluted with Ethyl Acetate) to afford pure $\mathbf{S 6}$ (569.5 mg, $58 \%$ isolated yield) as a yellow oil.

$\mathbf{R}_{\mathbf{f}}=0.44$ (silica gel, 3:1 Hexanes:EtOAc); ${ }^{1} \mathbf{H}$ NMR $(600 \mathrm{MHz}$, Chloroform- $d) \delta 6.84(\mathrm{~d}$, $J=7.7 \mathrm{~Hz}, 1 \mathrm{H}), 6.70$ (d, $J=8.4 \mathrm{~Hz}, 2 \mathrm{H}), 5.47$ (d, $J=0.9 \mathrm{~Hz}, 1 \mathrm{H}), 3.88$ (d, $J=0.9 \mathrm{~Hz}$, $4 \mathrm{H}), 2.58(\mathrm{q}, J=7.6 \mathrm{~Hz}, 2 \mathrm{H}), 1.22(\mathrm{td}, J=7.6,0.9 \mathrm{~Hz}, 4 \mathrm{H}) ;{ }^{13} \mathbf{C}$ NMR $(151 \mathrm{MHz}$, Chloroform- $d$ ) $\delta 146.29,143.46,136.25,120.23,114.13,110.45,55.81,28.55,15.94$; IR (neat) $\mathrm{v}=3442.9,2962.7,1611.5,1512.5,1452.8,1429.6,1230.5,1149.5,1121.8 \mathrm{~cm}^{-1}$. Analytical data is identical to that reported in the literature. ${ }^{4}$ 


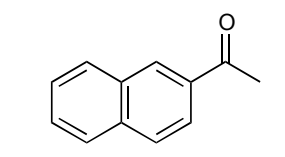

Cu-PMO (11 mol\%)

$180^{\circ} \mathrm{C}, 18 \mathrm{~h}$

2-Acetonaphthone

$\mathrm{H}_{2}(4 \mathrm{MPa})$

$\mathrm{MeOH}(0.21 \mathrm{M})$

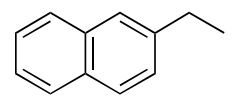

S7

Chemical Formula: $\mathrm{C}_{12} \mathrm{H}_{12}$ Exact Mass: 156.09

This reaction was performed following General Procedure A (Table S4, Entry 1). The crude reaction mixture was subjected to a silica plug (eluted with 7:1 Hexanes:Ethyl Acetate) to afford pure S7 (920.4 mg, $91 \%$ isolated yield) as a clear oil.

$\mathbf{R}_{\mathbf{f}}=0.81$ (silica gel, 7:1 Hexanes:EtOAc); ${ }^{1} \mathbf{H}$ NMR (600 MHz, Chloroform- $d$ ) $\delta 7.87$ (m, 3H), $7.71(\mathrm{~s}, 1 \mathrm{H}), 7.51(\mathrm{~m}, 2 \mathrm{H}), 7.43$ (d, $J=12 \mathrm{~Hz}, 1 \mathrm{H}), 2.89$ (q, $J=6 \mathrm{~Hz}, 2 \mathrm{H}), 1.42$ $(\mathrm{t}, J=6 \mathrm{~Hz}, 3 \mathrm{H}) ;{ }^{13} \mathbf{C}$ NMR $(151 \mathrm{MHz}$, Chloroform- $d) \delta 141.77,133.70,131.93,127.81$, $127.61,127.42,127.10,125.84,125.54,125.02,29.07,15.57$; IR (neat) $\mathrm{v}=3052.2$, 2964.1, 2930.0, 2871.9, 1632.0, 1601.0, 1508.4, 1452.5, 1374.2, 1319.4, 1269.4, 1124.5, $1054.6,1018.3 \mathrm{~cm}^{-1}$.

Analytical data is identical to that reported in the literature ${ }^{5}$.
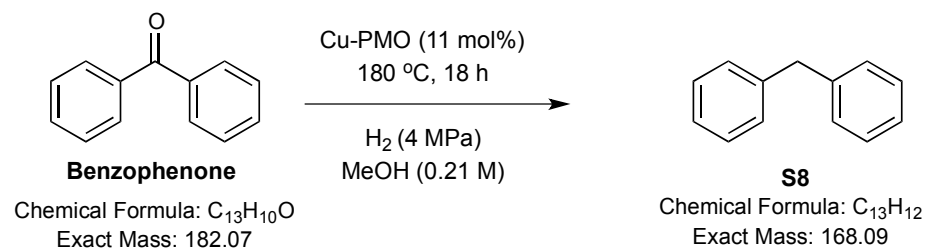

This reaction was performed following General Procedure A (Table S4, Entry 3). The crude reaction mixture was subjected to a silica plug (eluted with 5:1 Hexanes:Ethyl Acetate) to afford pure S8 (1041 mg, $96 \%$ isolated yield) as a clear oil.

$\mathbf{R}_{\mathbf{f}}=0.48$ (silica gel, 5:1 Hexanes:EtOAc); ${ }^{1} \mathbf{H}$ NMR (600 MHz, Chloroform- $d$ ) $\delta 7.31$ $(\mathrm{dd}, J=8.5,6.9 \mathrm{~Hz}, 4 \mathrm{H}), 7.26-7.20(\mathrm{~m}, 6 \mathrm{H}), 4.02(\mathrm{~s}, 2 \mathrm{H}) ;{ }^{13} \mathbf{C}$ NMR (151 MHz, Chloroform- $d$ ) $\delta 141.11,128.94,128.46,126.06,41.95$; IR (neat) $\mathrm{v}=3062.2,3026.5$, $1599.4,1493.4,1450.6,1075.7,1029.4 \mathrm{~cm}^{-1}$.

Analytical data is identical to that reported in the literature ${ }^{6}$. 

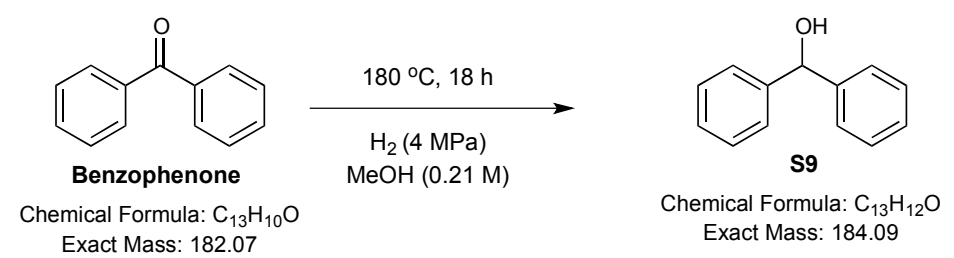

This reaction was performed following General Procedure C (Table S4, Entry 4). The crude reaction mixture was subjected to column chromatography (eluted with 6:1 Hexanes:Ethyl Acetate) to afford pure $\mathbf{S 9}$ (125.8 $\mathrm{mg}, 10.5 \%$ isolated yield) as a white solid.

$\mathbf{R}_{\mathbf{f}}=0.30$ (silica gel, 6:1 Hexanes:EtOAc); ${ }^{1} \mathbf{H}$ NMR $(600 \mathrm{MHz}$, Chloroform- $d$ ) $\delta 7.39$ (d, $J=6 \mathrm{~Hz}, 4 \mathrm{H}$ ), 7.34 (t, $J=6 \mathrm{~Hz}, 4 \mathrm{H}$ ), 7.27 (t, J = 6 Hz, 2H), 5.84 (s, 1H), 2.23 (br s, 1H); ${ }^{13}$ C NMR (151 MHz, Chloroform- $d$ ) $\delta$ 143.76, 128.49, 127.56, 126.51, 77.22, 77.01, 76.79, 76.26; IR (neat) $\mathrm{v}=3270.9,1596.7,1492.5,1453.8,1445.9,1344.0,1315.5$, $1196.8,1174.8,1084.0,1031.3,1015.6 \mathrm{~cm}^{-1}$.

Analytical data is identical to that reported in the literature ${ }^{7}$.

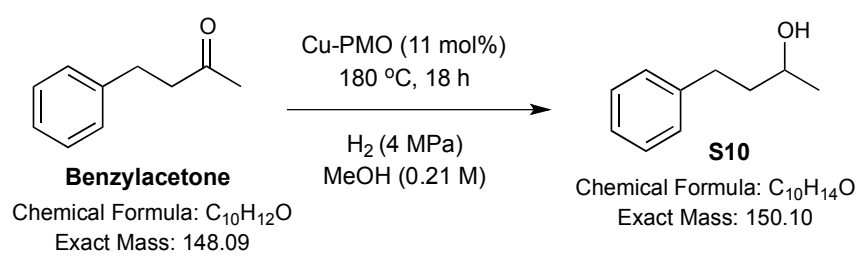

This reaction was performed following General Procedure A (Table S4, Entry 4). The crude reaction mixture was subjected to column chromatography (eluted with 5:1 Hexanes:Ethyl Acetate) to afford pure $\mathbf{S 1 0}$ (822 mg, $95 \%$ isolated yield) as a clear oil. $\mathbf{R}_{\mathbf{f}}=0.19$ (silica gel, 5:1 Hexanes:EtOAc); ${ }^{1} \mathbf{H}$ NMR $(600 \mathrm{MHz}$, Chloroform- $d) \delta 7.29(\mathrm{t}$, $J=7.5 \mathrm{~Hz}, 2 \mathrm{H}), 7.23-7.16(\mathrm{~m}, 3 \mathrm{H}), 3.87-3.79$ (m, 1H), $2.76(\mathrm{ddd}, J=13.7,9.5,6.1 \mathrm{~Hz}$, 1H), 2.67 (ddd, $J=13.8,9.3,6.8 \mathrm{~Hz}, 1 \mathrm{H}), 1.84-1.73(\mathrm{~m}, 2 \mathrm{H}), 1.47$ (d, $J=2.4 \mathrm{~Hz}, 1 \mathrm{H})$, 1.28 - $1.21(\mathrm{~m}, 3 \mathrm{H}) ;{ }^{13} \mathbf{C}$ NMR (151 MHz, Chloroform- $d$ ) $\delta$ 142.04, 128.38, 125.80, 67.50, 40.84, 32.13, 23.63; IR (neat) $\mathrm{v}=3345.1,2926.3,1495.1,1453.5,1373.5,1127.1$, $1053.4 \mathrm{~cm}^{-1}$.

Analytical data is identical to that reported in the literature ${ }^{8}$. 


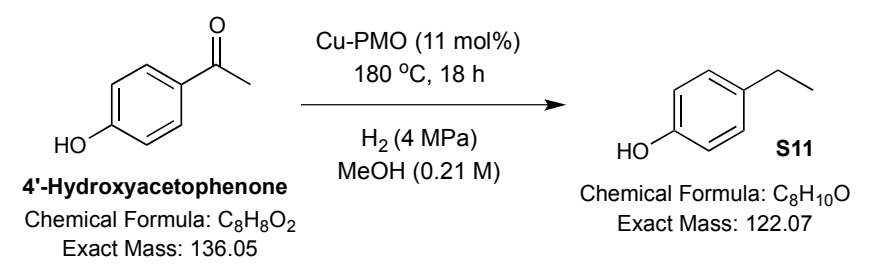

This reaction was performed following General Procedure A (Table S4, Entry 5). The crude reaction mixture was subjected to a silica plug (eluted with Ethyl Acetate) to afford pure $\mathbf{S 1 1}$ (748.8 mg, $95 \%$ isolated yield) as a white solid.

$\mathbf{R}_{\mathbf{f}}=0.54$ (silica gel, 5:1 Hexanes:EtOAc); ${ }^{1} \mathbf{H}$ NMR $(400 \mathrm{MHz}$, Chloroform- $d) \delta 7.08(\mathrm{~d}$, $J=8 \mathrm{~Hz}, 2 \mathrm{H}), 6.84(\mathrm{~d}, J=8 \mathrm{~Hz}, 2 \mathrm{H}), 2.61(\mathrm{q}, J=8 \mathrm{~Hz}, 2 \mathrm{H}), 1.25(\mathrm{t}, J=4 \mathrm{~Hz}, 3 \mathrm{H}) ;{ }^{13} \mathbf{C}$ NMR (151 MHz, Chloroform-d) $\delta 153.34,128.88,115.06,27.96,15.88$; IR (neat) v = 3232.6, 3022.0, 2962.2, 2929.7, 2869.7, 1612.8, 1598.3, 1511.0, 1449.3, 1369.1, 1215.9, $1173.2,1110.8,1063.5,1014.8 \mathrm{~cm}^{-1}$.

Analytical data is identical to that reported in the literature 9.

\section{f. Reduction of S3 with Cu-PMO}

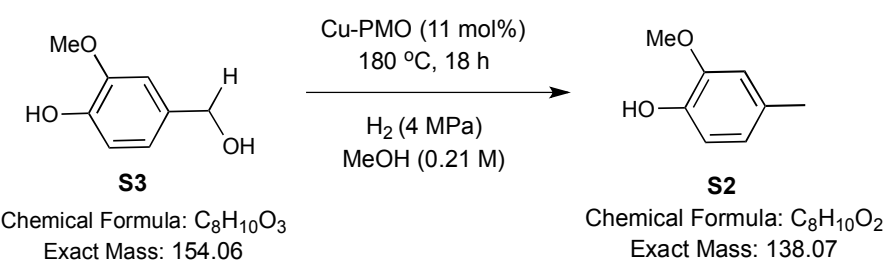

This reaction was performed following General Procedure A using S3 (1013.1 mg, 6.572 mmol, 1 equiv.) and Cu-PMO (239 mg, $0.723 \mathrm{mmol}, 0.11$ equiv.). The crude reaction mixture was analyzed directly by ${ }^{1} \mathrm{H}$ NMR after addition of DMF $(0.15$ equiv., $76 \mu \mathrm{L})$ as an internal standard. Analysis revealed complete conversion of $\mathbf{S 3}$ to creosol.

\section{g. Recycling studies with $\mathrm{Cu}-\mathrm{PMO}$}

General Procedure for recycling studies: Eugenol $(1.00 \mathrm{~mL}, 1060 \mathrm{mg}, 6.456 \mathrm{mmol}, 1$ equiv.) and $\mathrm{Cu}-\mathrm{PMO}(250 \mathrm{mg}, 0.750 \mathrm{mmol}, 11 \mathrm{~mol} \%$ ) were added to a $100 \mathrm{~mL}$ Parr reactor. Methanol $(0.21 \mathrm{M})$ was added by syringe. The reaction vessel was sealed and 
pressurized to $4 \mathrm{MPa} \mathrm{H}_{2}$ at room temperature. The sealed reactor was placed on the Parr stand and connected to the Parr controller. The heating mantle was lifted to the Parr reactor and heating was turned on to $180^{\circ} \mathrm{C}$. The reaction was allowed to stir vigorously for the appropriate amount of time at $180^{\circ} \mathrm{C}$. Pressure and temperature time points were recorded. Upon completion, the heating mantle was lowered and the Parr reactor was cooled with a slow stream of water until it reached $40^{\circ} \mathrm{C}$ internal temperature. At this point, the Parr reactor was lifted from its stand and placed in a tap water bath until internal temperature reached $19^{\circ} \mathrm{C}$. The internal pressure was released and the Parr reactor was opened. The mixture was filtered over a borosilicate glass filter, using $30 \mathrm{~mL}$ $\mathrm{MeOH}$ for transfer. The resulting filtrate was concentrated in vacuo to afford a residue that was analyzed directly by ${ }^{1} \mathrm{H}$ NMR after addition of dimethylformamide (DMF, $0.0746 \mathrm{~mL}, 0.968 \mathrm{mmol}, 0.15$ equiv.) as an internal standard. The isolated purple solid was washed twice with $5 \mathrm{~mL} \mathrm{MeOH}$, collected and placed in a dessicator until utilized in the next hydrogenation cycle. 
Table S6: Results of Recycling Experiments with $\mathrm{Cu}-\mathrm{PMO}$

\begin{tabular}{|c|c|c|}
\hline & Eugenol Conversion (\%) & Yield $S 1^{\mathrm{a}}(\%)$ \\
\hline Cycle 1 & 100 & 98 \\
\hline Cycle 2 & 100 & 100 \\
\hline Cycle 3 & 100 & 100 \\
\hline Cycle 4 & 100 & 99.5 \\
\hline Cycle 5 & 100 & 96 \\
\hline Cycle 6 & 100 & 95 \\
\hline Cycle 7 & 100 & 100 \\
\hline Cycle 8 & 100 & 100 \\
\hline Cycle 9 & 100 & 94 \\
\hline Cycle 10 & 100 & 95.5 \\
\hline Cycle 11 & 100 & 100 \\
\hline Cycle 12 & 92 & 92 \\
\hline Cycle 13 & 40 & 40 \\
\hline Cycle 14 & 27 & 15 \\
\hline
\end{tabular}

${ }^{a}$ NMR Yield as determined using DMF as internal standard

\section{h. Analysis of Cu-PMO After Reaction}

$\mathrm{Cu}-\mathrm{PMO}$ was recovered after reaction with Eugenol (General Procedure A) by filtration over a borosilicate glass filter, using $30 \mathrm{~mL} \mathrm{MeOH}$ to transfer the heterogeneous reaction mixture to the filter. The isolated purple solid was washed twice with $5 \mathrm{~mL}$ $\mathrm{MeOH}$ and placed in a dessicator until analysis by XRPD (Figure S8), SEM (Figure S9) and TEM (Figure S10). Elemental analysis of the recovered Cu-PMO was performed by ICP-OES (Table S7). XPS measurements of the recovered $\mathrm{Cu}-\mathrm{PMO}$ were performed to determine metal speciation (Figure S11). 




Figure S8: XRPD of Cu-PMO after reaction with Eugenol

Table S7: Metal Ion Composition of recovored Cu-PMO determined by ICP-OES

\begin{tabular}{|c|c|c|c|}
\hline & $\mathbf{C u}$ & Mg & Al \\
\hline Concentration (mg/L) & 37.17 & 56.94 & 28.46 \\
\hline Mass in solution (mg) & 1.859 & 2.847 & 1.423 \\
\hline Amount in solution (mmol) & 0.0293 & 0.117 & 0.0527 \\
\hline Normalized Ratio of Metals & 0.55 & 2.22 & 1.00 \\
\hline
\end{tabular}




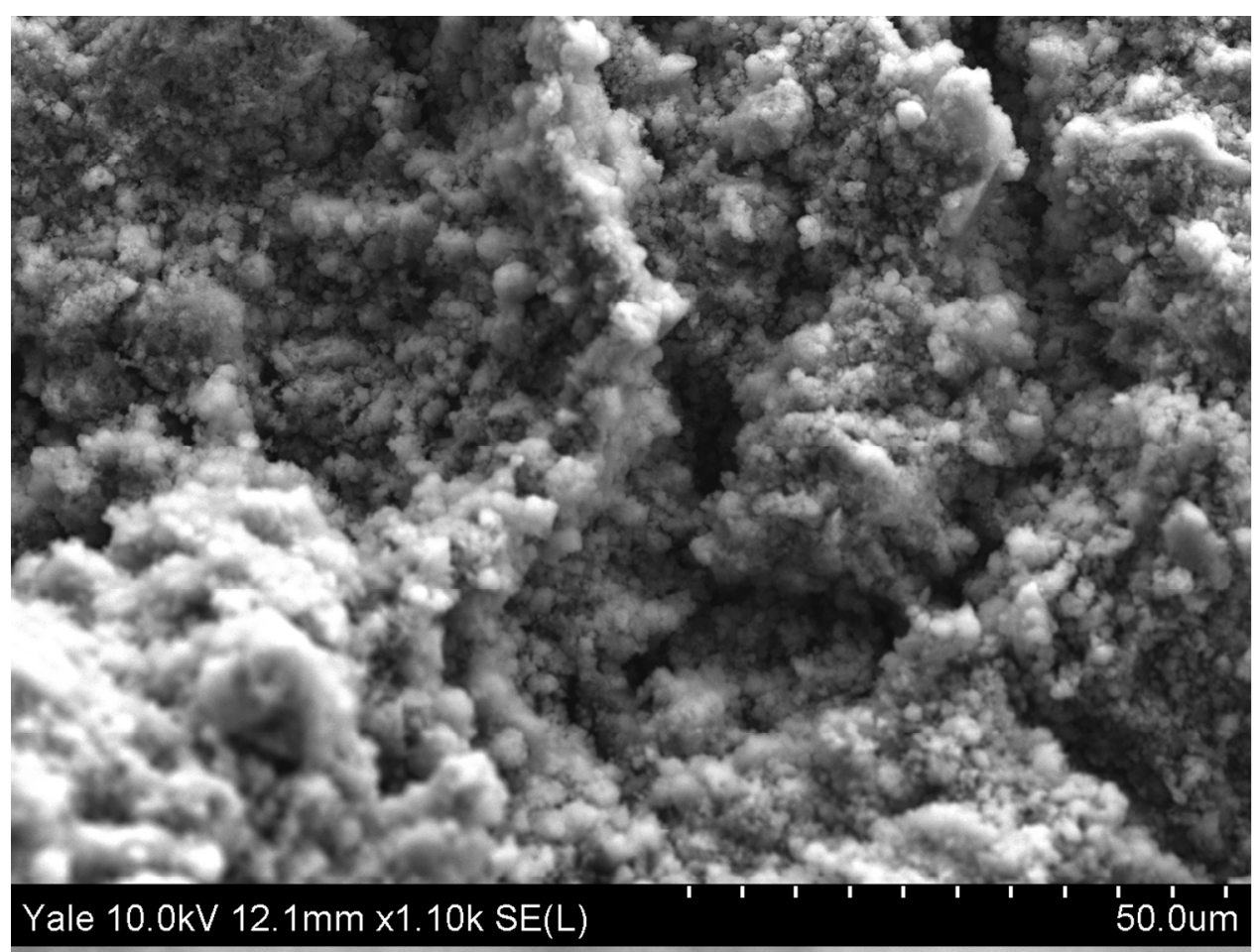

Yale $10.0 \mathrm{kV} 12.1 \mathrm{~mm} \times 25.0 \mathrm{k} \mathrm{SE}(\mathrm{M})$



Figure S9: SEM Images of Cu-PMO as recovered after hydrogenation of Eugenol 

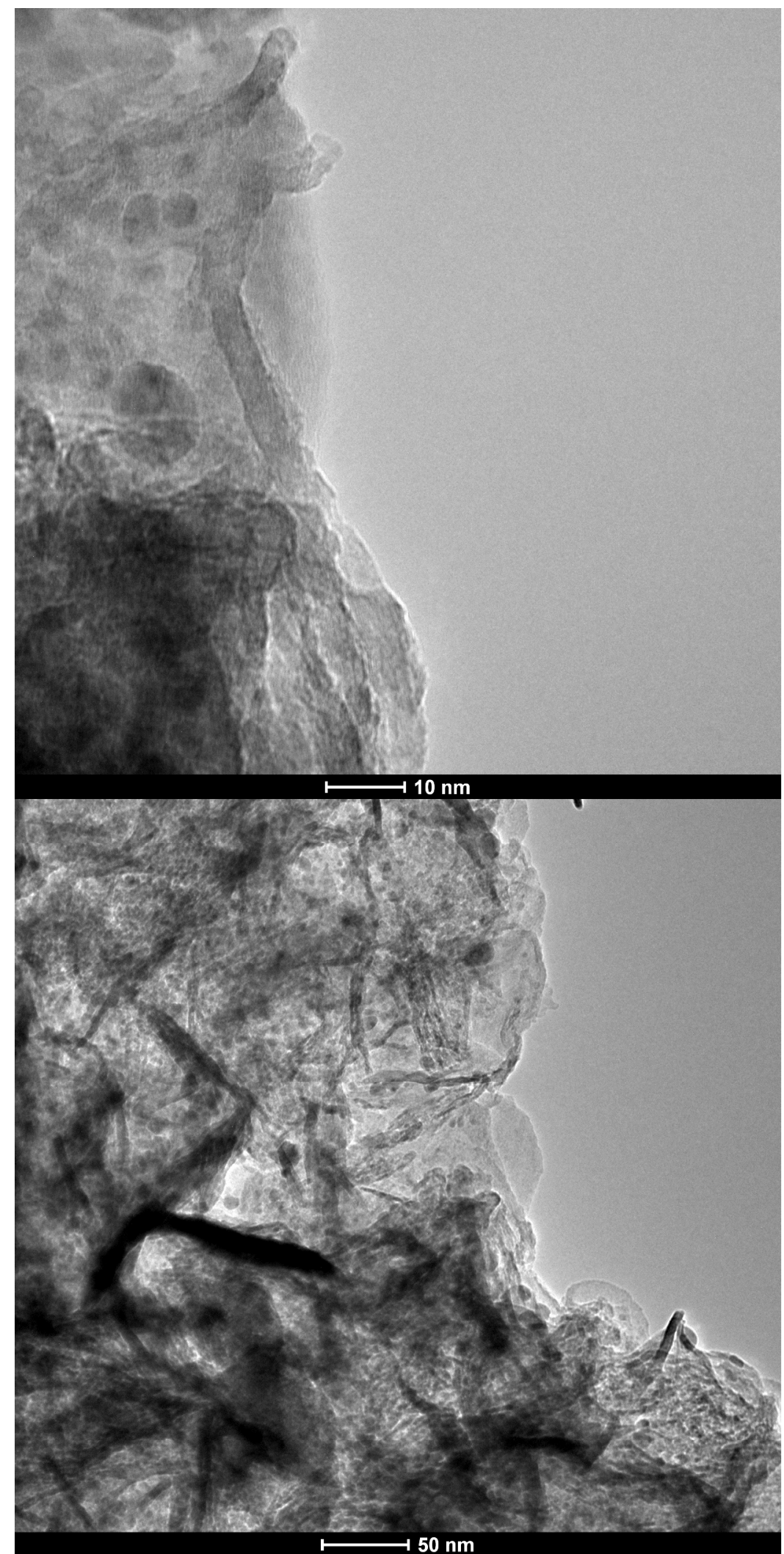

Figure S10: TEM Images of $\mathrm{Cu}-\mathrm{PMO}$ as recovered after hydrogenation of Eugenol 


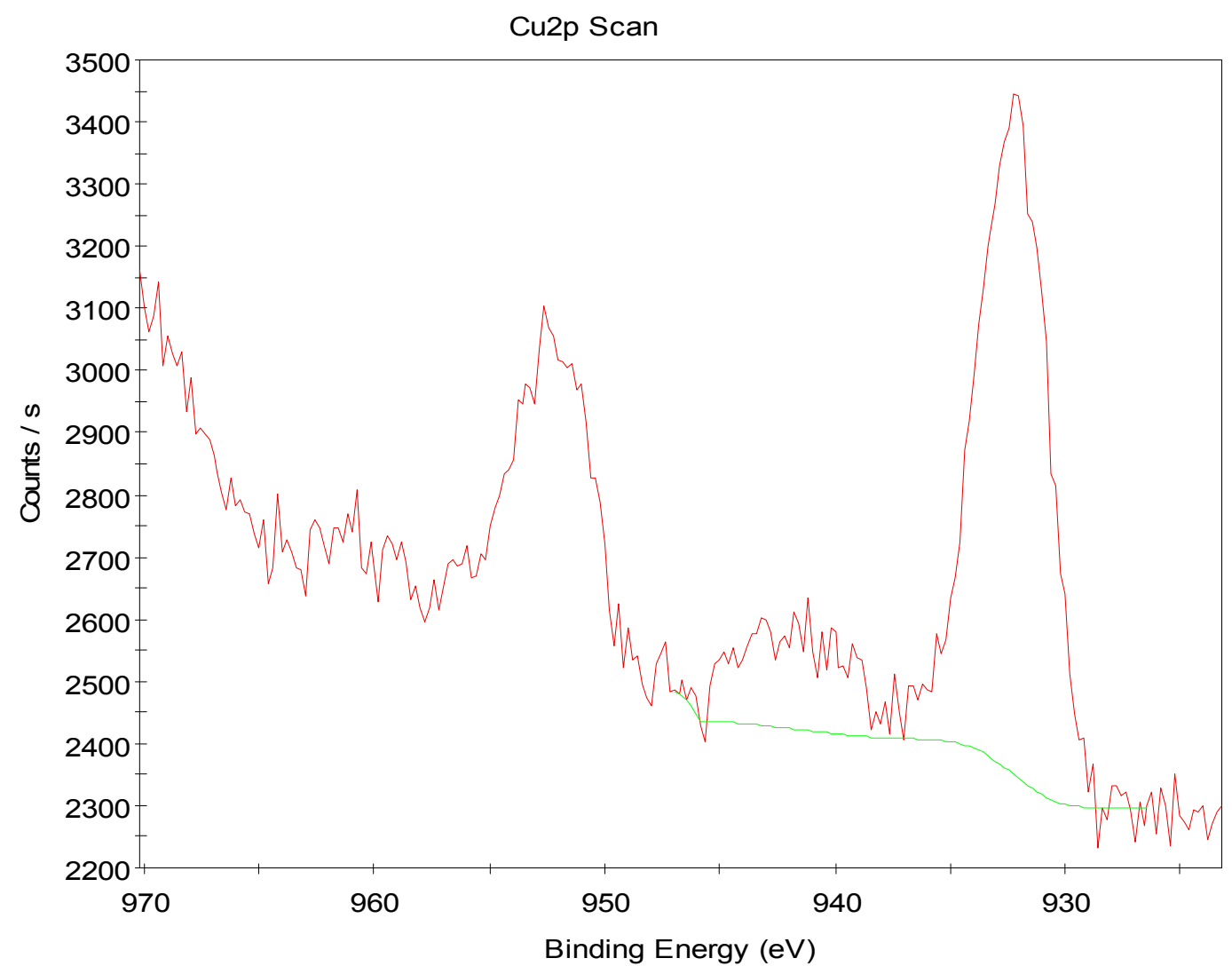

Figure S11: $\mathrm{Cu} 2 \mathrm{p} 3$ XPS of recovered Cu-PMO from reaction with eugenol

i. Born-Haber Cycle used for calculating Gibbs Free Energy of Reactions in Solution

$$
\begin{gathered}
\Delta G_{g} \\
R(g)+H_{2}(g) \rightarrow R H_{2}(g) \\
\Delta G_{s, R} \downarrow \downarrow \Delta G_{s, H_{2}} \downarrow^{\downarrow} \downarrow_{(\text {svıu })+H_{2}(\text { solu })} \rightarrow \stackrel{\Delta H_{s, R H_{2}}(\text { solu })}{\Delta G_{\text {solu }}}
\end{gathered}
$$

Scheme S1: Born-Haber Cycle for Gibbs Free Energy of Solutions

\section{Analytical Data}



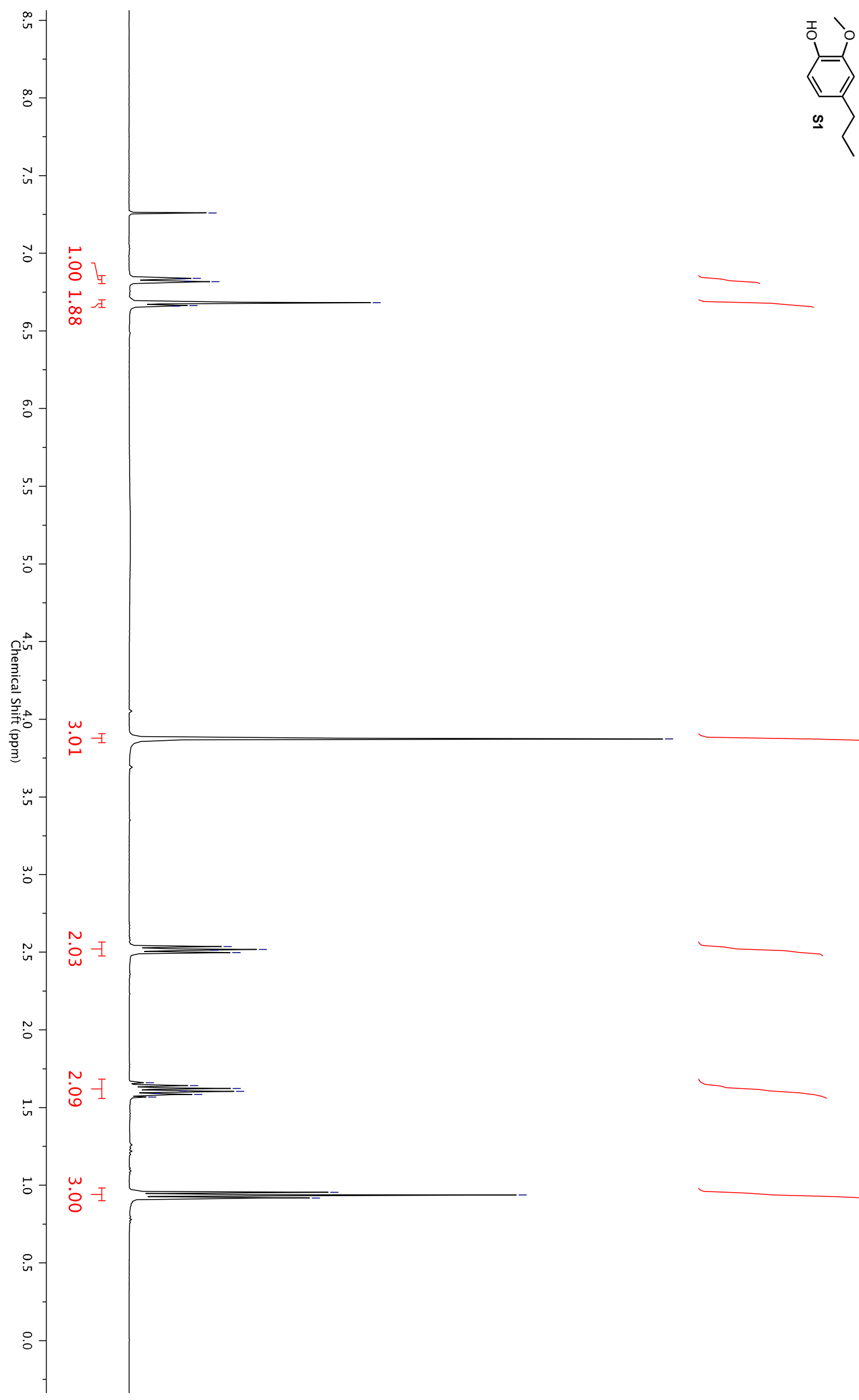

$\bigwedge 6.68$

6.66

ᄂ6.66

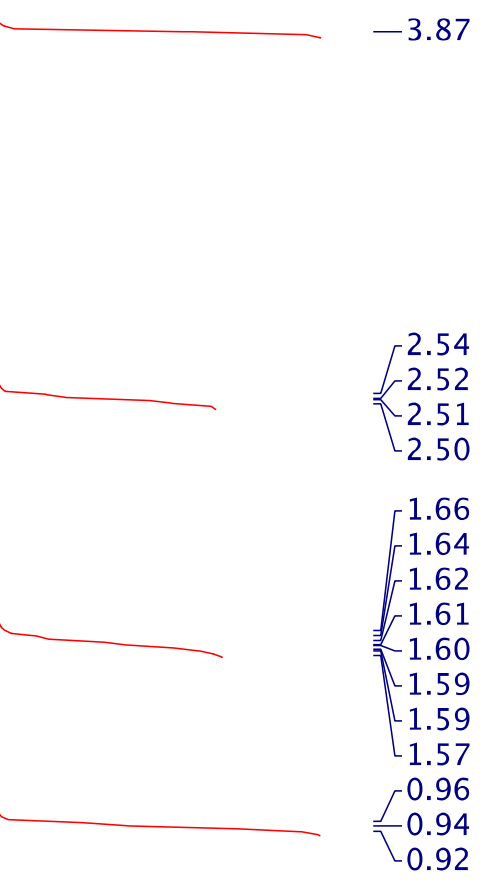



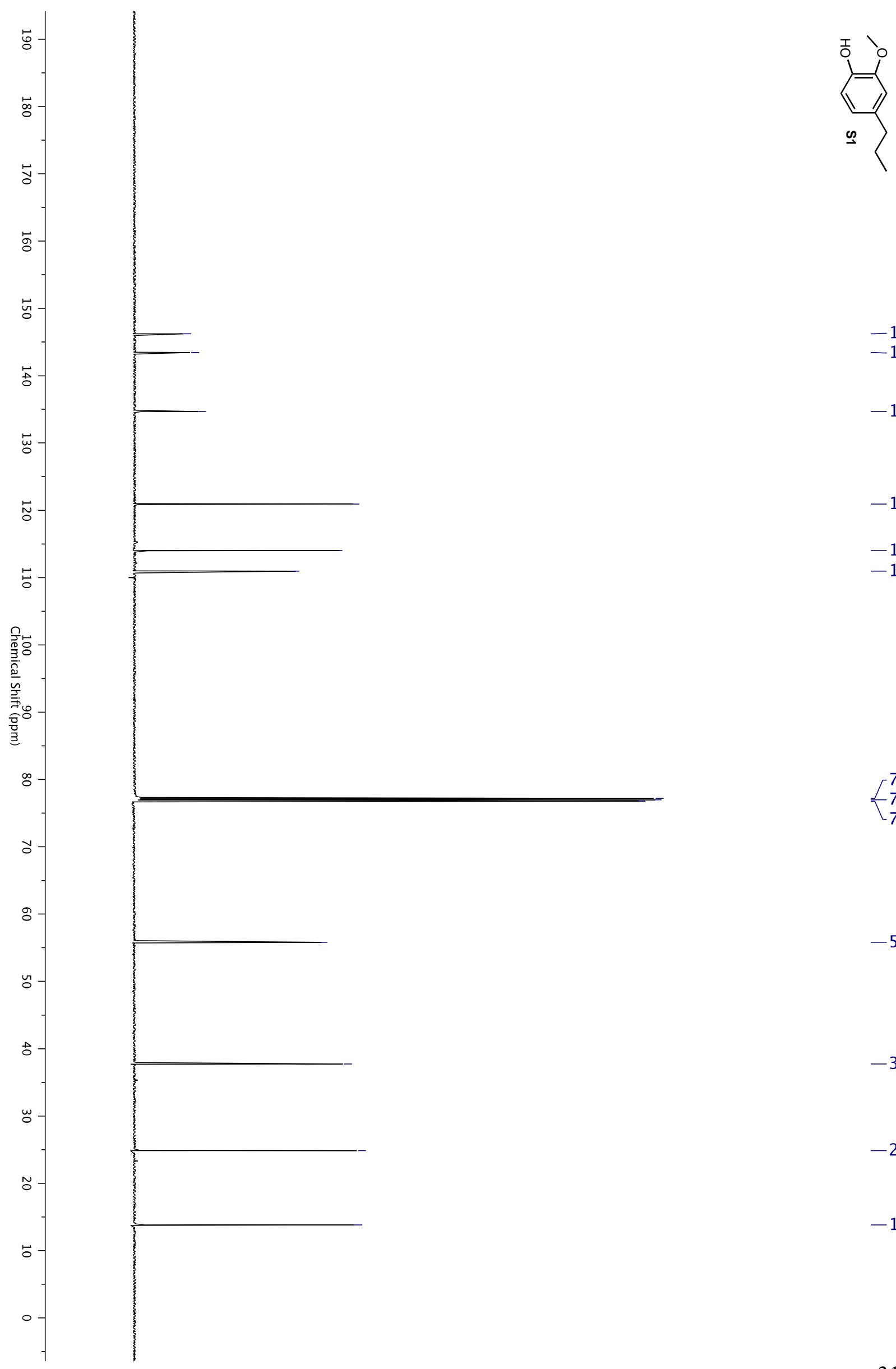

$-146.21$

$-143.46$

$-134.67$

$-120.92$

$-114.00$

$-110.95$

77.20

$\{76.99$

76.78

$-55.81$

$-37.74$

$-24.86$

$-13.80$ 


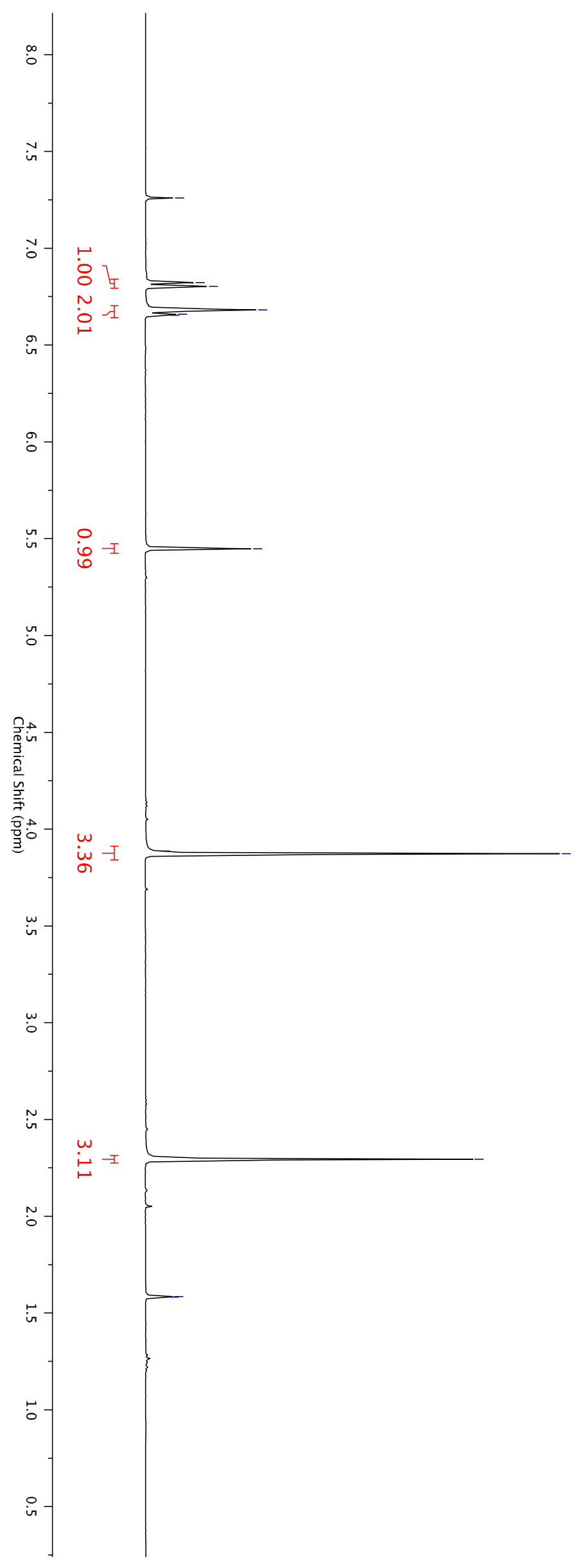

$-7.26$

6.82

$1-6.80$

6.68

6.66

6.65

$-5.45$

3.89

$\checkmark 3.87$

$-2.29$

1.59

1.58 


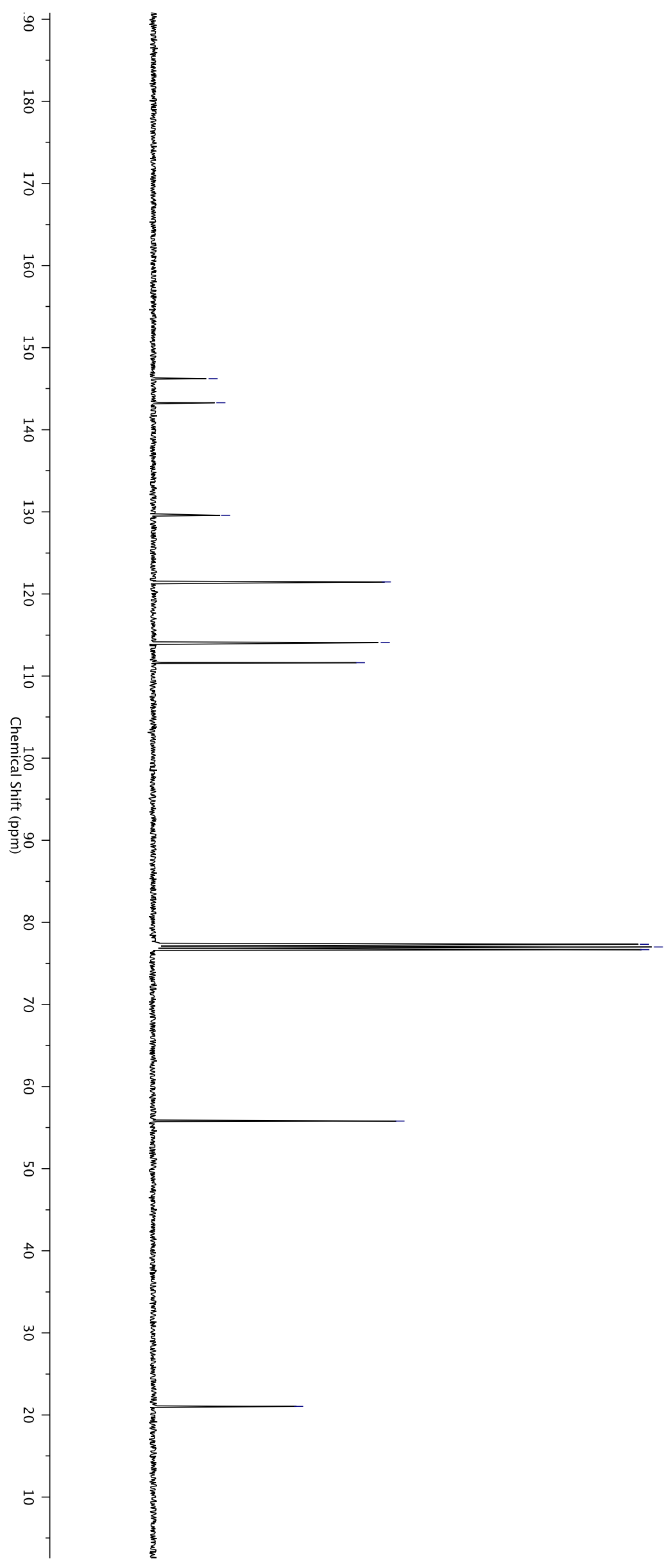

$-146.22$

$-143.28$

$-129.58$

$-121.47$

$-114.07$

$-111.62$

77.32

77.00

ᄂ76.68

$-55.80$

$-21.05$ 

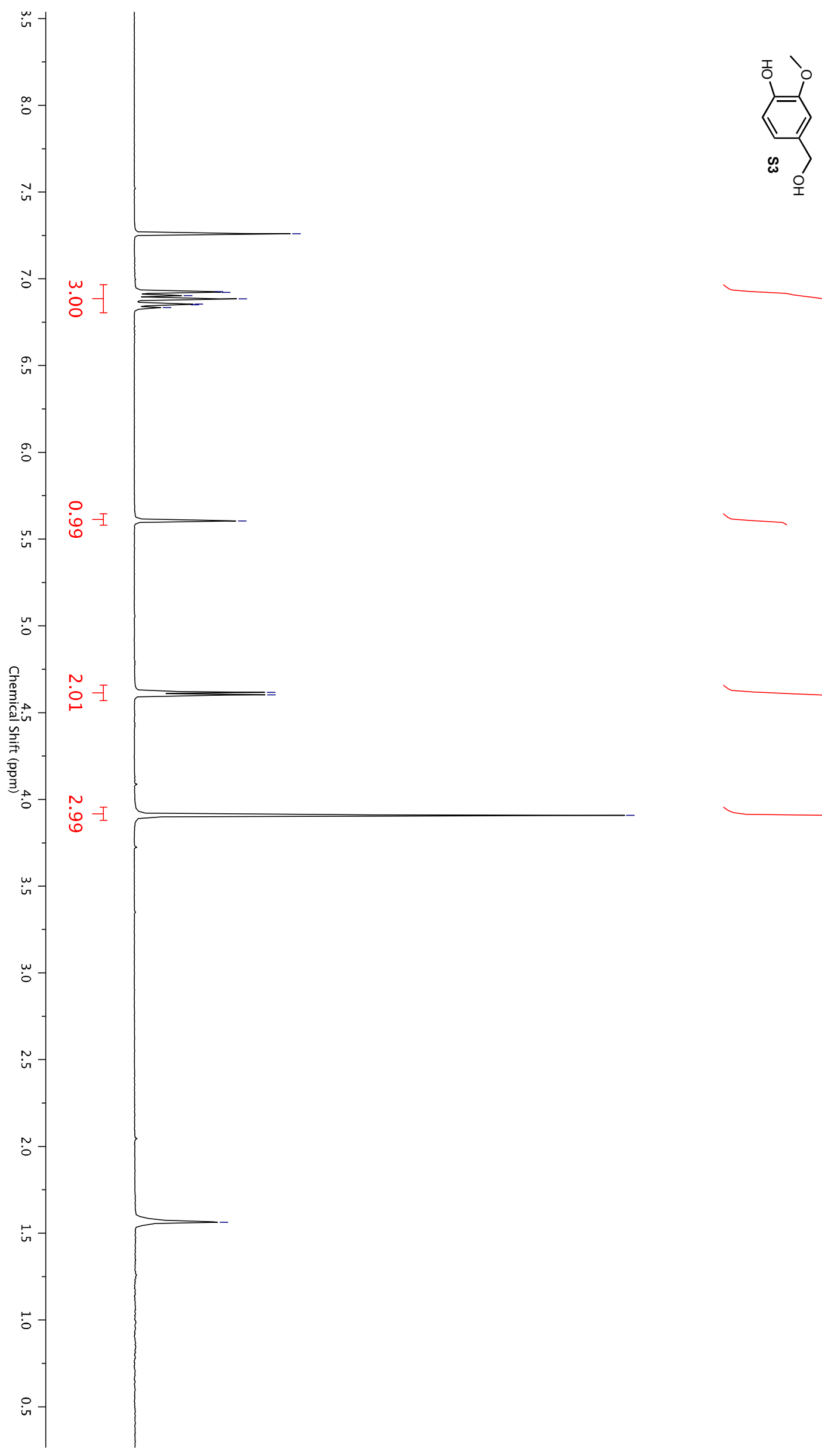


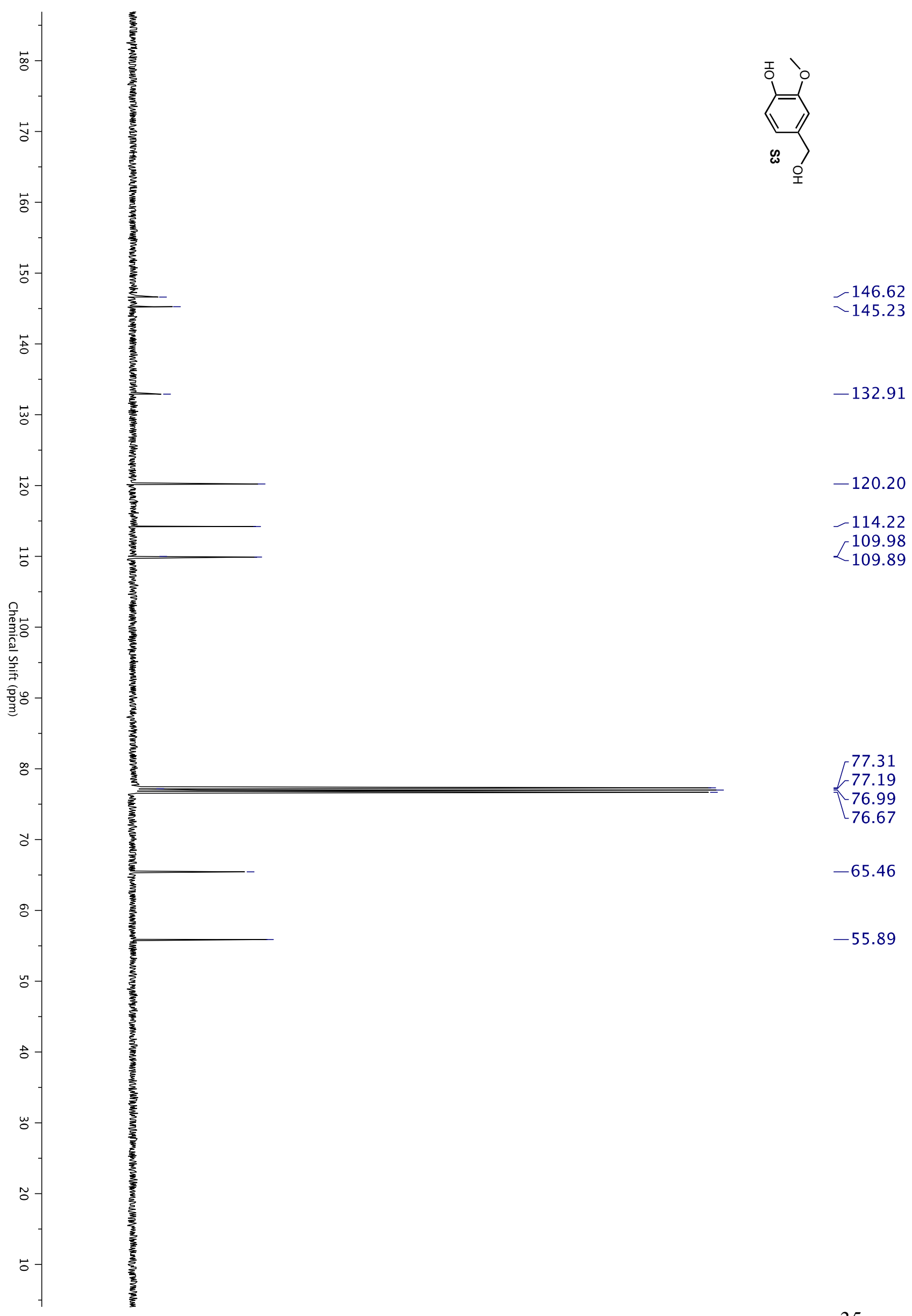



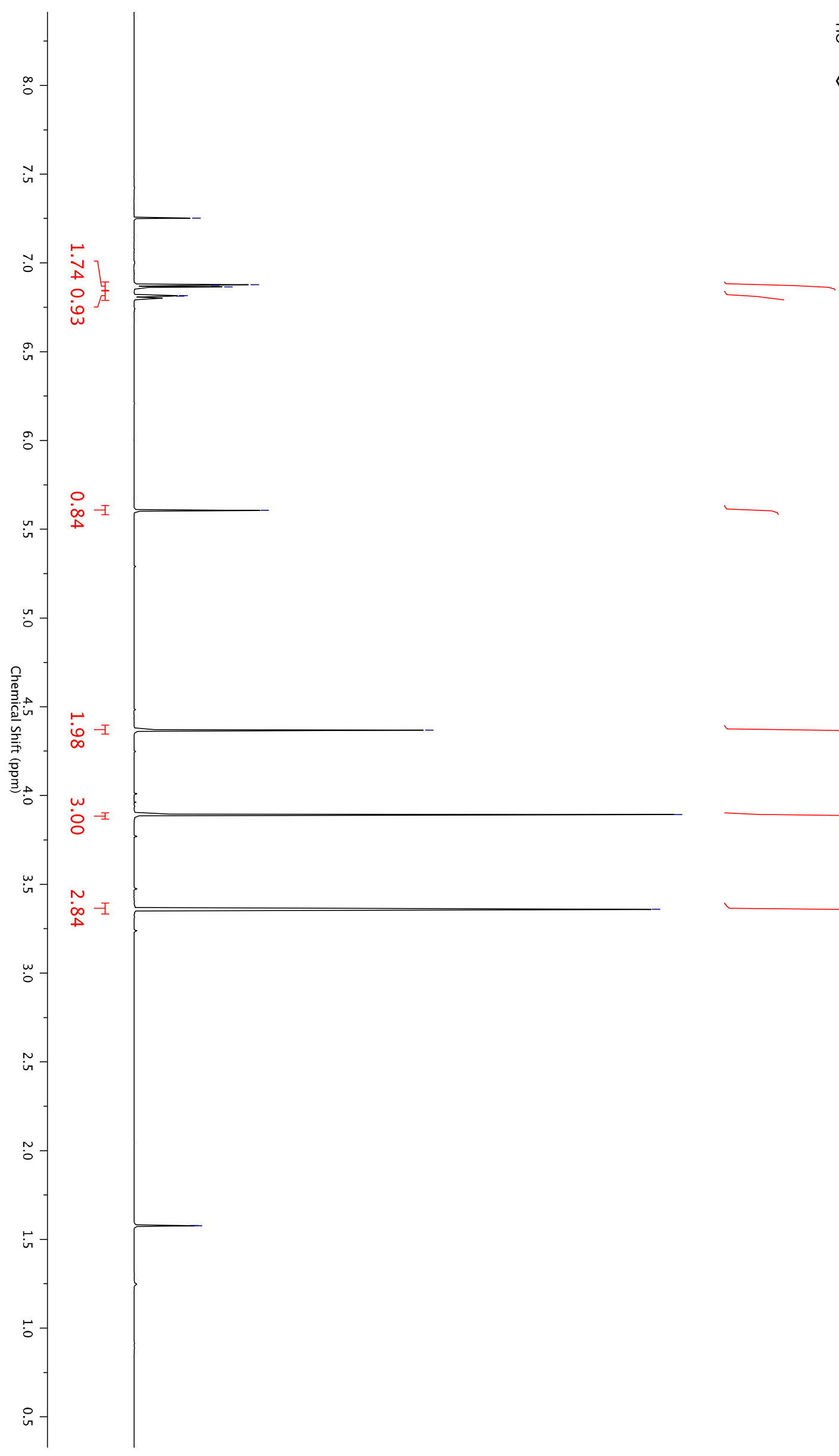

$-6.86$

$-6.82$

6.81

$-5.61$

$-4.37$

$-3.89$

$-3.36$

$<\begin{gathered}1.58 \\ 1.58\end{gathered}$

1.58 


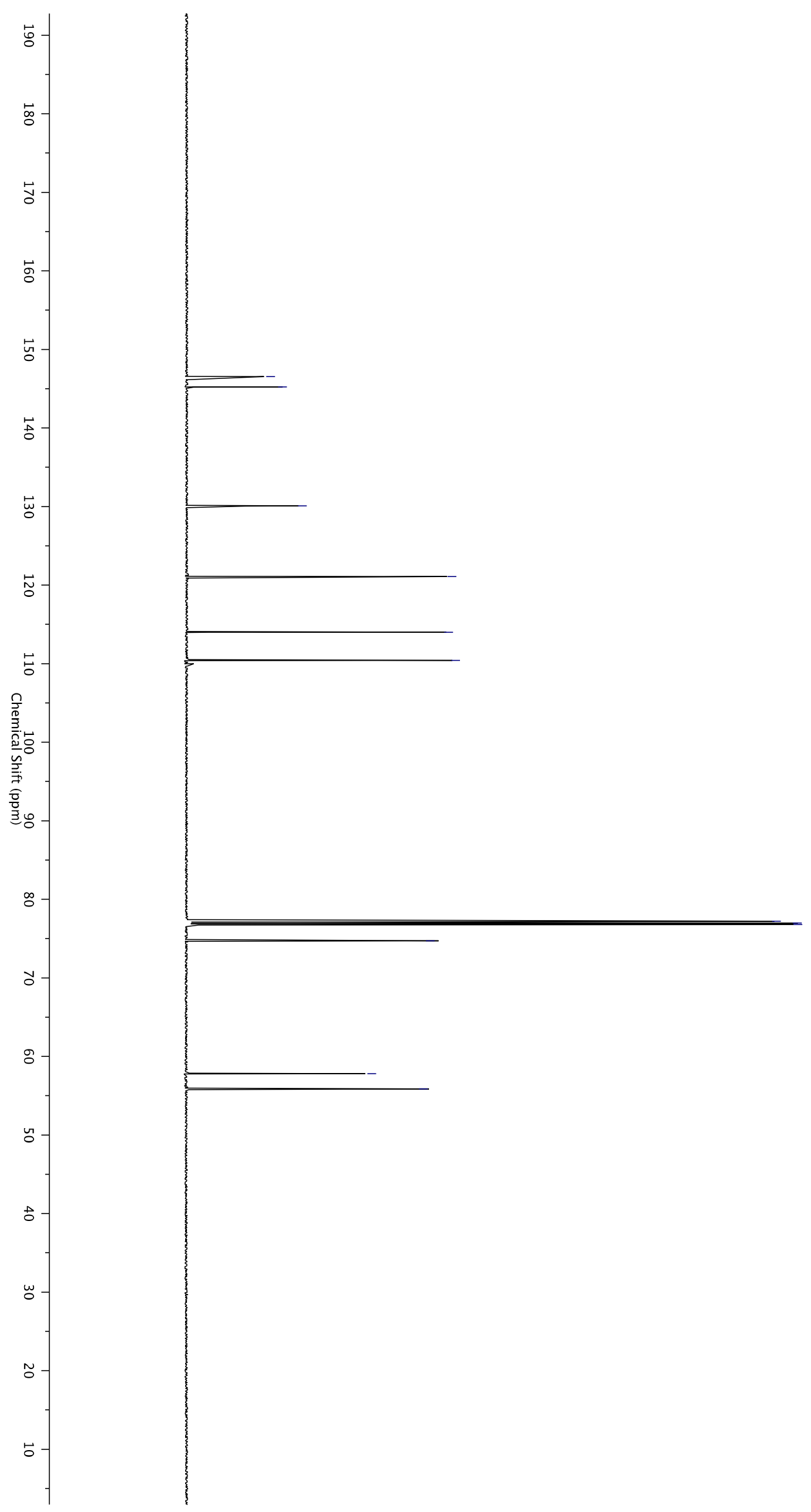

$-146.55$

$\sim 145.22$

$-130.07$

$-121.10$

$-114.01$

$-110.41$

77.20

76.99

76.78

74.72

$-57.81$

$-55.86$ 

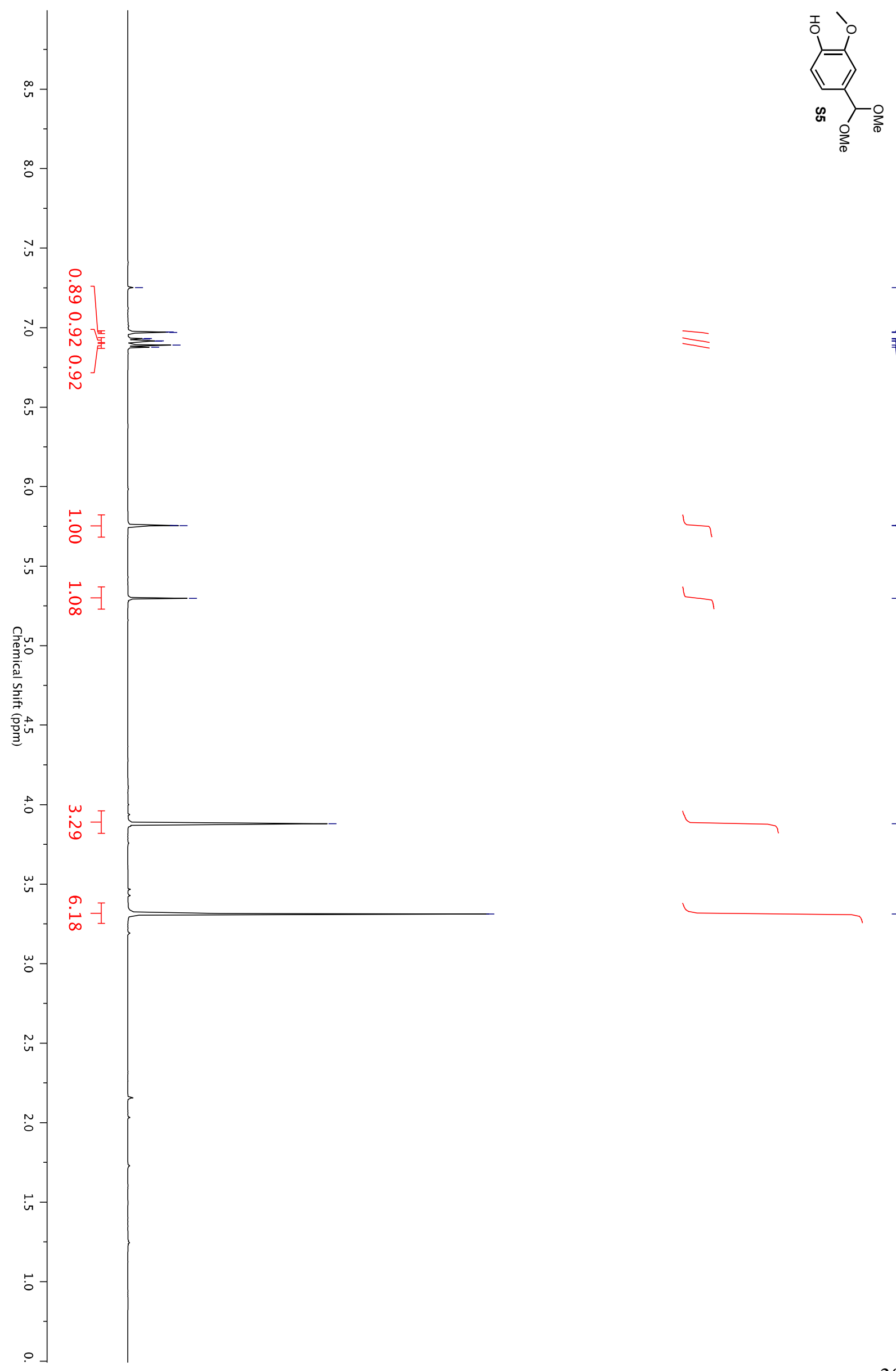

6.92

6.91

6.89

6.88

$<^{5.76}$

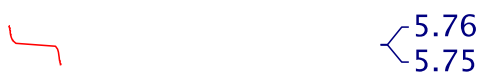

$-5.30$

$-3.88$

$-3.31$ 

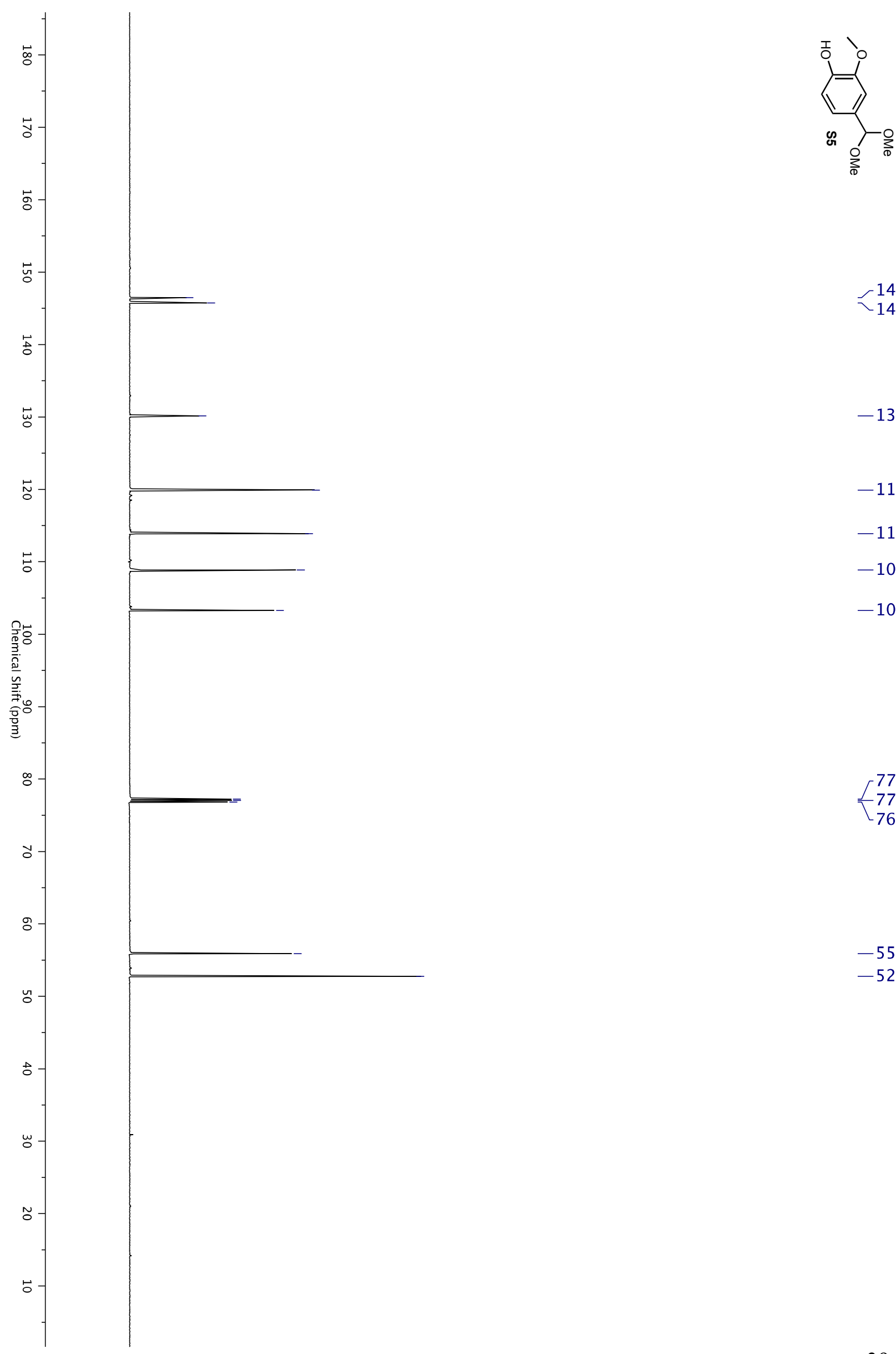

$-146.46$

145.75

$-130.15$

$-119.91$

$-113.89$

$-108.86$

$-103.28$

77.24
777.03

$-77.03$

76.82

$-55.89$

$-52.75$ 


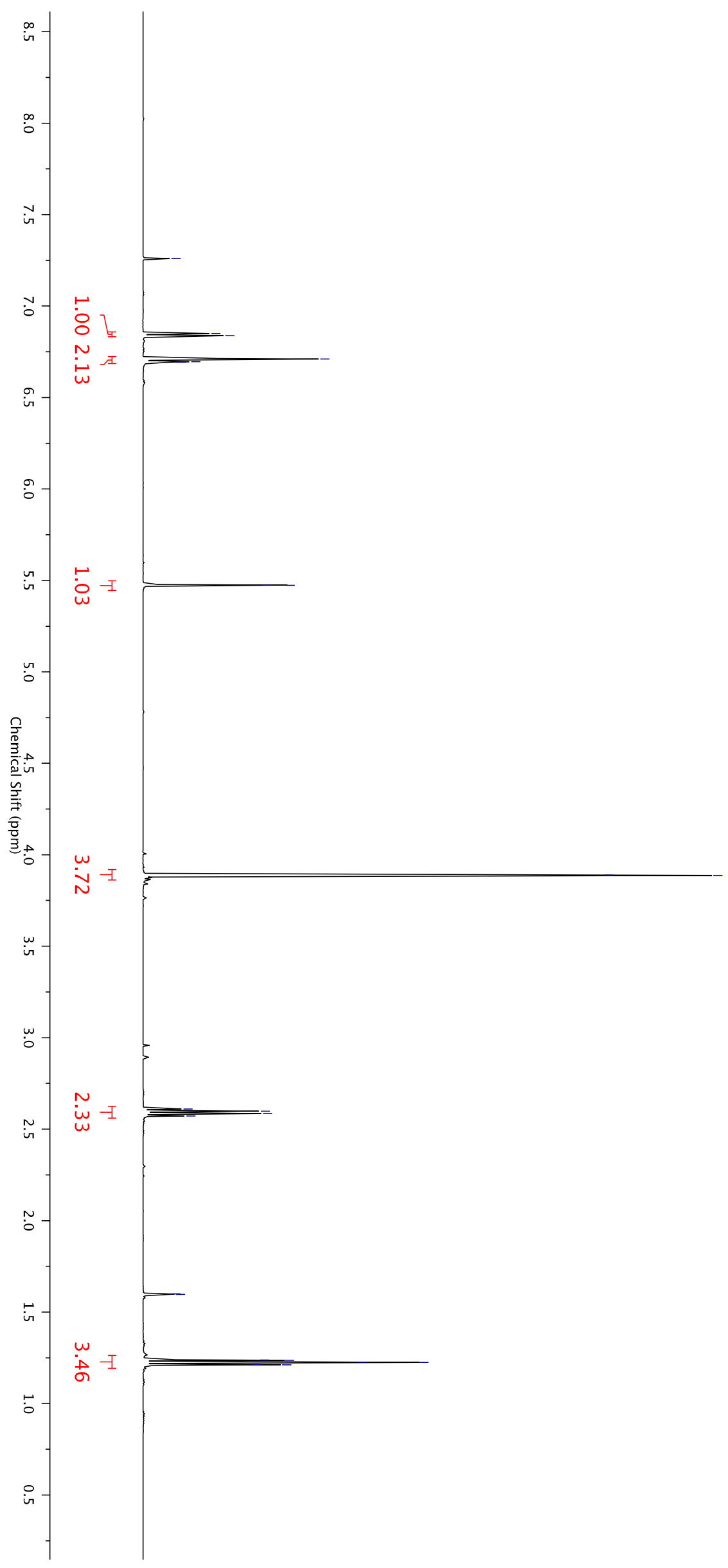

$-7.26$

6.85
-6.84

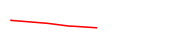

6.71

6.70

6.69

5.48

5.47

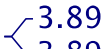

3.89

2.61
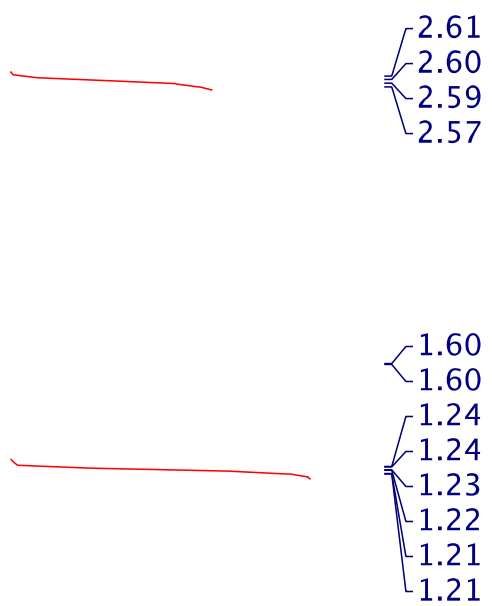


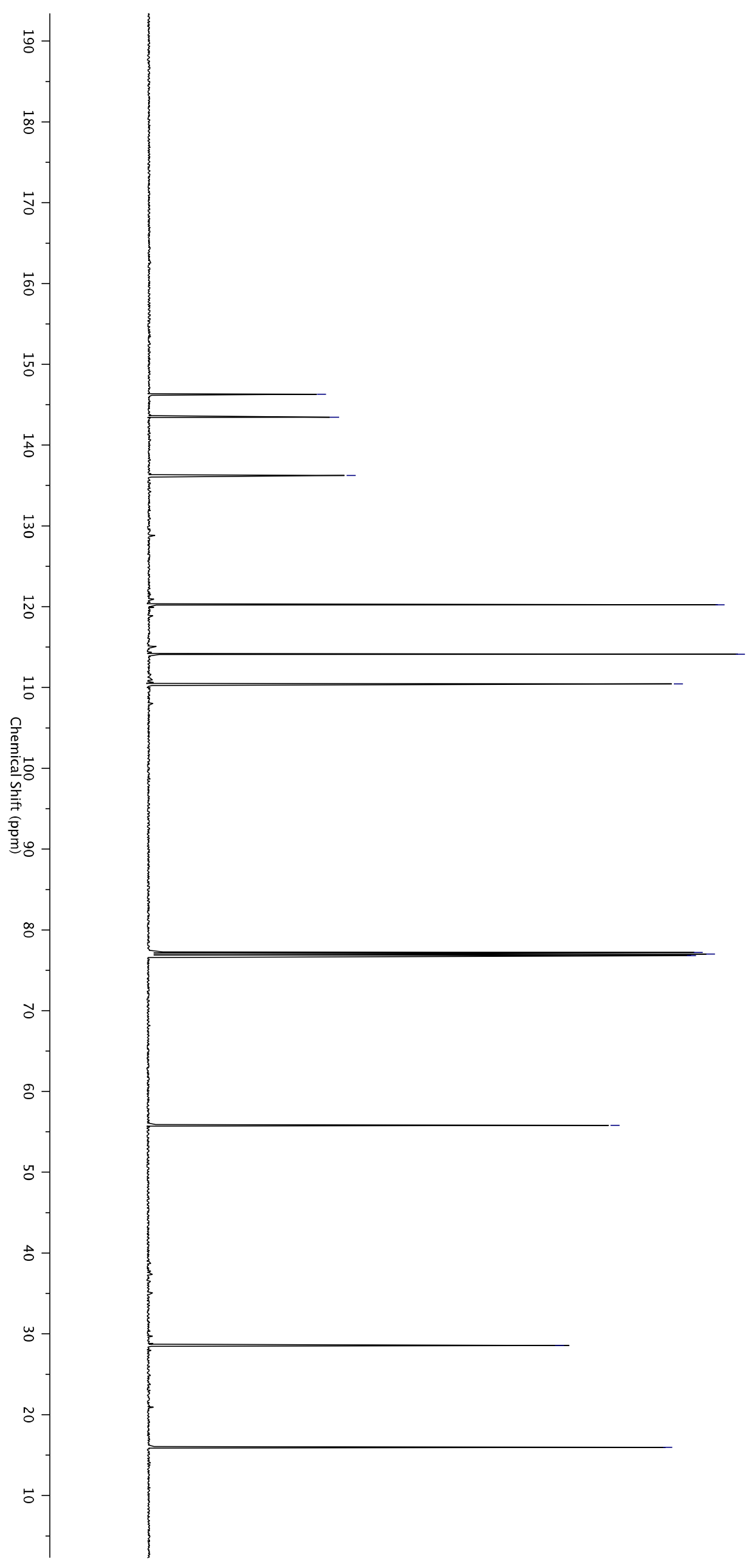

$-146.29$

$-143.46$

$-136.25$

$-120.23$

$-114.13$

$-110.45$

77.22

$-77.00$

76.79

$-55.81$

$-28.55$

$-15.94$ 

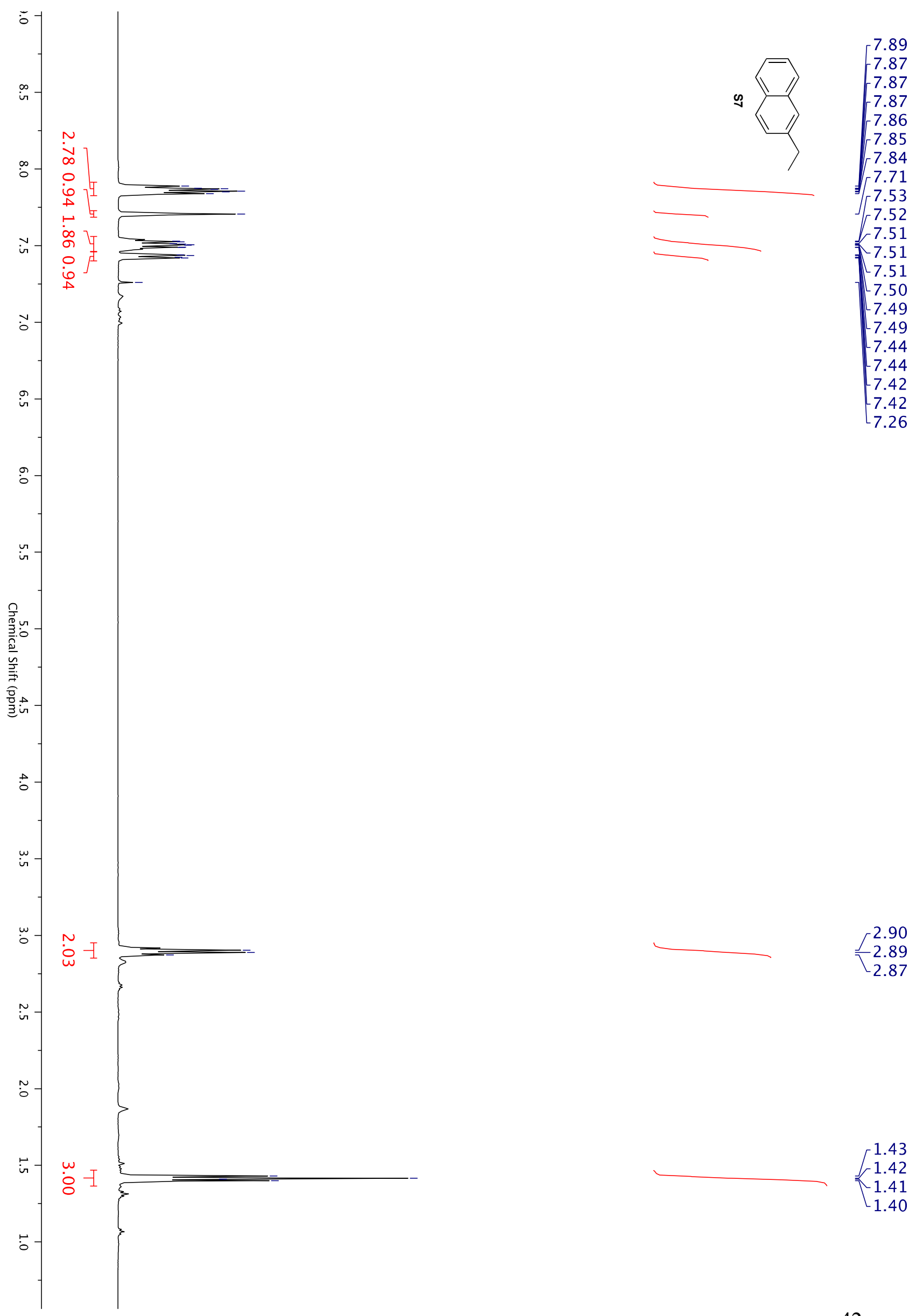


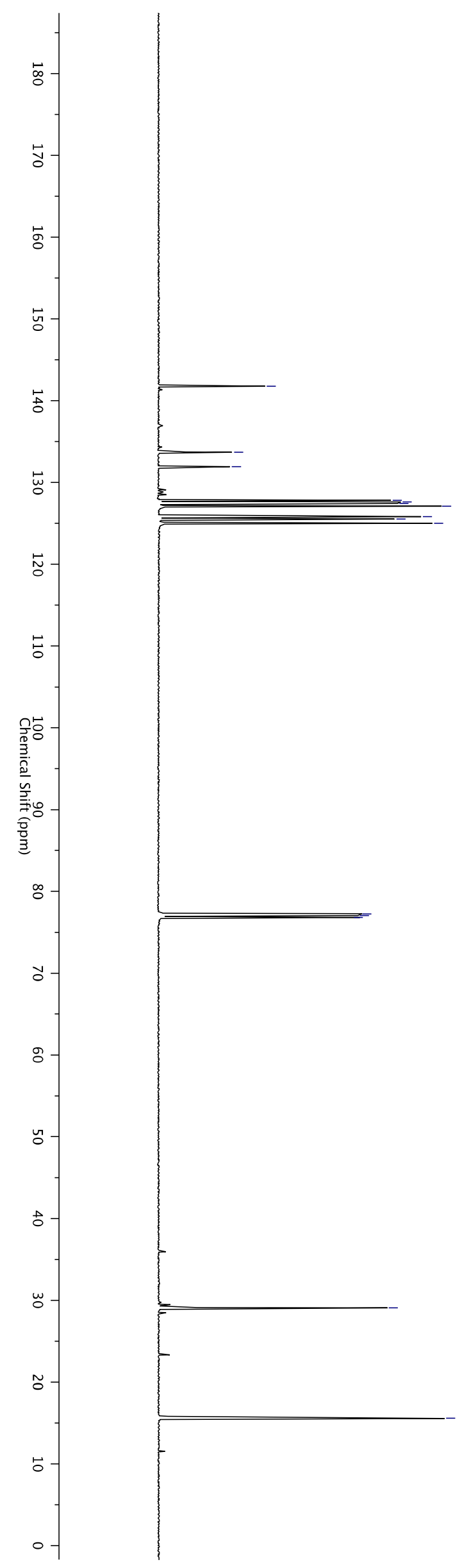

$-141.77$

133.70

131.93

127.81

127.61

$-127.42$

- 127.10

125.84

125.54

125.02 


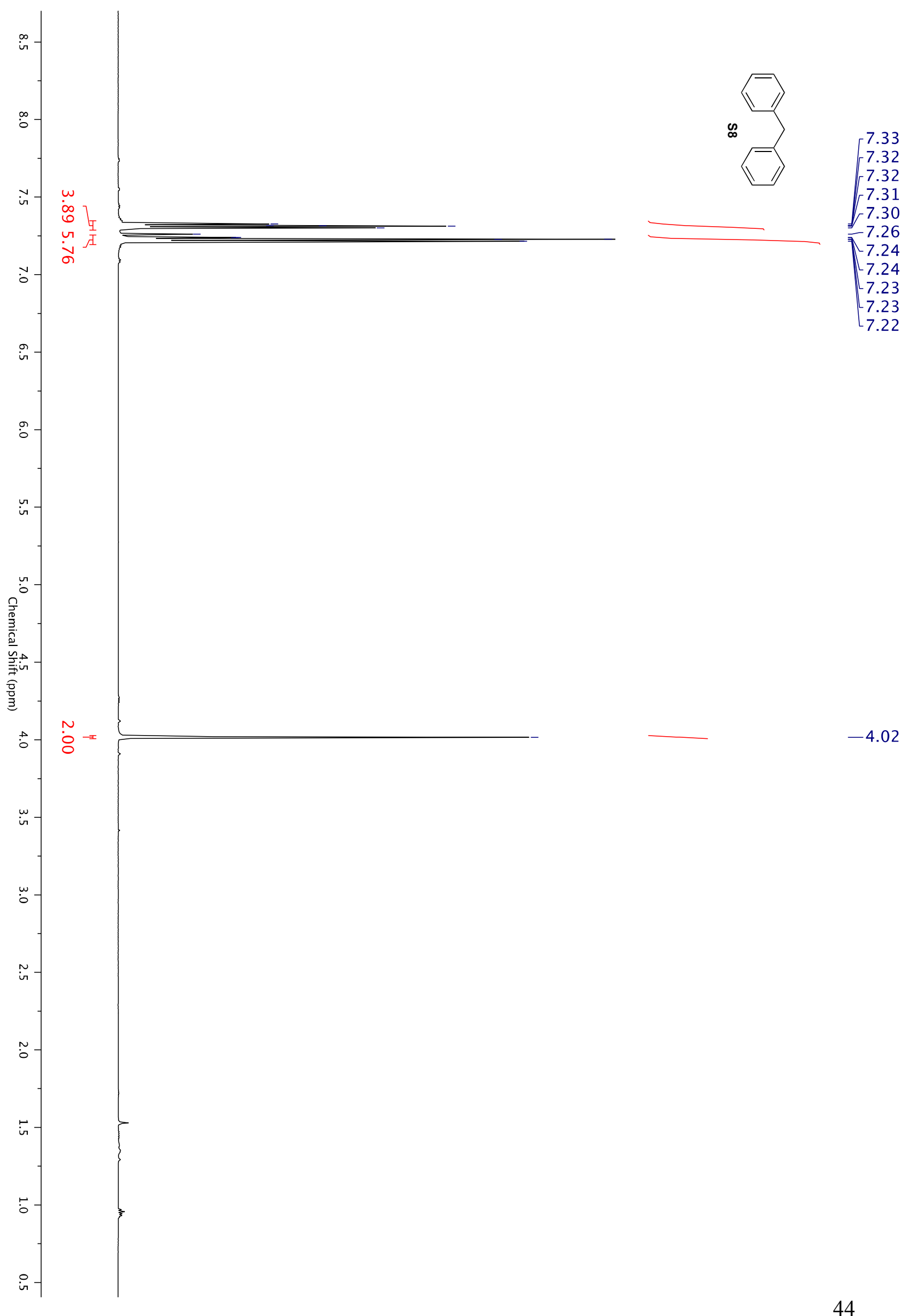




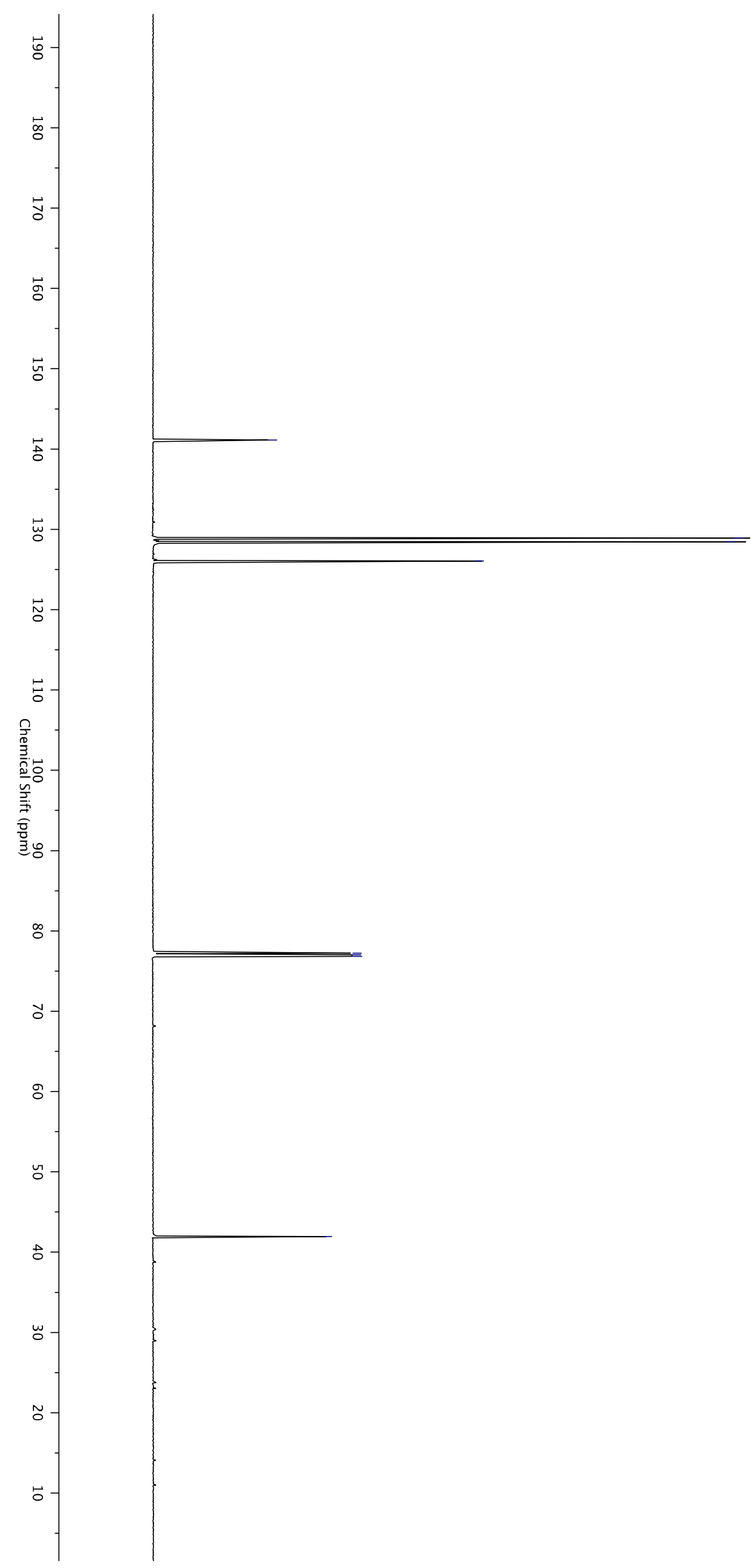

$-141.11$

128.94

$\Upsilon_{128.46}$

$\backslash 126.06$

77.24
-77.03

76.82

$-41.95$ 

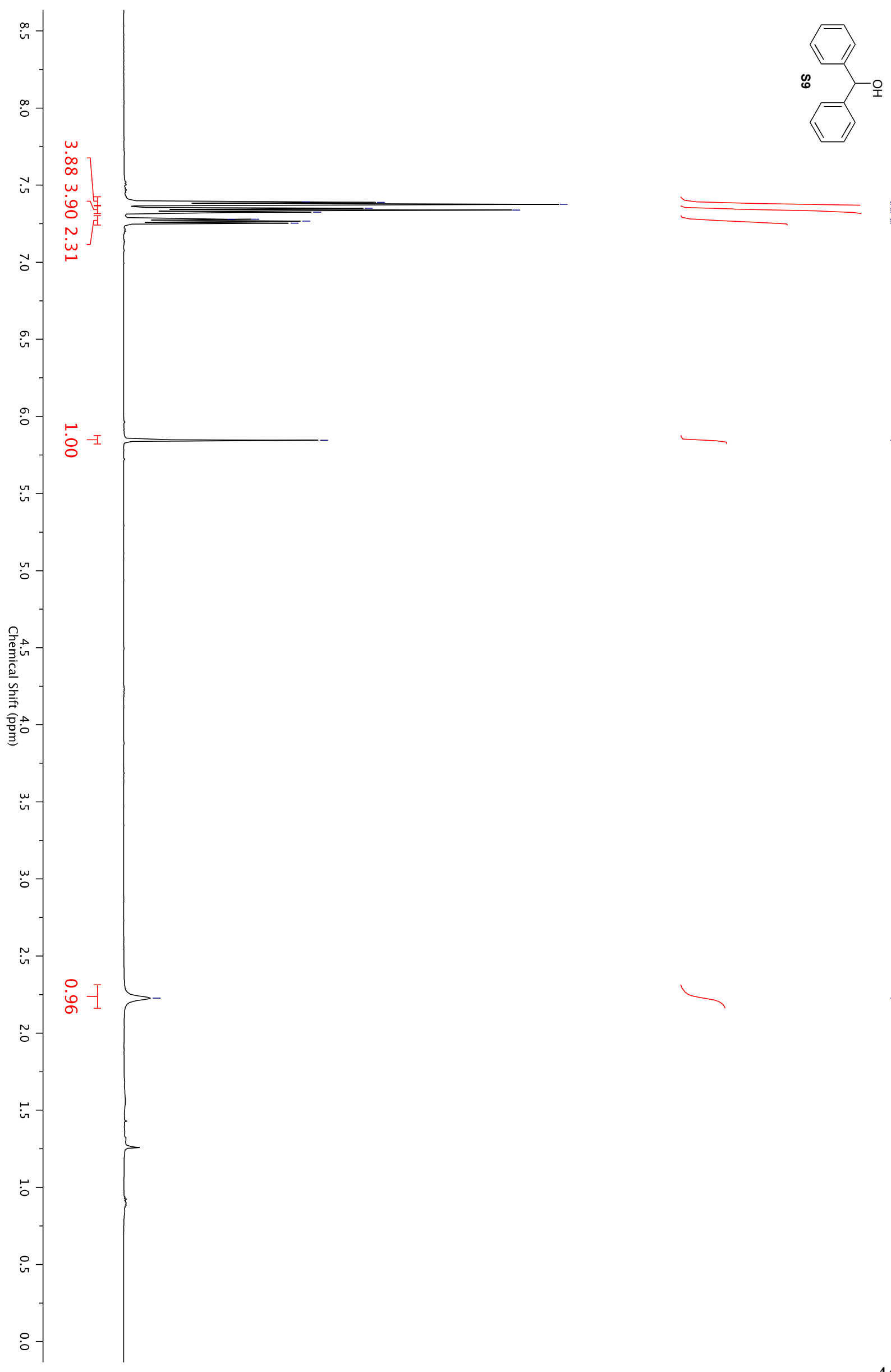

7.39

7.39

7.38

7.35

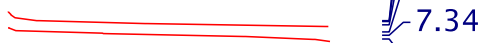

$-7.32$

7.28

7.28

7.27

7.25

$-5.84$

$-2.23$ 


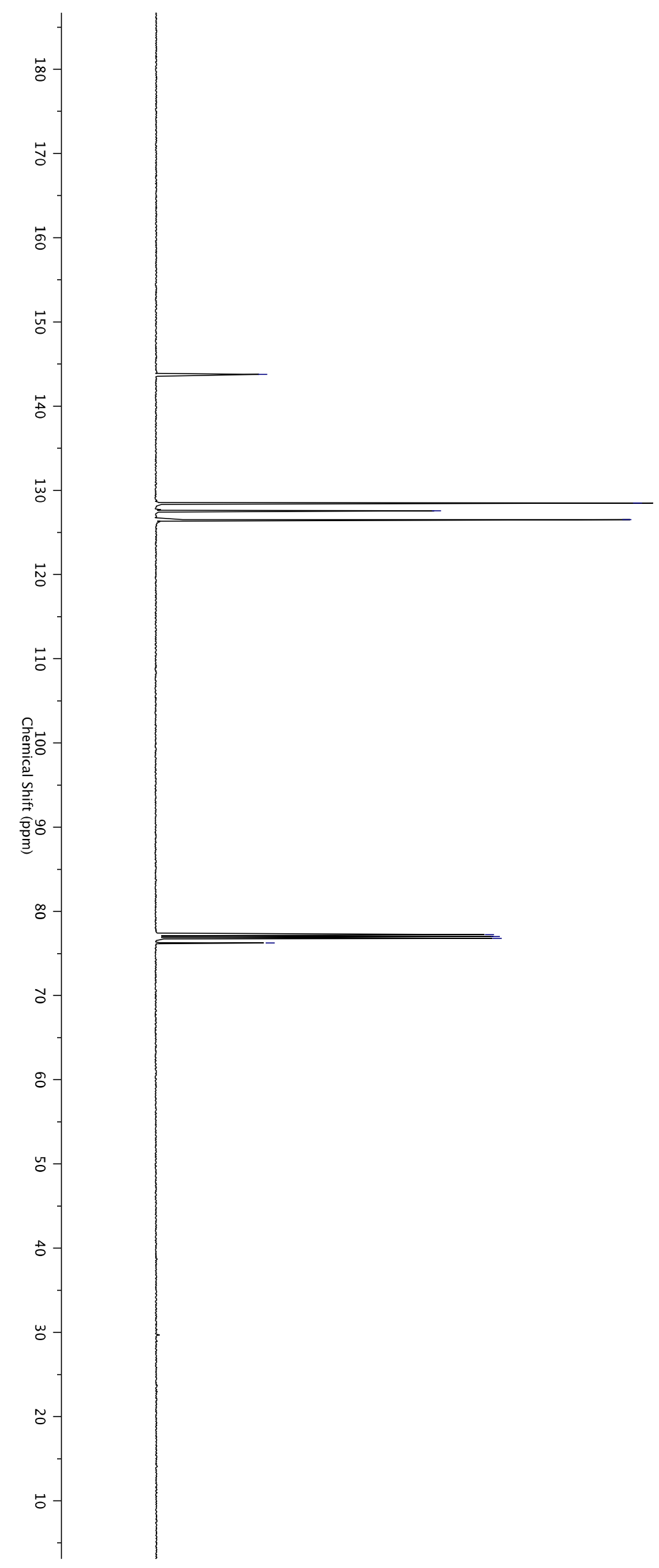

128.49

$-127.56$

$\chi_{126.51}$

77.22

77.01

76.79

76.26 

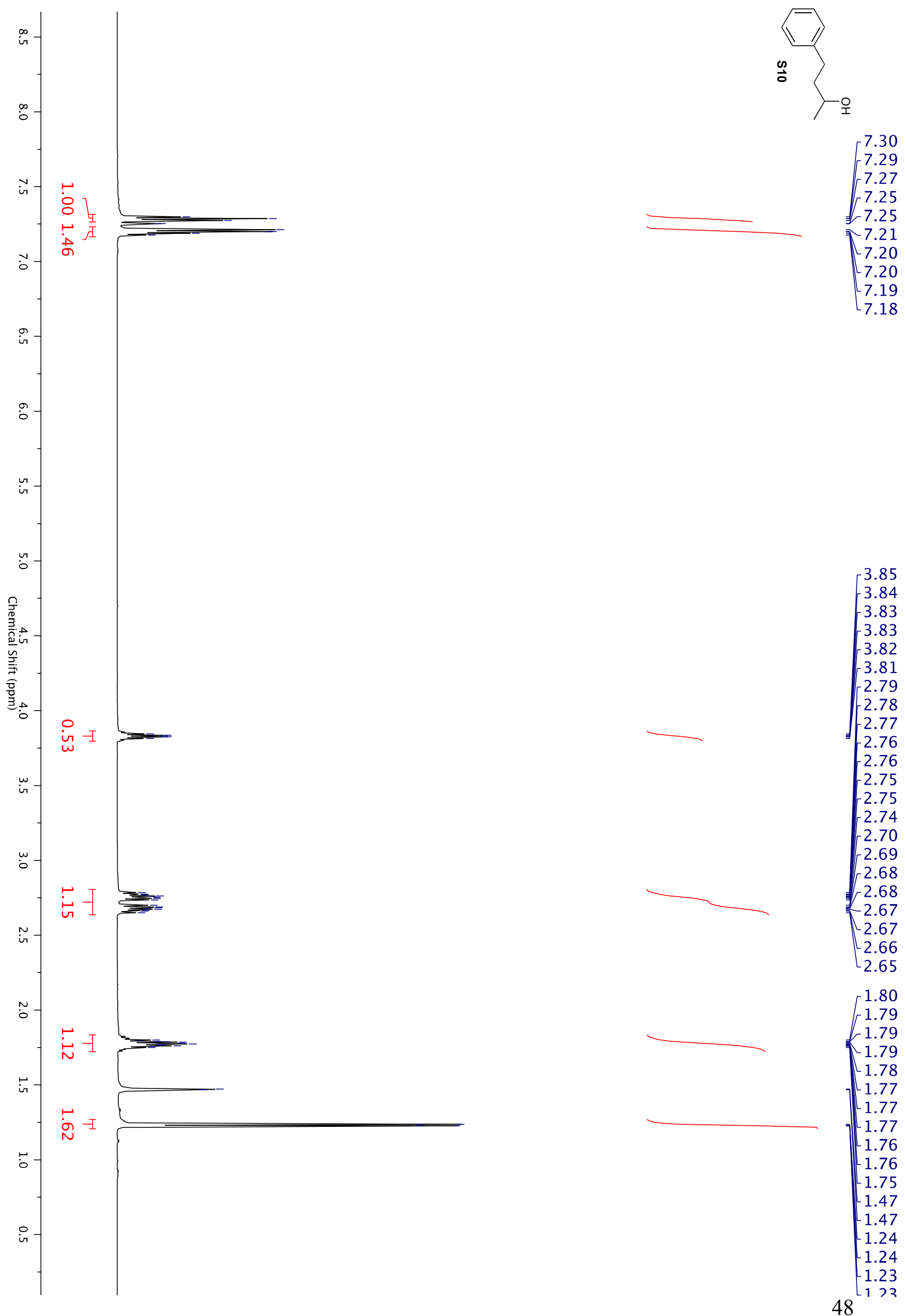


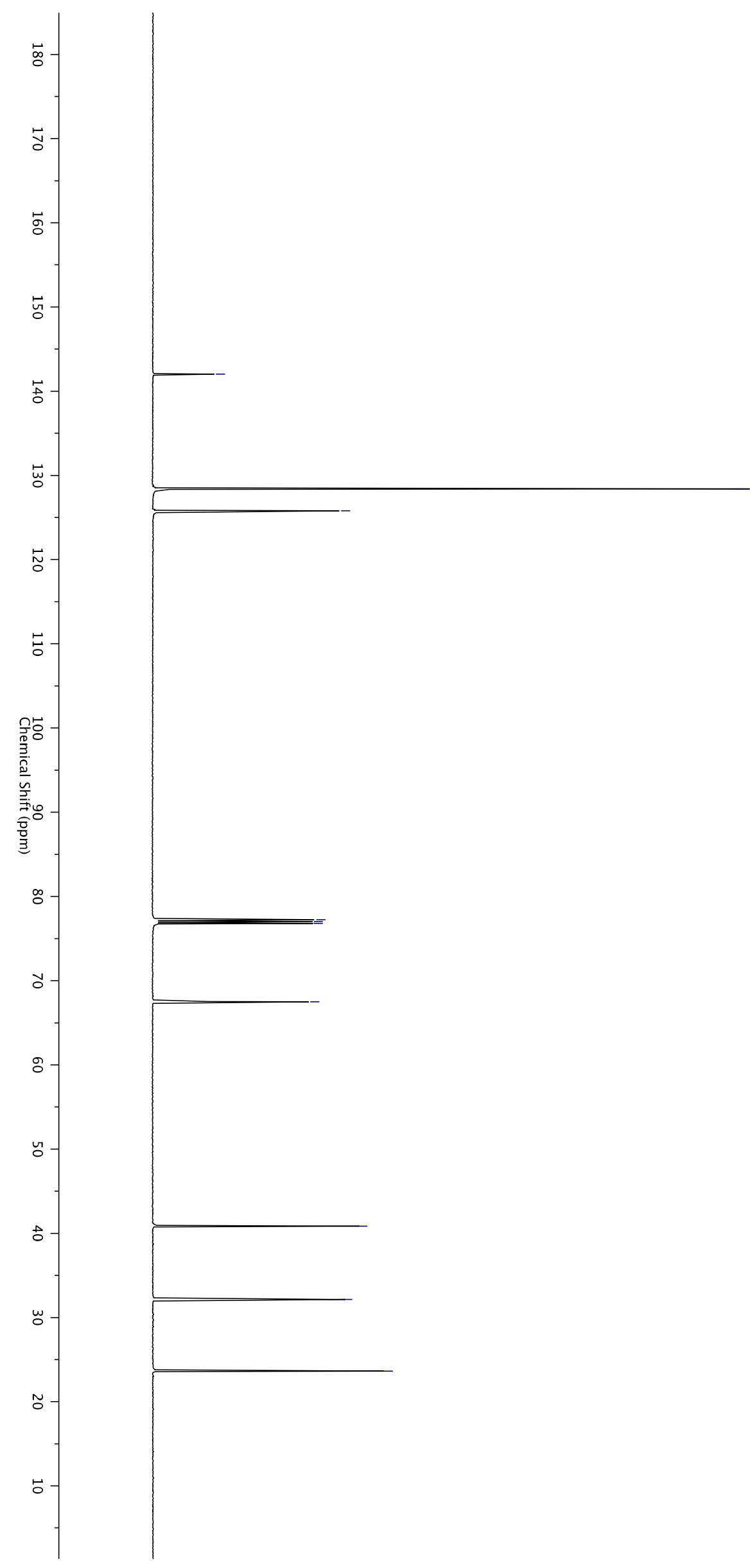

$-142.04$

$-128.38$

$-125.80$

77.23

$-77.02$

76.81

$-67.50$

$-40.84$

$-32.13$

$-23.63$ 


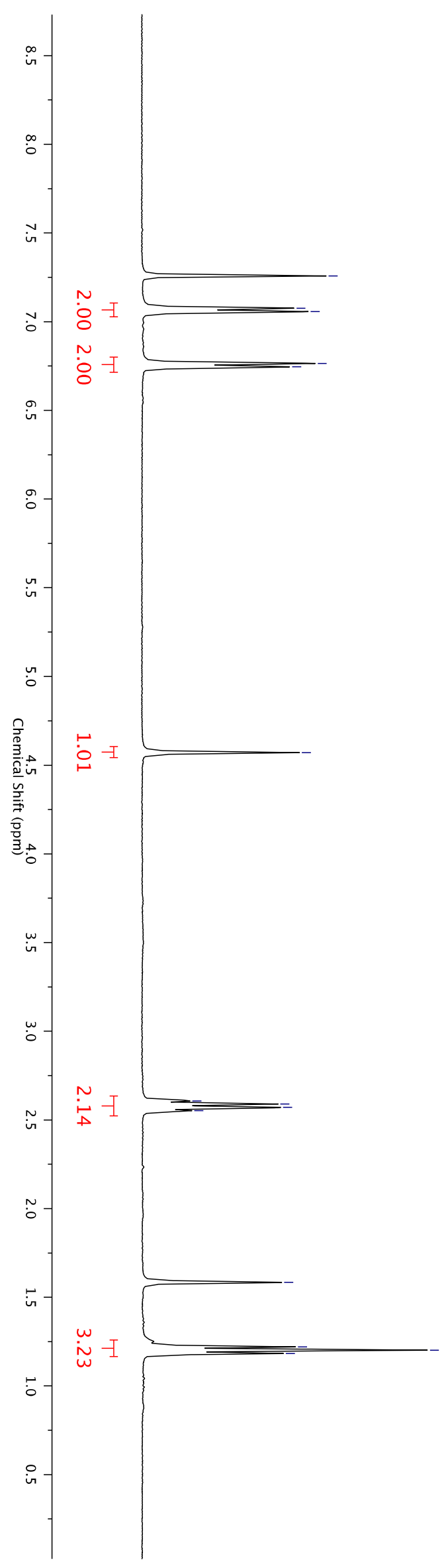

$-7.26$

7.08
7.06

7.06

6.76

$\checkmark 6.75$

$-4.57$

2.61

$-2.59$

$-2.57$

2.55

$-1.58$

1.22

$\_1.20$

${ }_{1.18}$ 


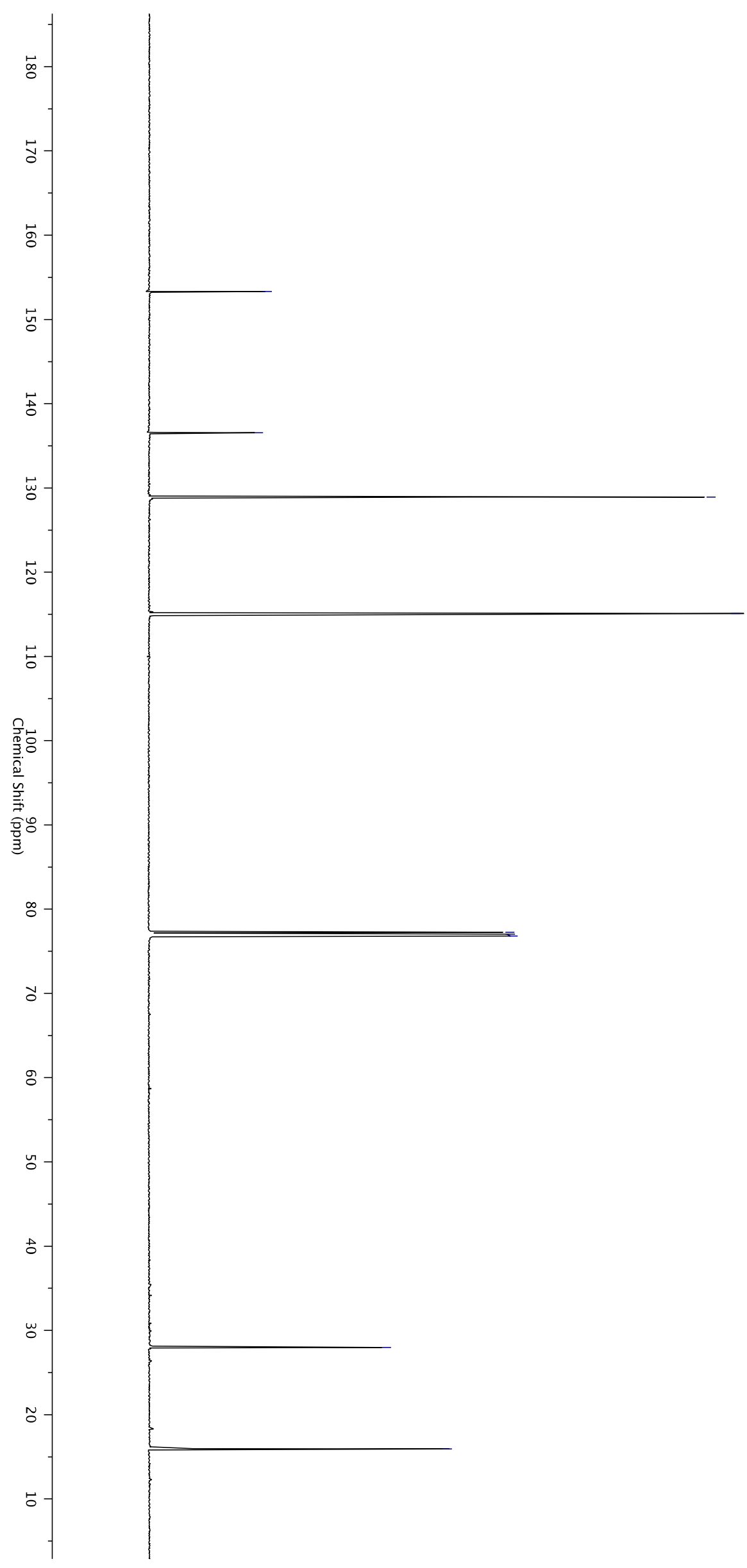

$-153.31$

$-136.56$

$-128.92$

$-115.09$

77.25

$-77.04$

76.83

$-27.98$

$-15.94$ 


\section{References}

1. C. Smit, M. W. Fraaije and A. J. Minnaard, J. Org. Chem., 2008, 73, 9482-9485.

2. A. Modvig, T. L. Andersen, R. H. Taaning, A. T. Lindhardt and T. Skrydstrup, J. Org. Chem., 2014, 79, 5861-5868.

3. S. P. Cook and S. J. Danishefsky, Org. Lett., 2006, 8, 5693-5695.

4. J. R. Hwu, Y. S. Wein and Y.-J. Leu, J. Org. Chem., 1996, 61, 1493-1499.

5. $\quad$ K. Saito, K. Kondo and T. Akiyama, Org. Lett., 2015, 17, 3366-3369.

6. J. J. Dunsford, E. R. Clark and M. J. Ingleson, Angew. Chem. Int. Ed., 2015, 54, 5688-5692.

7. K. Zhu, M. P. Shaver and S. P. Thomas, Eur. J. Org. Chem., 2015, 2015, 21192123.

8. M. Szostak, M. Spain and D. J. Procter, J. Am. Chem. Soc., 2014, 136, 8459-8466.

9. R. Nakamura, Y. Obora and Y. Ishii, Chem. Commun., 2008, DOI: 10.1039/B804055A, 3417-3419. 


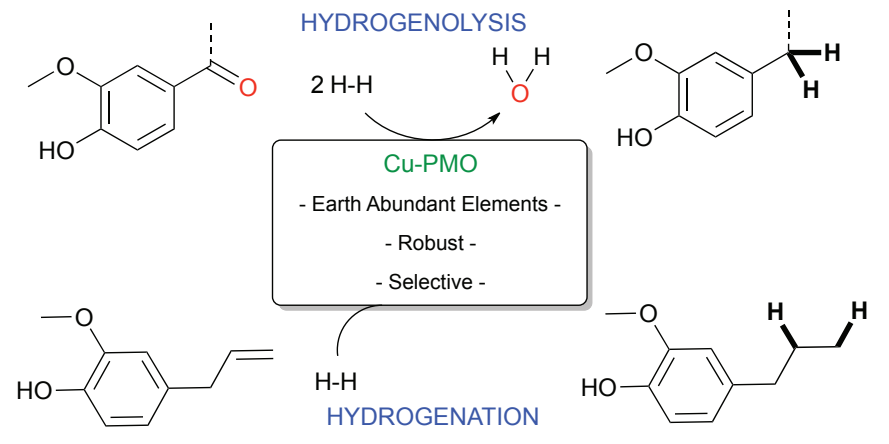




\section{COMMUNICATION}

Cite this: DOI: 10.1039/x0xx00000x

Received 00th January 2012, Accepted 00th January 2012

DOI: $10.1039 / \times 0 \times x 00000 x$

\section{Highly Selective Hydrogenation and Hydrogenolysis using a Copper-doped Porous Metal Oxide Catalyst}

\author{
Laurene Petitjean ${ }^{a}$, Raphael Gagne ${ }^{b}$, Evan S. Beacha, Dequan Xiaob* ${ }^{\text {b* }}$ Paul T. \\ Anastas $^{\text {a* }}$
}

www.rsc.org/

\begin{abstract}
A copper-doped porous metal oxide catalyst in combination with hydrogen shows selective and quantitative hydrogenolysis of benzyl ketones and aldehydes, and hydrogenation of alkenes. The approach provides an alternative to noble-metal catalysed reductions and stoichiometric Wolff-Kishner and Clemmensen methods.
\end{abstract}

Sustainability has emerged as a global concern and has prompted chemists to develop procedures that minimize impact on the environment. Catalysis is the basis for many improvements in sustainable chemical transformations, facilitating the use of reduced energy and material inputs for processes that society requires'. Heterogeneous catalysis, in particular, provides many advantages such as increased catalyst stability and lifetime, as well as ease of catalyst separation from the product mixture ${ }^{2}$. Additionally, methods based on supported heterogeneous catalysts show superior applicability for industrial scale-up ${ }^{3}$. Supply vulnerabilities and depletion of natural resources have increased the attractiveness of catalysts based on earth-abundant metals ${ }^{1}$.

The hydrogenation of unsaturated functional groups such as carbon-carbon double bonds and the hydrogenolysis of carbonoxygen bonds are both important reactions in synthetic chemistry ${ }^{4}$ particularly in the liquid fuels sector ${ }^{5}$ where catalytic methods are used to reduce oxygen content and improve hydrogen/carbon ratios ${ }^{6}$. Reductions of alkenes are typically conducted with high selectivity using noble metal catalysts that are active under mild conditions ${ }^{3}$. For example, hydrogenation of the propene moiety in eugenol can be performed using $\mathrm{Pd} / \mathrm{C}$ in combination with stoichiometric triethylsilane and an acid quench ${ }^{7}$. One of the earliest reports of eugenol reduction used an insoluble rhodium catalyst in water ${ }^{8}$. Even with noble metal catalysts, selectivity can frequently be difficult to achieve. The reduction of eugenol with a heterogeneous $\mathrm{Pt} / \mathrm{Y}-\mathrm{Al}_{2} \mathrm{O}_{3}$ catalyst in combination with $0.14 \mathrm{MPa}$ of $\mathrm{N}_{2} / \mathrm{H}_{2}$ stream (90/10) at 300 ${ }^{\circ} \mathrm{C}$ yielded dozens of products in addition to guaiacol and $\mathrm{n}$ propylguaiacol'. Hydrogenolysis of ketones or aldehydes from aryl- substituted compounds is even more difficult to effect selectively. Catalytic methods commonly use noble metals and typically require forcing conditions ${ }^{3}$. A recent report of selective catalytic vanillin hydrogenolysis utilizes $\mathrm{Au}$ on carbon nanotubes ${ }^{10}$, while another employs Pd nanoparticles supported on mesoporous $\mathrm{N}$-doped carbon to provide creosol ${ }^{11}$. Various other supported Pd catalysts have been used but show lower selectivity in the reduction of vanillin to creosol ${ }^{12-14}$, yielding mixtures of creosol and vanillyl alcohol.

Alternatively, selective but stoichiometric methods such as WolffKishner ${ }^{15}$ or Clemmensen ${ }^{16}$ conditions are extensively utilized for carbonyl removal. They historically employ toxic reagents such as hydrazine and mercury and generate hazardous waste. Recently, methods have been developed to avoid use of noble metals or the above stoichiometric reactions for hydrogenation and hydrogenolysis. Both $\mathrm{Ni}$ nanoparticles ${ }^{17}$ and a Ni/Al alloy catalyst ${ }^{18}$ are capable of hydrogenating eugenol to propyl-guaiacol. Unfortunately, the catalysts' synthesis either employs several equivalents of toxic reagent or is energy intensive. Thus, easily synthesized green catalysts based on earth abundant elements could provide promising solutions for the large-scale applications of catalytic hydrogenation and hydrogenolysis.

A general challenge for all catalytic methods of hydrogenation or hydrogenolysis, particularly by those based on earth abundant elements, is improving selectivity. For example, using a $\mathrm{CoMo} / \mathrm{Al}_{2} \mathrm{O}_{3}$ catalyst to reduce vanillin at $300^{\circ} \mathrm{C}$ and $5 \mathrm{MPa} \mathrm{H}_{2}$ showed poor conversion and provided mixtures of over four compounds including creosol $^{19}$. Copper has the advantages of being an earth-abundant metal and having low tendency to catalyze arene hydrogenation, preventing over-reduction and thus improving selectivity ${ }^{3}$. Recently, Kong et al. reported the use of copper-doped HZSM-5 zeolite for hydrogenolysis of aryl aldehydes and ketones ${ }^{20}$. Porous metal oxides (PMOs), derived from hydrotalcite-like precursors of general formula $\mathrm{Mg}_{6} \mathrm{Al}_{2} \mathrm{CO}_{3}(\mathrm{OH})_{16} .4 \mathrm{H}_{2} \mathrm{O}$, are promising catalysts for a wide range of applications. This is due to their high potential for tunability through 
altering the $\mathrm{M}^{2+}: \mathrm{M}^{3+}$ ratio and metal dopants. Other advantages include high surface area, stability against sintering, simplicity of preparation, and ease of handling ${ }^{21,22}$. Thus, doping copper into hydrotalcite-derived compounds can be a promising strategy for a wide range of reduction methods. For example, Kaneda et Al. successfully utilised a copper-nanoparticle catalyst synthesized from Cu-Al hydrotalcite to effect the quantitative hydrogenolysis of glycerol to 1,2-propanediol ${ }^{23}$.

In this communication, the reactivity and selectivity of copperdoped PMO (Cu-PMO) is evaluated. Our previous work with the catalyst suggested it was capable of very selective transformations ${ }^{24}$. This work clarifies the scope of the reactivity towards various $\mathrm{C}-\mathrm{C}$ and $\mathrm{C}-\mathrm{O}$ bond configurations. Density functional theory (DFT) calculations were performed to evaluate the thermodynamic bias of each reaction at relevant pressures. The computational results are integrated with experimental data from Cu-PMO catalysed reductions to show improvements in efficiency and selectivity provided by the catalyst.

$\mathrm{Cu}$-PMO is synthesized by co-precipitation of $\mathrm{Cu}, \mathrm{Mg}$ and $\mathrm{Al}$ nitrate salts in aqueous media. Copper constitutes $20 \mathrm{~mol} \%$ of $\mathrm{M}^{2+}$, with $\mathrm{M}^{2+}: \mathrm{M}^{3+}$ kept at 3:1. Elemental analyses proved that the metals are incorporated in the anticipated amounts, furnishing a catalyst with metal ratios of $\mathrm{Cu}_{0.57} \mathrm{Mg}_{2.25} \mathrm{Al}_{1.00}$ (See ESI). XRPD measurements indicate that $\mathrm{Cu}-\mathrm{PMO}$ changes from a hydrotalcite-like structure to become an amorphous material after calcination in air for 24 hours at $460^{\circ} \mathrm{C}$. Cu-PMO was previously reported to have a surface area of $\sim 137 \mathrm{~m}^{2} / \mathrm{g}^{25}$

The Gibbs free energy of different reaction pathways was determined using the high-performance computational chemistry software NWChem ${ }^{26}$. The structures were built in .xyz format using the model-building program Avogadro ${ }^{27}$. Initial molecular geometries were then optimized using density functional theory at the B3LYP/6-31 g* level. The optimized structures were subjected to thermochemistry analysis based on vibrational frequency calculations and solvation energy calculations using the COSMO solvation model ${ }^{28}$. The output of the vibrational frequency calculations provided the zero-point correction to energy $\left(E_{1}\right)$, thermal correction to enthalpy $(\mathrm{H})$ and total entropy (S). The solvation calculation provided the total density function theory (DFT) energy $\left(E_{0}\right)$ and the electrostatic solvation energy $\left(E_{s}\right)$. Equation 1 was used to determine the change in Gibbs free energy (dG).

$$
d G=H-T S(1)
$$

This information was then used to compute Gibbs free energy (G) of each structure in gas phase by equation 2 .

$$
G=d G+E_{0}+E_{1}(2)
$$

For specific hydrogenation or hydrogenolysis reactions, we followed the Born-Haber cycle to compute the reaction Gibbs energy in solutions (see ESI). $\mathrm{R}$ is the organic molecule prior to hydrogenation, $\mathrm{H}_{2}$ is molecular hydrogen, and $\mathrm{RH}_{2}$ is the organic molecule after hydrogenation. In the notations of $\Delta G$ terms, ' $\mathrm{g}$ ' denotes gas phase, 'solu' denotes solution, and ' $s$ ' denotes solvation.

The reaction Gibbs free energy in gas phase was first computed using equation (3):

$$
\Delta G_{g}=G\left(R H_{2}, g\right)-G(R, g)-G\left(H_{2}, g\right)(3)
$$

Then, the reaction Gibbs free energy in solution was computed by equation (4):

$$
\Delta G_{\text {solu }}=\Delta G_{g}+\Delta G_{s, R H_{2}}-\Delta G_{s, R}-\Delta G_{s, H_{2}}
$$

To examine the chemoselectivity of eugenol reduction, DFT calculations were performed to evaluate the thermodynamic feasiblity of potential products at varying pressures of hydrogen
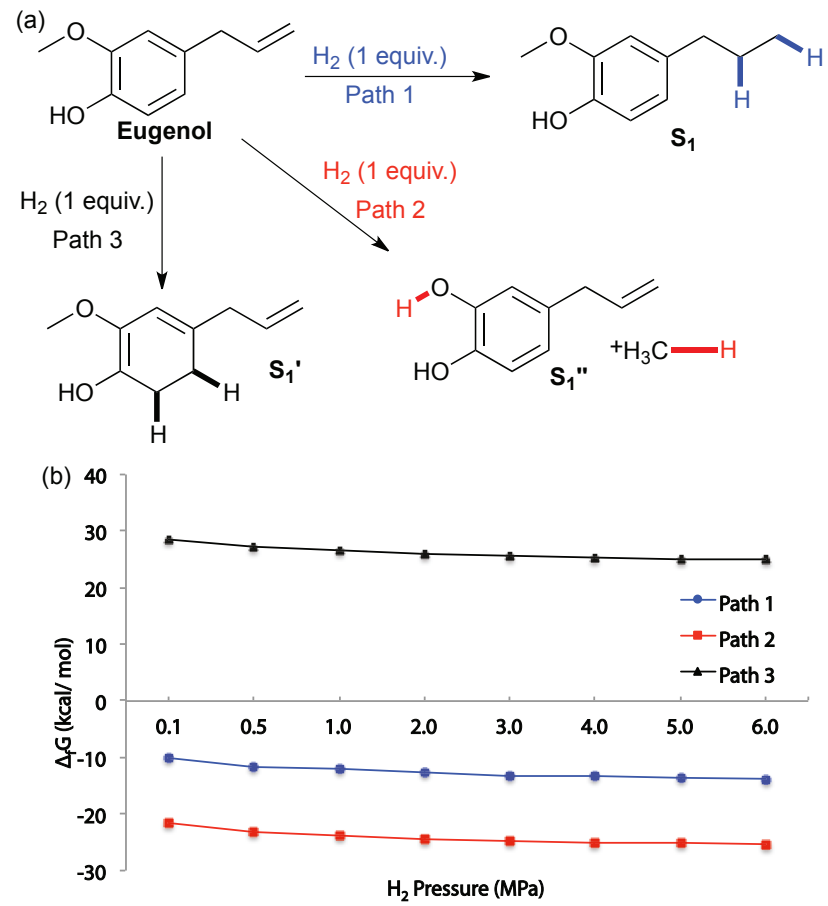

Fig 1 (a) Potential pathways of eugenol reduction (b) Changes in Gibbs free energy with varying $\mathrm{H}_{2}$ pressure at $180^{\circ} \mathrm{C}$

\begin{tabular}{|c|c|c|c|c|c|c|c|}
\hline Entry & $\begin{array}{l}\text { Catalyst } \\
(\mathrm{mol} \%)\end{array}$ & $\begin{array}{l}\text { Temp } \\
\left({ }^{\circ} \mathrm{C}\right)\end{array}$ & $\begin{array}{l}\text { Time } \\
\text { (h) }\end{array}$ & $\begin{array}{l}\mathrm{H}_{2}^{\mathrm{c} C \mathrm{C}} \\
(\mathrm{MPa})\end{array}$ & $\begin{array}{l}\text { onversion } \\
\text { (\%) }\end{array}$ & $\begin{array}{l}\text { Yield }^{b} \\
\text { S1 (\%) }\end{array}$ & $\begin{array}{l}\text { Yield }^{b} \\
\text { IsoE (\%) }\end{array}$ \\
\hline (1) & Cu-PMO (11) & 180 & 18 & 4 & 100 & $>95$ & 0 \\
\hline (2) & Cu-PMO (11) & 100 & 18 & 4 & 100 & $>95$ & 0 \\
\hline (3) & Cu-PMO (11) & 60 & 18 & 4 & 53 & 39 & 0 \\
\hline (4) & Cu-PMO (11) & 22 & 18 & 4 & 0 & 0 & 0 \\
\hline (5) & Cu-PMO (11) & 100 & 3 & 4 & 100 & $>95$ & 0 \\
\hline (6) & Cu-PMO (11) & 70 & 3 & 4 & $<5$ & $\operatorname{tr}$ & 0 \\
\hline (7) & Cu-PMO (11) & 100 & 3 & 1 & 40 & 40 & 0 \\
\hline$(8)$ & Cu-PMO (11) & 100 & 4 & 1 & 100 & $>95$ & 0 \\
\hline (9) & PMO (250 mg) & 180 & 18 & 4 & 57.5 & 35 & 18 \\
\hline (10) & - & 180 & 18 & 4 & 26 & 15 & 0 \\
\hline (11) $\mathrm{Cu}$ & $\mathrm{u}(\mathrm{OAc})_{2} \mathrm{H}_{2} \mathrm{O}(0.3)$ & 3) 180 & 18 & 4 & 90 & 60 & 0 \\
\hline (12) & PMO (250 mg) & 100 & 4 & 1 & 0 & 0 & 0 \\
\hline (13) & - & 100 & 4 & 1 & $<5$ & $\operatorname{tr}$ & 0 \\
\hline (14) Cu & $\mathrm{u}(\mathrm{OAc})_{2} \cdot \mathrm{H}_{2} \mathrm{O}(0.3)$ & 3) 100 & 4 & 1 & 15 & $\operatorname{tr}$ & 0 \\
\hline
\end{tabular}

Table 1 Reduction of eugenol ${ }^{a}$

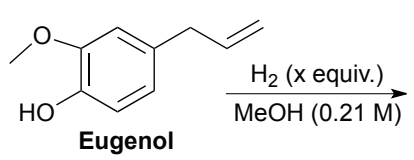<smiles>C/C=C/c1ccc(O)c(OC)c1</smiles>

(a) All reactions were carried out in a high pressure $100 \mathrm{~mL}$ Parr Reactor using Eugenol $(6.456 \mathrm{mmol})$ in $\mathrm{MeOH}(30 \mathrm{~mL})$ (b) Conversion and Yield determined by ${ }^{1} \mathrm{H}$ NMR Spectroscopy using DMF or Dodecane as internal standards (c) Pressure as added at room temperature; $\mathrm{tr}=\mathrm{trace}$ 
(Figure 1). At reaction conditions over $1 \mathrm{MPa}$ of hydrogen pressure at $180{ }^{\circ} \mathrm{C}$, several pathways are calculated to be thermodynamically favourable: hydrogenation of the alkene, as well as hydrogenolysis of the methoxy-aryl bonds. Interestingly, the most thermodynamically favorable product at $\mathrm{H}_{2}$ pressures of 0.1-6 MPa is predicted to be the catechol resulting from aryl-ether bond cleavage (Path 2, Figure 1). This is potentially due to the added entropy gain from methane release after bond cleavage. However, experiments with Cu-PMO did not yield catechol product, suggesting that the production of catechol is subjected to the kinetic control of the catalysis.

The hydrogenation of the propene group occurs under our reaction conditions, as it is thermodynamically allowed at various $\mathrm{H}_{2}$ pressure (see Figure 1b, path 1),, Experiments also found that the hydrogenation of propene is under the control of reaction kinetics (Table 1). Product $\mathrm{S} 1$ is obtained quantitatively after stirring for $18 \mathrm{~h}$ in a sealed Parr Reactor at $180^{\circ} \mathrm{C}$ with an initial pressure of $4 \mathrm{MPa}$ of hydrogen (Table 1, Entry 1). The efficiency was excellent at temperatures as low as $100^{\circ} \mathrm{C}$, but dropped with further decrease in temperature (Table 1, Entries 2-4). Optimal conditions appear to be around $3 \mathrm{~h}$ reaction at $100^{\circ} \mathrm{C}$ (Table 1, Entry 5). Lowering hydrogen pressure slows the reaction, yet quantitative yields of $\mathrm{S} 1$ can be obtained in only $4 \mathrm{~h}$ at $100{ }^{\circ} \mathrm{C}$ and $1 \mathrm{MPa}$ of hydrogen (Table 1, comparing Entries 5, 7 and 8). The control experiments suggest that hydrogenation of eugenol is kinetically controlled. Only trace reactivity was observed even after $21 \mathrm{~h}$ at $180^{\circ} \mathrm{C}$ with $4 \mathrm{MPa}$ of hydrogen (Table 1, Entry 10).

The phase of the reaction mixture could play an important role in the efficiency and selectivity of reduction, by altering the mechanism of catalysis ${ }^{29,30}$. In the present system, methanol remains in the liquid phase throughout the reaction under all conditions reported ${ }^{31}$. The system pressure increased as the temperature approached the set point, typically reaching $1.4 \mathrm{MPa}$ at $100{ }^{\circ} \mathrm{C}$ and $5.9 \mathrm{MPa}$ at $180{ }^{\circ} \mathrm{C}$. Accordingly the density varies in the early stages of the reaction. For a transformation performed at $180{ }^{\circ} \mathrm{C}$ and $4 \mathrm{MPa}$, the hydrogen pressure is introduced at room temperature and a density of 790.5 $\mathrm{g} / \mathrm{mL}$ is expected for methanol ${ }^{31}$. Once the set temperature is reached, the pressure has increased and the density of methanol is calculated to be $608.6 \mathrm{~g} / \mathrm{mL}^{31}$. For the milder reaction conditions, the effect is lower; at the start of the reaction, a density of $787.6 \mathrm{~g} / \mathrm{mL}$ is expected at room temperature and $1 \mathrm{MPa} \mathrm{H}_{2}$. A lower experimental density of methanol at $712.6 \mathrm{~g} / \mathrm{mL}$ can be reached with $100{ }^{\circ} \mathrm{C}$ and 1.4 $\mathrm{MPa}_{2}$. A lower solvent density may facilitate hydrogen solvation and increase the reaction rate. Changes in solvent density could also alter solvent polarity, in turn affecting reduction efficiency and selectivity ${ }^{32}$.

Cu-PMO is able to overcome the transition state barrier associated with hydrogenation of eugenol. Interestingly, the Cu-free porous-metal oxide (PMO) material derived from $\mathrm{Mg} / \mathrm{Al}$ hydrotalcite is also active for eugenol hydrogenation (Table 1, Entry 9). This control indicates that $\mathrm{Cu}$ is essential for reaction efficiency as well as selectivity, since the PMO-promoted hydrogenation of eugenol yields isoeugenol in $15 \%$ yield (2:1 ratio trans:cis). Eugenol isomerization is known to be catalyzed by hydrotalcite-like compounds due to their solid base character ${ }^{33}$. With hydrotalcite-like compounds, reduced reactivity for isomerization is observed if the catalyst is calcined to a $\mathrm{PMO}$, or when polar solvents are utilized ${ }^{34}$. In the present case, a calcined catalyst is utilized in polar methanol, yet isomerization is still observed. This suggests that the rate of PMO-catalysed hydrogenation of both eugenol and isoeugenol are low enough to allow isoeugenol to be observed as a co-product.

The use of a homogeneous copper catalyst for eugenol hydrogenation is not as effective as Cu-PMO (Table 1, Entry 11). The Cu-PMO loading (11 mol \%) furnishes $0.3 \mathrm{~mol} \%$ of $\mathrm{Cu}$ which is identical to the absolute amount of $\mathrm{Cu}$ in the $\mathrm{Cu}(\mathrm{OAc})_{2}$ experiment, yet $\mathrm{Cu}$-PMO performs significantly better. Control experiments with milder conditions were performed (Table 1, Entries 12-14) and it is evident that the Cu-PMO structure and composition are essential for overcoming the transition state energy barrier leading to the reduction product $\mathrm{S} 1$.

In an effort to explore the applicability of our method towards C$O$ bonds, DFT calculations of vanillin reduction products thermodynamic stability, at varying hydrogen pressure, were first performed (Figure 2). As for eugenol, the most thermodynamically favored product is predicted to be that from cleavage of the arylmethoxy moiety, due to entropy gain. For analogous reasons, formation of creosol also displays negative Gibbs free energy at all studied hydrogen pressures. Hydrogenation of the aromatic unit is calculated to be particularly disfavored. It is more difficult to obtain the product of aromatic hydrogenation for vanillin than eugenol, correlating with the increased electron-donating ability of the propene unit versus the aldehyde (as also indicated by a pKa of 10.19 for eugenol and 7.38 for vanillin) ${ }^{35}$. Hydrogenation of the aldehyde to the corresponding benzylic alcohol also displays a positive change in Gibbs free energy, most likely because the conjugation of the aldehyde to the aromatic unit makes it more difficult to reduce.
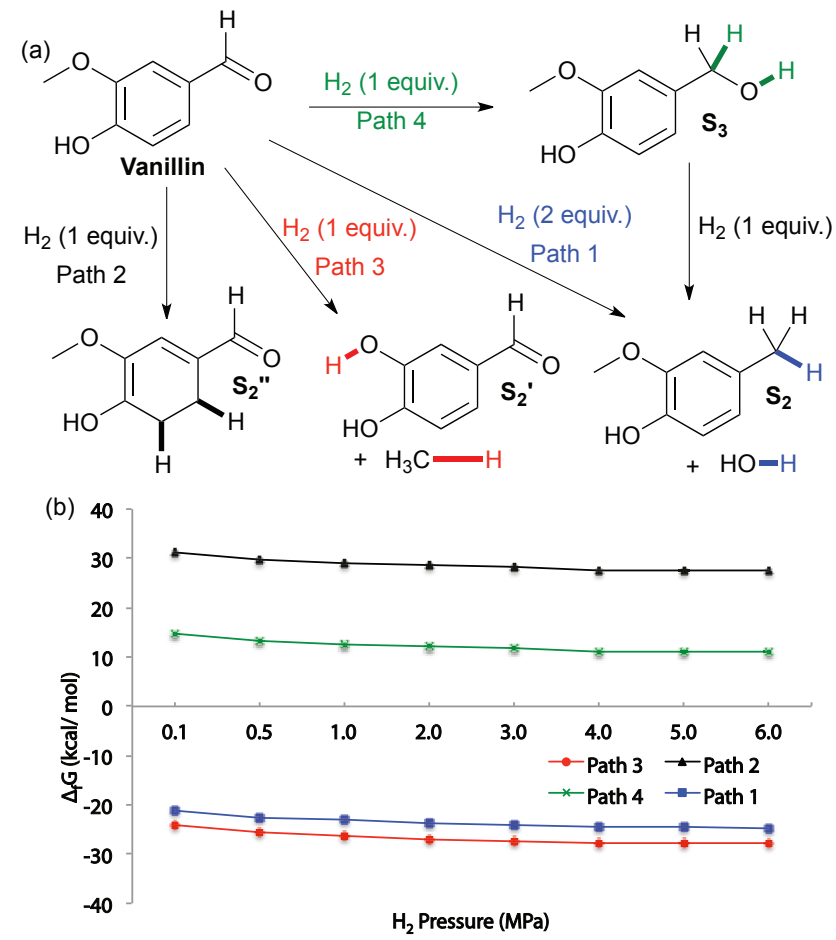

Fig 2 (a) Potential pathways of vanillin reduction (b) Changes in Gibbs free energy with varying $\mathrm{H}_{2}$ pressure at $180^{\circ} \mathrm{C}$ 
Table 2 Reduction of vanillin ${ }^{a}$

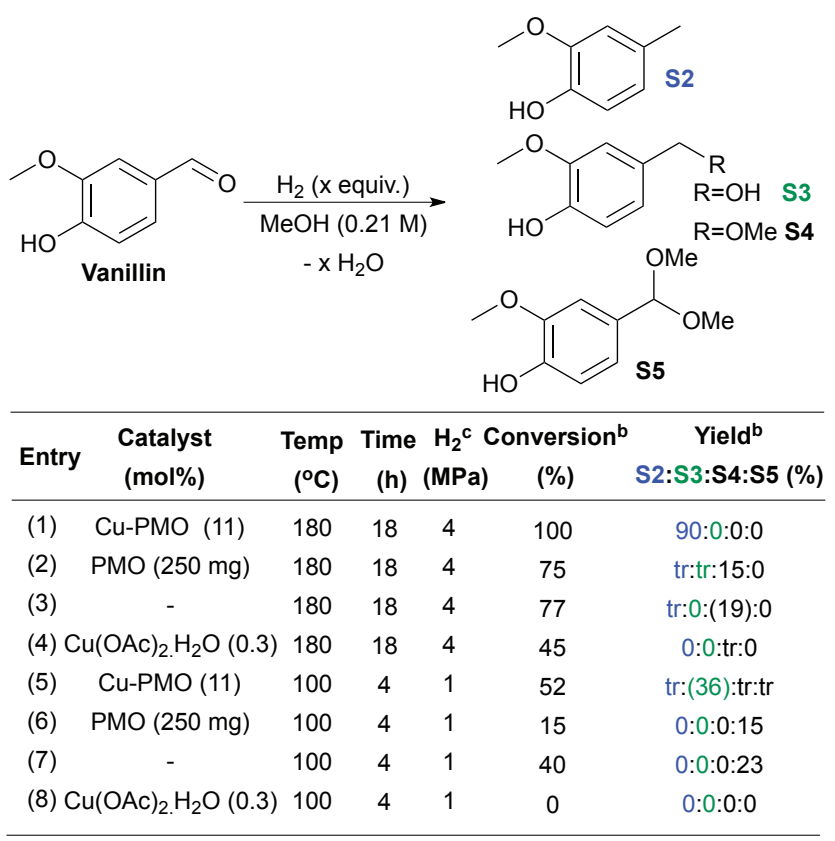

(a) All reactions were carried out in a high pressure $100 \mathrm{~mL}$ Parr Reactor using vanillin $(6.572 \mathrm{mmol})$ in $\mathrm{MeOH}(31.3 \mathrm{~mL})$ (b) Conversion and yield determined by ${ }^{1} \mathrm{H}$ NMR spectroscopy using Dodecane or DMF as internal standards, isolated yield in parentheses (c) Pressure measured at room temperature; $\operatorname{tr}=$ trace
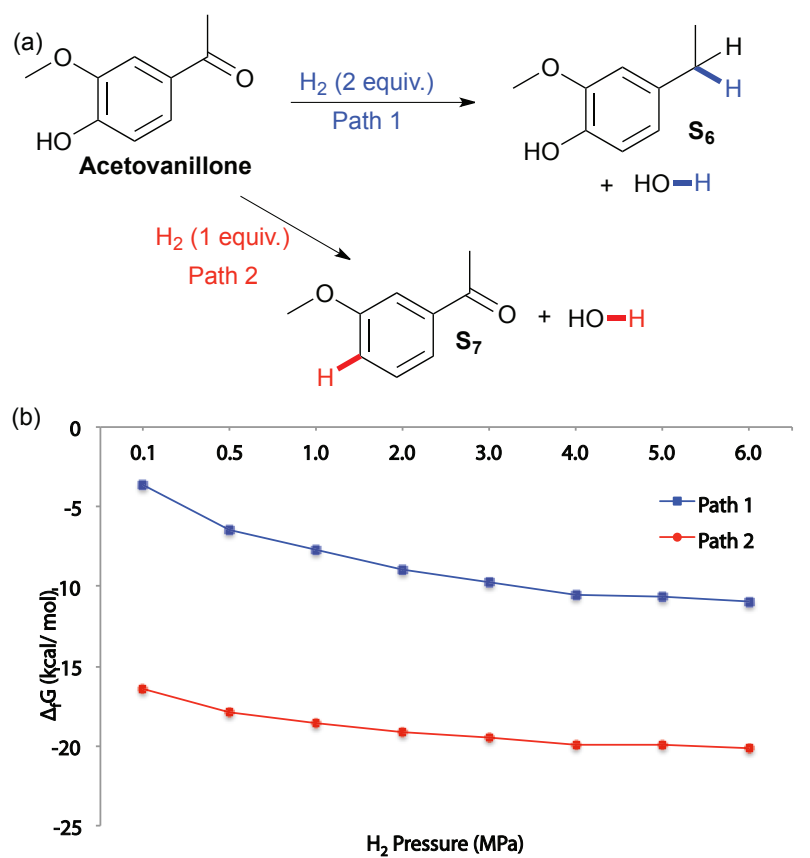

Fig 3 (a) Potential pathways of acetovanillone reduction (b) Changes in Gibbs free energy with varying $\mathrm{H}_{2}$ pressure at $180^{\circ} \mathrm{C}$

It is interesting that experimentally, Cu-PMO does not favor cleavage of the methoxy bond that is predicted to be the most thermodynamically favored pathway (Table 2), implicating highly selective kinetic control by the Cu-PMO catalyst. Many other systems have shown similar, although less pronounced, selectivity ${ }^{10-14,36-38}$. At
Table 3 Reduction of acetovanillone ${ }^{a}$

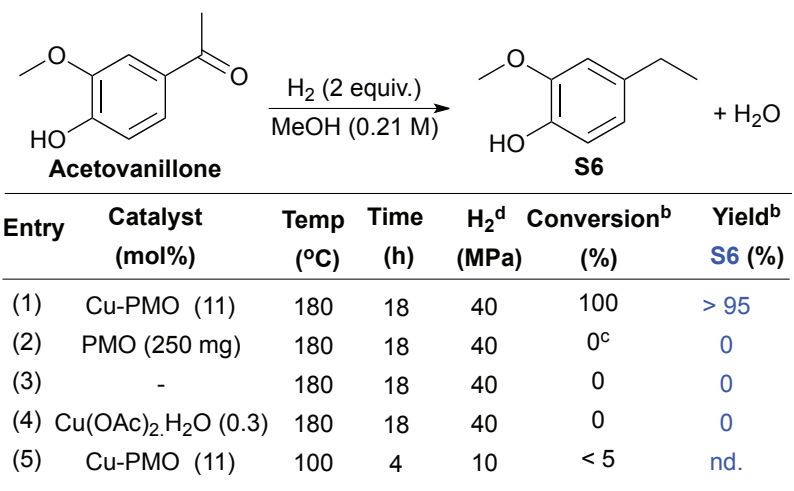

(a) All reactions were carried out in a high pressure $100 \mathrm{~mL}$ Parr Reactor using acetovanillone $(6.456 \mathrm{mmol})$ in $\mathrm{MeOH}(30 \mathrm{~mL})$ (b) Conversion and Yield determined by ${ }^{1} \mathrm{H}$ NMR Spectroscopy using DMF as internal standard (c) Conversion determined by recovery of starting material (d) Pressure as measured at room temperature; nd = not determined

$4 \mathrm{MPa}$ of hydrogen and $180^{\circ} \mathrm{C}$ for $18 \mathrm{~h}$, full hydrogenolysis of vanillin to creosol (S2) was observed (Table 2, Entry 1). Interestingly, the catalyst seems to be required for hydrogenolysis, as a different product distribution is seen in its absence (Table 2, Entries 2-3). S4 is obtained in $15-19 \%$ yield with poor mass balance using Cu-free PMO or no catalyst. Using homogeneous copper acetate, conversion of vanillin and formation of S4 is suppressed compared to the same reaction with no catalyst (Table 2 , Entries 3 \& 4). Importantly, no creosol was observed with copper acetate, suggesting that both the $\mathrm{Cu}$ loading (overall composition) and structure of Cu-PMO are necessary for selective conversion to S2. At lower temperature, lower hydrogen pressure and shorter time, Cu-PMO yields a different product distribution, mainly $\mathbf{S} 3$ (Table 2, Entry 5). This result suggests that $\mathbf{S} 3$ may be an intermediate in the formation of $\mathbf{2}$, as expected. This was confirmed by the direct quantitative reduction of S3 to S2 using $\mathrm{Cu}-\mathrm{PMO}$ at $180^{\circ} \mathrm{C}$ and $4 \mathrm{MPa} \mathrm{H}_{2}$ (see ESI). If $\mathrm{Cu}$ is excluded from the reaction at lower temperature and pressure, no reduction of vanillin is observed (Table 2, Entries 6-7). Instead, acetal S5 is obtained which probably results from addition of methanol to the aldehyde, followed by elimination of water and addition of a second equivalent of methanol. The observation of product $\mathbf{5}$ is significant since acetal formation is typically effected by acid catalysis, yet there is no explicit source of acid in the present conditions ${ }^{39}$. The catalysis provided by $\mathrm{PMO}$ or $\mathrm{Cu}(\mathrm{OAc})_{2}$ is not sufficient to overcome transition state barriers for hydrogenolysis of vanillin. Overall, the vanillin studies again lead to the conclusion that the Cu-PMO structure and copper loading are essential for efficiency and selectivity.

The effect of increased steric hindrance and a more electron rich reduction centre was probed by studying acetovanillone (Figure 3). Calculations of the change in Gibbs free energy with varying pressure at $180^{\circ} \mathrm{C}$ indicate that both hydrogenolysis of the aryl ketone and cleavage of the aryl ether are thermodynamically favored. Although fission of the phenolic ring appears more thermodynamically favourable than hydrogenolysis of the ketone, the catalyst biases selectivity so that solely the ethyl-substituted phenol is obtained experimentally (Table 3). Indeed, no conversion of acetovanillone 
Table 4 Scope of hydrogenolysis of ketones by $\mathrm{Cu}-\mathrm{PMO}^{\mathrm{a}, \mathrm{c}}$

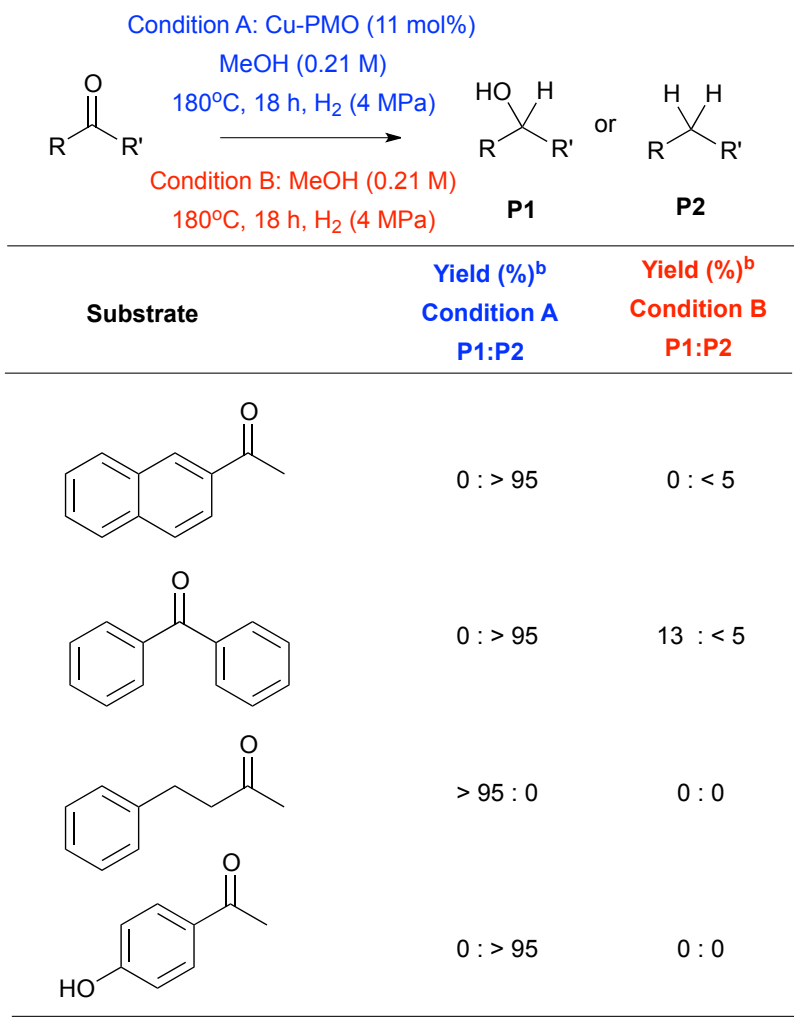

(a) All reactions were carried out in a high pressure $100 \mathrm{~mL}$ Parr Reactor using $6.456 \mathrm{mmol}$ substrate (b) Conversion and Yield determined by ${ }^{1} \mathrm{H}$ NMR Spectroscopy using DMF as internal standard (s) Pressure as measured at room temperature; nd = not determined

was seen except when using $\mathrm{Cu}-\mathrm{PMO}$ at $180^{\circ} \mathrm{C}, 4 \mathrm{MPa}$ of hydrogen for $18 \mathrm{~h}$ (Table 3, Entry 1) which effected selective and efficient hydrogenolysis of the ketone, yielding $\mathbf{S 6}$ quantitatively.

To investigate the robustness, selectivity and utility of Cu-PMO, several other ketones were investigated (Table 4). Benzyl ketones are very well tolerated, as evidenced by the quantitative hydrogenolysis of 2-acetonaphthone, 4'-hydroxyacetophenone and benzophenone. In contrast, the aliphatic ketone benzylacetone furnishes the corresponding alcohol quantitatively under the same conditions. Control experiments attribute both reactivity and selectivity to $\mathrm{Cu}$ PMO.

Even though the hydrogenolysis of methoxy-aryl bonds or phenol groups are also thermodynamically allowed, our Cu-PMO catalyst showed has a high selectivity (with mostly $>95 \%$ yields) for the hydrogenation or hydrogenolysis of carbonyl groups and C-C double bonds, indicating strong kinetic control of the catalysis. Many other catalytic systems have shown similar product distributions but with lower selectivity ${ }^{10-14,36-38}$.

Moreover, our Cu-PMO catalyst has the advantage of being composed entirely of earth-abundant materials and of operating at very low loadings of $\mathrm{Cu}(0.3 \mathrm{~mol} \%)$. Compared to other earthabundant metal catalysts ${ }^{20,21}, \mathrm{Cu}-\mathrm{PMO}$ is resilient to phenolic units and is able to accommodate electron-rich and sterically hindered substrates.
Recycling experiments of eugenol hydrogenation (see ESI) showed that it was possible to recycle the catalyst up to 11 times before noticing a decrease in activity. Analyses by ICP-OES of the spent catalyst revealed that the original metal ratio is retained after reaction. SEM and TEM images of CU-PMO before and after reaction show little changes in the aggregation pattern and structure of the catalyst. XRPD pattern of spent Cu-PMO shows it is still amorphous after reaction. XPS investigations of recovered Cu-PMO versus fresh catalyst indicate some reduction of $\mathrm{Cu}(\mathrm{II})$ to $\mathrm{Cu}(\mathrm{I})$ and possibly $\mathrm{Cu}(0)$ after reaction (see ESI).

In summary, we have developed a very selective method for hydrogenolysis of benzyl ketones and aldehydes as a greener alternative to Wolff-Kishner and Clemmensen conditions or noblemetal catalysed reductions. Additionally, our method allows selective reductions of alkenes. Ongoing investigations in our laboratory aim to extend the utility of the Cu-PMO system and elucidate its mechanism of reduction.

Research at University of New Haven is supported by the new faculty start-up fund and 2014 summer research grant and research fellowship of the University of New Haven. The Center for Green Chemistry and Green Engineering at Yale U. thanks the Yale School of Forestry and Environmental Studies for its support. We thank Amanda Lounsbury for the TEM images of Cu-PMO.

\section{Notes and references}

1. P. T. Anastas and J. C. Warner, Green Chemistry: Theory and Practice, Oxford University Press, Oxford, 1998.

2. R. A. Sheldon, I. Arends and U. Hanefeld, Green Chemistry and Catalysis, WILEY-VCH, Weinheim, Germany, 2007.

3. S. Nishimura, Handbook of Heterogeneous Catalytic Hydrogenation for Organic Synthesis, John Wiley \& Sons, Inc., United States of America, 2001.

4. M. R. Arnold, Industrial \& Engineering Chemistry, 1956, 48, 1629-1642.

5. D. D. Laskar, B. Yang, H. Wang and J. Lee, Biofuels, Bioprod. Biorefin., 2013, 7, 602-626.

6. C. Zhang, J. Xing, L. Song, H. Xin, S. Lin, L. Xing and X. Li, Catal. Today, 2014, 234, 145-152.

7. S. Tuokko and P. M. Pihko, Org. Process Res. Dev., 2014, 18, 1740-1751.

8. C. Larpent, R. Dabard and H. Patin, Tet. Lett., 1987, 28, 2507-2510.

9. T. Nimmanwudipong, R. C. Runnebaum, S. E. Ebeler, D. E. Block and B. C. Gates, Catal. Lett., 2012, 142, 151-160.

10.X. Yang, Y. Liang, X. Zhao, Y. Song, L. Hu, X. Wang, Z. Wang and J. Qiu, RSC Adv., 2014, 4, 31932-31936.

11.X. Xu, Y. Li, Y. Gong, P. Zhang, H. Li and Y. Wang, J. Am. Chem. Soc., 2012, $134,16987-16990$.

12.Z. Zhu, H. Tan, J. Wang, S. Yu and K. Zhou, Green Chem., 2014, 16, 26362643.

13.A. Modvig, T. L. Andersen, R. H. Taaning, A. T. Lindhardt and T. Skrydstrup, J. Org. Chem., 2014, 79, 5861-5868.

14.Q. Wang, Y. Yang, Y. Li, W. Yu and Z. J. Hou, Tetrahedron, 2006, 62, 6107-6112.

15.L. Wolff, Justus Liebigs Annalen der Chemie, 1912, 394, 86-108.

16.E. Clemmensen, Berichte der deutschen chemischen Gesellschaft, 1913, 46, 1837-1843.

17.F. Alonso, P. Riente and M. Yus, Tetrahedron, 2009, 65, 10637-10643.

18.J. Petro, L. Hegedus and I. E. Sajo, Appl. Catal., A, 2006, 308, 50-55.

19.A. L. Jongerius, R. Jastrzebski, P. C. A. Bruijnincx and B. M. Weckhuysen, J. Catal., 2012, 285, 315-323.

20.X. Kong and L. Chen, Catal. Commun., 2014, 57, 45-49. 
21.M. R. Sturgeon, M. H. O'Brien, P. N. Ciesielski, R. Katahira, J. S. Kruger, S. C. Chmely, J. Hamlin, K. Lawrence, G. B. Hunsinger, T. D. Foust, R. M. Baldwin, M. J. Biddy and G. T. Beckham, Green Chem., 2014, 16, 824-835. 22.D. P. Debecker, E. M. Gaigneaux and G. Busca, Chem. Eur. J., 2009, 15, 3920-3935.

23.T. Mizugaki, R. Arundhathi, T. Mitsudome, K. Jitsukawa and K. Kaneda, Chem. Lett., 2013, 42, 729-731.

24.K. Barta, G. R. Warner, E. S. Beach and P. T. Anastas, Green Chem., 2014, 16, 191-196.

25.G. S. Macala, T. D. Matson, C. L. Johnson, R. S. Lewis, A. V. Iretskii and P. C. Ford, ChemSusChem, 2009, 2, 215-217.

26.M. Valiev, E. J. Bylaska, N. Govind, K. Kowalski, T. P. Straatsma, H. J. J. Van Dam, D. Wang, J. Nieplocha, E. Apra, T. L. Windus and W. A. de Jong, Comp. Phys. Comm., 2010, 181, 1477-1489.

27.M. Hanwell, D. Curtis, D. Lonie, T. Vandermeersch, E. Zurek and G. Hutchison, J. Cheminformatics, 2012, 4, 17.

28.A. Klamt and G. Schuurmann, J. Chem. Soc., Perkin Trans. 2, 1993, DOI: 10.1039/P29930000799, 799-805.

29.H. Wang, A. Sapi, C. M. Thompson, F. Liu, D. Zherebetskyy, J. M. Krier, L. M. Carl, X. Cai, L.-W. Wang and G. A. Somorjai, J. Am. Chem. Soc., 2014, 136, 10515-10520.

30.U. K. Singh and M. A. Vannice, App. Cat. A.: Gen., 2001, 213, 1-24.

31.I. H. Bell, J. Wronski, S. Quoilin and V. Lemort, Ind. \& Eng. Chem. Res., 2014, 53, 2498-2508.

32.C. Reichardt and T. Welton, Solvents and Solvent Effects in Organic Chemistry, Wiley-VCH, Weinheim, Germany, 4th edn., 2011.

33.C. M. Jinesh, C. A. Antonyraj and S. Kannan, Catal. Today, 2009, 141, 176-181.

34.D. Kishore and S. Kannan, App. Cat. A.: Gen., 2004, 270, 227-235.

35.N. V. Shorina, D. S. Kosyakov and K. G. Bogolitsyn, Russ J App/ Chem, 2005, 78, 125-129.

36.X. Yang, Y. Liang, Y. Cheng, W. Song, X. Wang, Z. Wang and J. Qiu, Catal. Commun., 2014, 47, 28-31.

37.F. H. Mahfud, S. Bussemaker, B. J. Kooi, G. H. Ten Brink and H. J. Heeres, J. Mol. Cat. A: Chem., 2007, 277, 127-136.

38.M. B. Ezhova, A. Z. Lu, B. R. James and T. Q. Hu, Chem. Ind. (Boca Raton, FL, U. S.), 2005, 104, 135-143.

39.P. G. M. Wuts and T. W. Greene, Greene's Protective Groups in Organic Synthesis, John Wiley \& Sons, Inc., Hoboken, New Jersey, 4th edn., 2007. 